MEASUREMENT OF TURBULENT VELOCITY, INTENSITY AND SCALE IN ROD BUNDLE FLOW CHANNELS CONTAINING A GRID SPACER

D.S. Rowe and C.C. Chapman

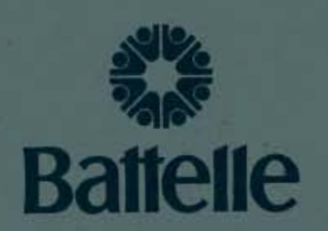

Pacific Northwest Laboratories

Richland, Washington 99352

JUNE 1973

Prepared for the U.S. Atomic Energy

Commission under Contract AT(45-1):1830 


\section{NOTICE}

The report was prepared as an account of work sponsored by the United States Government. Neither the United States nor the United States Atomic Energy Commission, nor any of their employees, nor any of their contractors, subcontractors, or their employees, makes any warranty, express or implied, or assumes any legal liability or responsibility for the accuracy, completeness or usefulness of any information, apparatus, product or process disclosed, or represents that its use would not infringe privately owned rights.

\section{PACIFIC NORTHWEST LABORATORY \\ operated by \\ BATTELLE \\ for the}

U.S. ATOMIC ENERGY COMMISSION

Under Contract AT(45-1)-1830

Printed in the United States of America

$$
\text { Available from }
$$

National Technical Information Service

U.S. Department of Commerce

5285 Port Royal Road

Springfield, Virginia 22151

Price: Printed Copy 55.45: Microfiche 50.95 


\title{
MEASUREMENT OF TURBULENT VELOCITY, INTENSITY AND SCALE IN ROD BUNDLE FLOW CHANNELS CONTAINING A GRID SPACER
}

\author{
By \\ D. S. Rowe and C. C. Chapman
}

June 1973

BATTELLE

PACIFIC NORTHWEST LABORATORIES

RICHLAND, WASHINGTON 99352

AEC-RL RICHLAND. WASH. 


\author{
MEASUREMENT OF TURBULENT VELOCITY, INTENSITY AND SCALE \\ IN ROD BUNDLE FLOW CHANNELS CONTAINING A GRID SPACER \\ D. S. Rowe and C. C. Chapman
}

\begin{abstract}
An experimental study was performed to evaluate the effect of grid spacers on the axial turbulent flow structure in a model rod bundle with a pitch-to-diameter ratio of 1.25. Experimental measurements were performed in water at a nominal Reynolds number of 100,000. Local axial velocity, turbulence intensity and Eulerian time correlations were measured at selected positions downstream from the spacer by using a laser-Doppler velocimeter.
\end{abstract}

The results show that flow passing through the spacer emerges with increased axial turbulence intensity and decreased axial macroscale. The effect of the spacer on the turbulent structure was found to be weakly dependent on Reynolds number with decreased influence downstream from the spacer.

With increased distance downstream from the spacer the axial macroscale increased monotonically to its fully developed values. The turbulence intensity for an interior channel varied significantly with distance downstream from the spacer. The high intensity observed at the trailing edge of the spacer rapidly decayed to values below the fully developed condition at a moderate distance from the spacer. Further downstream the level of intensity increased to nearly twice the level of intensity of fully developed flow before finally decaying to approximately the developed 
state. A qualitative analysis of the kinetic energy equation for turbulence indicated that the intermediate position of low intensity was probably due to a change from strongly nonisotropic turbulence at the spacer to nearly isotropic turbulence at the "quiet" position.

Crossflow mixing estimates based on the product of axial intensity and scale would indicate reduced crossflow mixing downstream from the spacer. However, the inherent assumption of a constant ratio of Lagrangian lateral intensity and scale to the Eulerian axial intensity and scale is invalid for the developing flow downstream of the spacer. If the decrease of axial intensity is due to a change toward isotropy, the product of the lateral intensity and scale would probably not decrease. The net effect would not be a decrease but possibly an increase in crossflow mixing. 
BNWL-1757

$$
\text { v }
$$

TABLE OF CONTENTS

Page

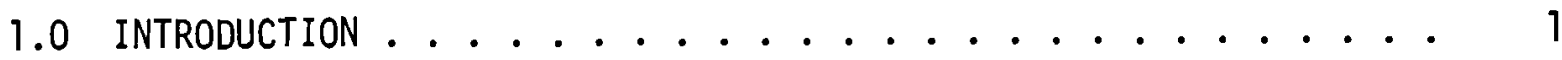

2.0 SUMMARY AND CONCLUSIONS. . . . . . . . . . . . . 3

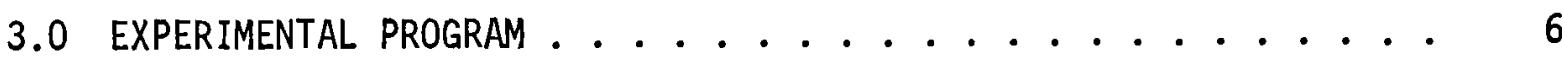

3.1 Description of Test Section . . . . . . . . . . 6

3.2 Instrumentation ..................... 11

3.3 Method of Data Acquisition. ............. 14

4.0 EXPERIMENTAL RESULTS . . . . . . . . . . . . . 17

4.1 Interior Region Flow Structure. . . . . . . . . 18

4.1.1 Mean Velocity. ............. 18

4.1 .2 Turbulence Intensity ............ 26

4.1 .3 Turbulence Scale . . . . . . . . . . . . 37

4.1.4 Effect of Reynolds Numbers . . . . . . . . . . 39

4.2 Wall Region Flow Structure. . . . . . . . . 43

4.2.1 Mean Velocity. .............. 43

4.2 .2 Turbulence Intensity ............ 46

4.2 .3 Turbulence Scale............. 50

5.0 DISCUSSION OF RESULTS. . . . . . . . . . . . 53

5.1 Production and Decay of Turbulence. . . . . . . . . . 53

5.2 Implications Regarding Crossflow Mixing ........ 65

6.0 CONCLUSIONS AND RECOMMENDATIONS. . . . . . ..... 68

7.0 NOMENCLATURE ........................ 70

8.0 BIBLIOGRAPHY . . . . . . . . . . . . . . 72

APPENDIX A - Tabulation of Reduced Data . . . . . . . . 73

DISTRIBUTION. . . . . . . . . . . . . . . . 91 
BNWL-1757

\author{
MEASUREMENT OF TURBULENT VELOCITY, \\ INTENSITY AND SCALE IN ROD BUNDLE FLOW \\ CHANNELS CONTAINING A GRID SPACER
}

\title{
1.0 INTRODUCTION
}

The objective of this report is to present the results of an experimental study of axial flow and turbulence through a rod bundle containing a "grid" spacer. This study represents an extension of an earlier study ${ }^{(2)}$ where axial flow and turbulence parameters were measured in the same rod bundle but without the spacer.

As in the previous study, the motivation for performing this study is to obtain a more complete understanding of the turbulent flow processes in rod bundles so that an improved understanding of crossflow mixing processes can be developed. Crossflow mixing is important to the thermal hydraulic performance of rod bundles since it provides a mechanism to equalize temperature within a rod bundle. Crossflow mixing is often an important fuel design consideration; since fuel design are often selected with the thought of using grid spacers to promote mixing and to improve the thermal-hydraulic performance of rod bundles in addition to providing fuel rod support. In the design process, however, fuel designers are confronted with decisions concerning the configuration and placement of grid spacers to optimize mixing and rod bundle performance. Presently, such decisions must be made with very little knowledge of the effect of grid spacers on the turbulent flow and mixing processes. Most of what 
is known has been inferred from experimental studies of crossflow mixing by using tracers or subchannel sampling methods. There is no known data in the open literature concerning the effect of grid spacers on the turbulent flow structure in rod bundles. This study represents a first step in understanding the influence of grid spacers on the structure of rod bundle turbulence. 


\subsection{SUMMARY AND CONCLUSIONS}

An experimental study was performed to evaluate the effect of a "simple-grid" spacer on the turbulent flow in a model bundle flow channel with a pitch-to-diameter ratio of 1.25. Experimental measurements were performed in water at a nominal Reynolds number of 100,000. Local axial velocity, turbulence intensity and Eulerian time correlations were measured at several positions downstream of the grid by using a laser-Doppler velocimeter (1) (LDV). The autocorrelation function provided an indication of the dominant frequency of turbulence and an estimate of the axial macroscale of turbulence by using Taylor's hypothesis.

The experimental results generally show the following characteristics:

1. The grid spacer causes significant local velocity perturbations in the wake of the grid spacer; however, they recover in a rather short distance $(<18 \mathrm{X} / \mathrm{D})$. Larger perturbations associated with gross flow redistribution generally recover before encountering the second grid spacer at $53 \times / D$.

2. Flow passing through the grid spacer emerges with increased axial turbulence intensity and decreased axial macroscale.

3. The wall and interior subchannels exhibit significantly different turbulence intensity recovery behavior downstream of the grid. The interior subchannel intensity decreases by about a factor of two at only 14.25 inches $(18 \times / D)$ downstream of the grid followed by an increase and gradual decay to near fully developed conditions. The wall subchannel does not show this intermediate decrease 
of intensity but generally decays monotonicaily downstream of the grid spacer to the fully developed condition.

4. The axial macroscale of turbulence as estimated by Taylor's hypothesis increases monotonically from $\sim 0.15$ of the average hydraulic diameter (D) at 2.25 inches $(3 \mathrm{X} / \mathrm{D})$ downstream from the grid spacer to $\sim 0.4 \mathrm{D}$ at 38.25 inches $(47 \mathrm{X} / \mathrm{D})$ downstream from the spacer.

5. The turbulence intensity shows a moderate decrease with increase in Reynolds number. The effect becomes more pronounced near the trailing edge of the spacer.

The observed region of low turbulence intensity behind the grid spacer is believed to be caused by a shift toward isotropic turbulence. A qualitative analysis of the turbulence kinetic energy equation shows that the axial component turbulence intensity is normally nonisotropic with higher values in the axial direction. In the wake of the grid, however, turbulence and pressure-velocity diffusion processes are believed to make the turbulence more isotropic, thus reducing the axial intensity and increasing the lateral intensities.

Crossflow mixing estimates based on the product of axial intensity and scale would indicate reduced crossflow mixing downstream from the spacer. However, the inherent assumption of a constant ratio of Lagranglan lateral intensity and scale to the Eulerian axial intensity and scale is invalid for the developing flow downstream of the spacer. If 
the decrease of axial intensity is due to a change toward isotropy, the product of the lateral intensity and scale would probably not decrease. The net effect would not be a decrease but possibly an increase in crossflow mixing. 


\subsection{EXPERIMENTAL PROGRAM}

The experiments were performed in Battelle-Northwest's thermalhydraulic laboratory located in 189-D building on the Hanford Atomic Project near Richland, Washington. All experimental work was done in the hydraulics loop which is an isothermal recirculating flow loop with flow capability of $900 \mathrm{gpm}$ at temperatures up to $200^{\circ} \mathrm{F}$.

Axial velocity measurements of the turbulent flow were made within a rod bundle test section by using a laser-Doppler velocimeter. The following sections describe the test section, instrumentation and the method of data acquisition.

\subsection{Description of Test Section}

Figure 3.1 shows an overall view of the test section used for the experimental program. Flow entered the bottom of the flow housing, flowed verticaliy up through the test section, emerged at the top of the flow housing, and returned to the flow loop. Rubber expansion bellows were used to help isolate the flow housing from the normal vibrations of the flow loop.

Figure 3.2 shows a cross-sectional view of the test section. It consisted of a front and back plate and flow housing body. The back plate contained the inlet and outlet nozzles and was permanently installed in the flow facility. The front plate was bolted to the back plate with the flow housing body placed between them. A continuous "0-ring" sealed the joint between the plates and the flow housing body. Dimensions of the test section ( $4.00 \times 1.25$ inches) were maintained by the restraining shoulder next to the "0-ring" groove on the front and back plates. 
BNWL-1757
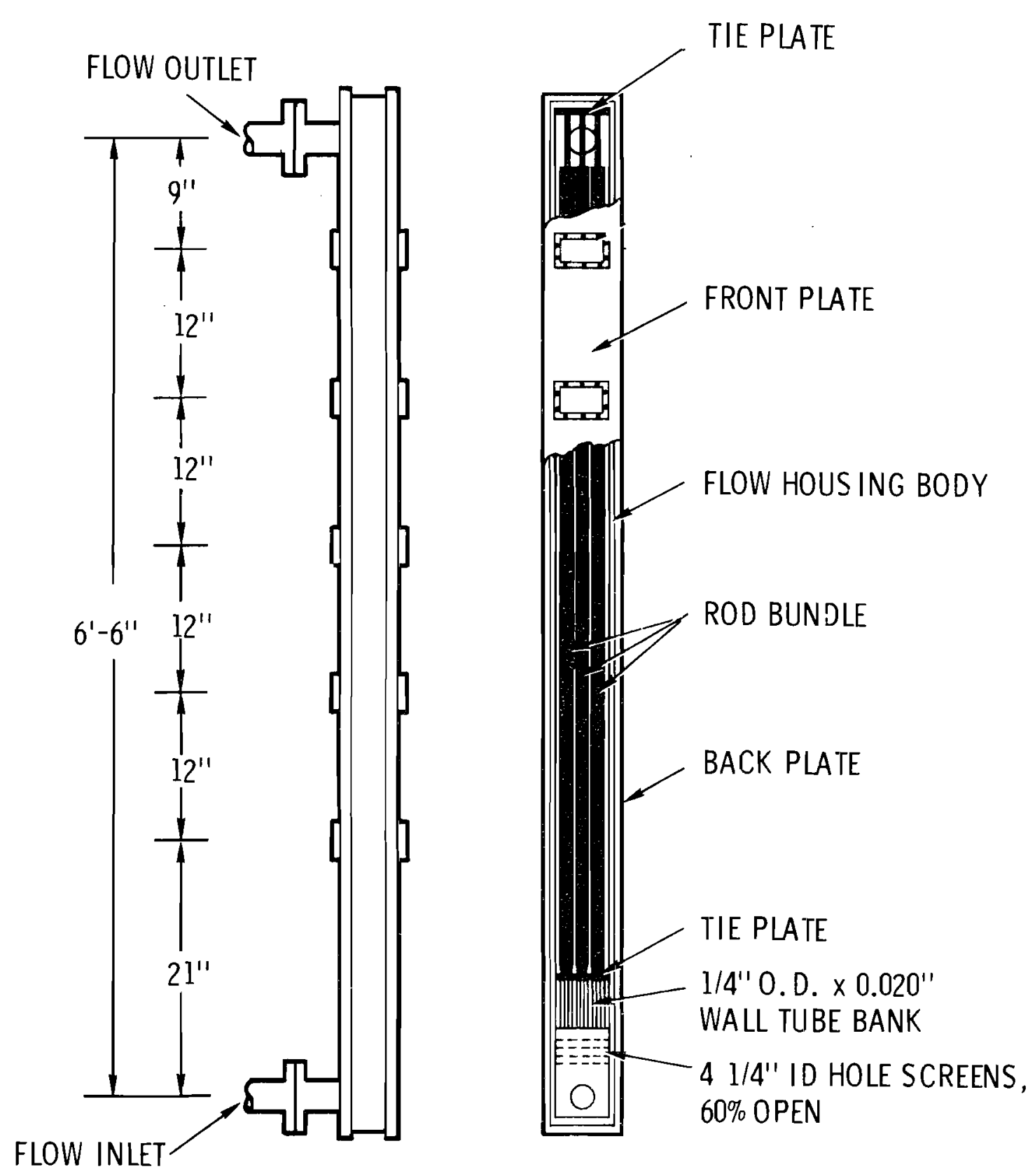

FIGURE 3.1. Flow test section. 
BNWL- 1757

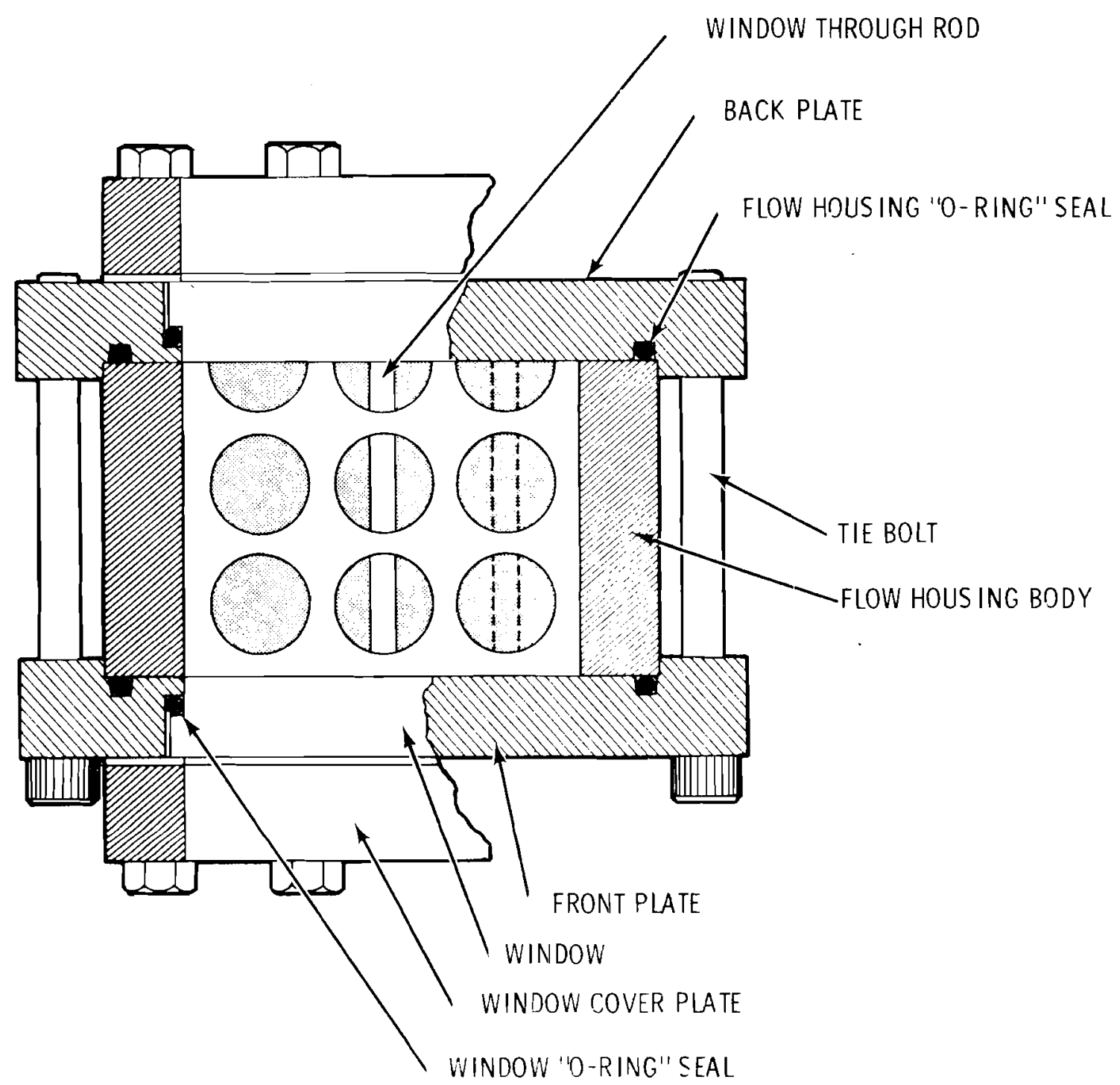

FIGURE 3.2 Test section construction details. 
The front and back plate each contained 5 window ports 2 inches high by 4 inches wide located at 1 foot intervals. The optically flat $(\lambda / 4)$ viewing windows, fabricated from quartz, transmitted the laser beam. The windows were sealed by an "0-ring" and were held in place by thick cover plates. A shim was placed between the window and cover plate to position the window to be "flush" with the inner surface of the flow housing $( \pm 0.001$ inch $)$.

An 8 inch long flow straightening section was placed at the inlet of the flow channel. The flow conditioner consisted of four eccentric screens ( $60 \%$ open) with $1 / 4$ inch holes in a triangular array followed by a bank of $1 / 4$ inch 0 . D. tubes $(0.020$ inch wa 11) $3-1 / 4$ inch 1ong. The screens tended to equalize the inlet velocity distribution and the tubes helped to establish a fixed scale of turbulence and straighten the flow. The inlet ends of the rods had a $60^{\circ}$ taper to minimize the flow disturbance due to flow area change upon entering the rod bundle.

The 3 by 2-1/2 rod bundle array used for this study had a pitch to diameter ratio of 1.25 . The rod bundle consisted of six 1 inch diameter full rods, three half rods, a lower and an upper tie plate, and two grid spacers. The three half rods were bolted onto the back plate. Except for the addition of the two grid spacers, the test section used for this report was the same as the test section used in the previous study. (2) Figure 3.3 shows a cross sectional view of the rod bundle at a grid spacer. The grid spacer was constructed from $1-1 / 2$ inch high by 0.050 inch thick stainless steel sheet stock and 1/4" 0.D. tubing (0.020 inch wal1). The sheet stock was slit and fitted together as an "egg crate". Similarly 
BNWL-1757

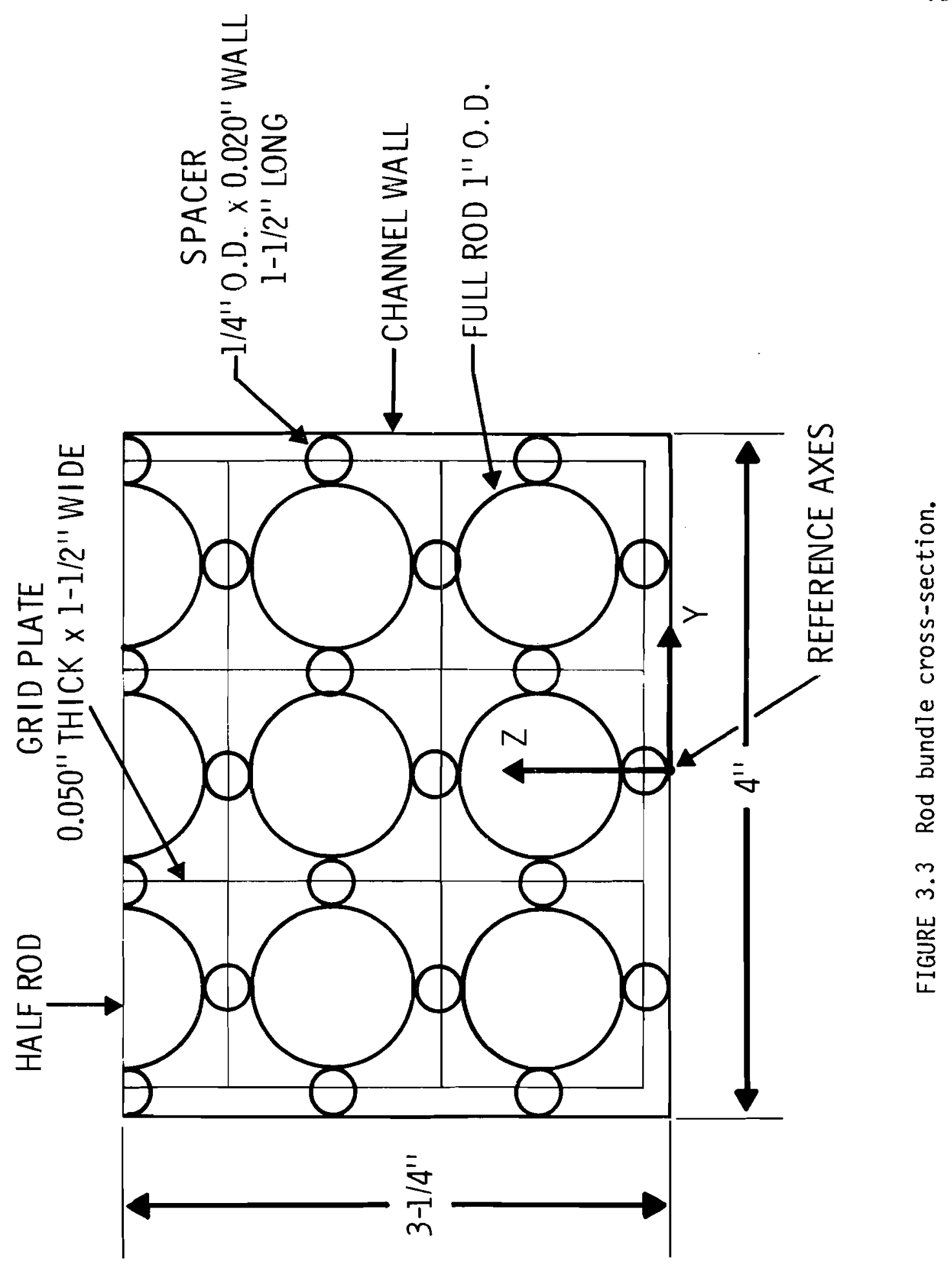


the tubing was fit into companion slots and were fixed to the plates by tack welds. The assembled grid spacer was positioned on the rod bundle and held by retaining pins driven through holes in the rods. All data, except for one set, was taken using the test section configuration shown in Figure 3.4. To enable measurements downstream of the second spacer, both spacers were moved upstream six inches as shown by the dotted outline.

\subsection{Instrumentation}

A two-component laser-Doppler velocimeter (LDV) manufactured by Laser Systems and Electronics was used to measure the turbulent flow velocities in the test section. The LDV operates from the principle that light scattered from a moving particle experiences a frequency shift. (1) This frequency shift depends upon the scattering angle, wavelength of laser light and the local velocity of the scattering particles. By using a system of optics and electronics the frequency shift can be detected and measured.

A11 measurements performed for this study used the single component optics system shown in Figure 3.5. This is the same system as the one used in the previous study ${ }^{(2)}$ of rod bundle turbulence without grids.

An electronic readout system ${ }^{(2)}$ was used to measure the local velocity and instantaneous fluctuating velocity component from the Doppler signal. The fluctuating velocity output signal of the readout was amplifed, low pass filtered, and then electronically processed to obtain the "rms" fluctuating velocity and the Eulerian time correlation (autocorrelation) function. 
BNWL-1757

12

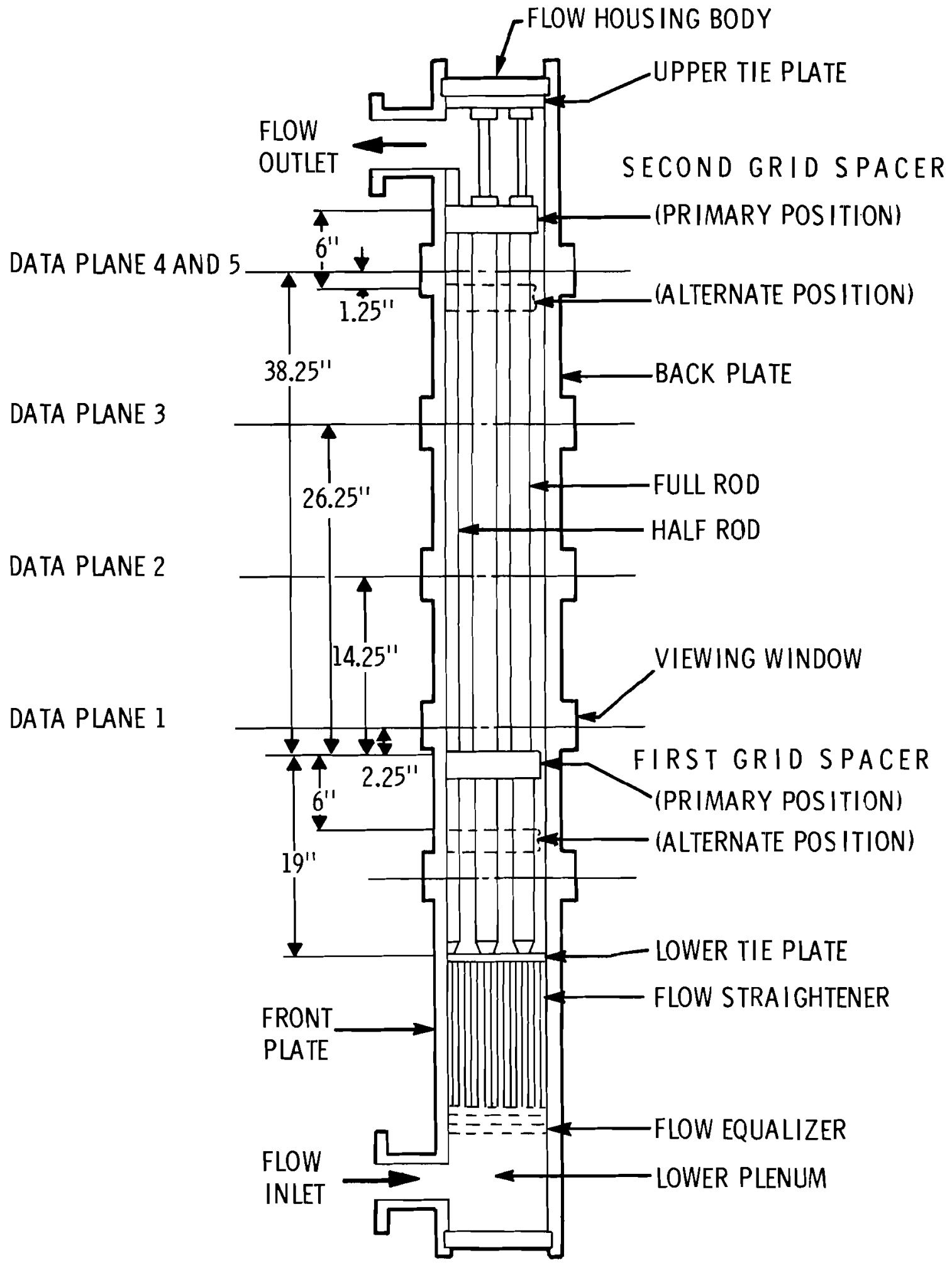

FIGURE 3.4 Flow test section with grid spacer locations. 
BNWL-1757

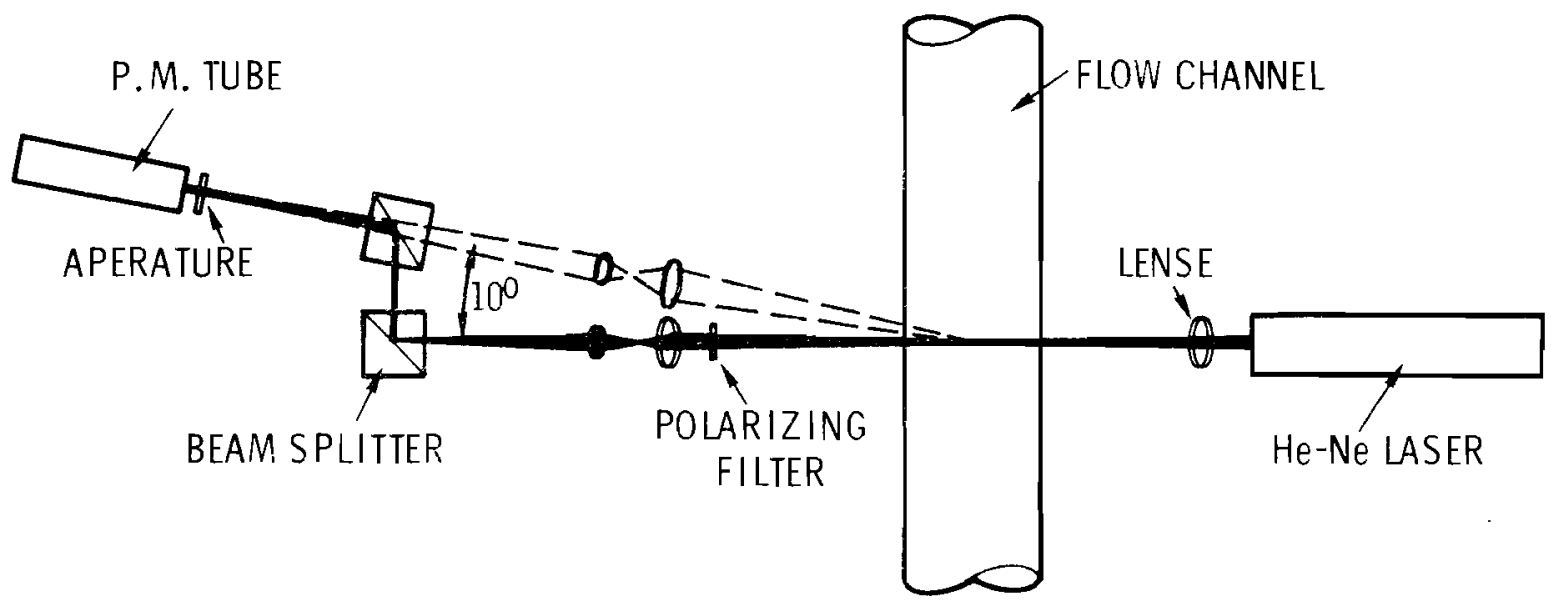

FIGURE 3.5 One-conponent laser-Doppler velocimeter optical arrangement. 
The laser and optics system were mounted on a traversing table that was used to position the entire LDV system as an integral body. The table could be positioned arbitrarily in a horizontal plane by moving the table along its two orthogonal axes. The table could also be adjusted vertically to position the LDV unit at any of the five viewing windows.

\subsection{Method of Data Acquisition}

After adjusting the flow rate and/or the fluid temperature to achieve the desired Reynolds number, the loop was allowed to stabilize. The loop maintained a very stable flow rate and temperature; therefore, adjustment during data acquisition was not required.

The LDV signal was optimized by injecting a small amount of milk into the loop to provide a sufficient concentration of scattering centers in the sample volume. The signal to noise ratio was maximized by adjusting the polarizing filters to attenuate the reference beam and, thus, improve the heterodyning of the two beams. After an optimum LDV signal was achieved, the reference coordinates within the rod bundle were established from the loss of the LDV signal at the channel boundaries. This provided the required information for locating the interior or wall gap center line and the window surfaces. This procedure was followed at each of the window positions.

With the local corrdinates established, data was taken by stepping across the flow channel along the lines as shown in Figure 3.6. At selected positions within the flow field, data readings were recorded and were used as "raw" input data for the data reduction program. ${ }^{(2)}$ The data reduction program took the raw data and computed a consistent set of 
BNWL- 1757

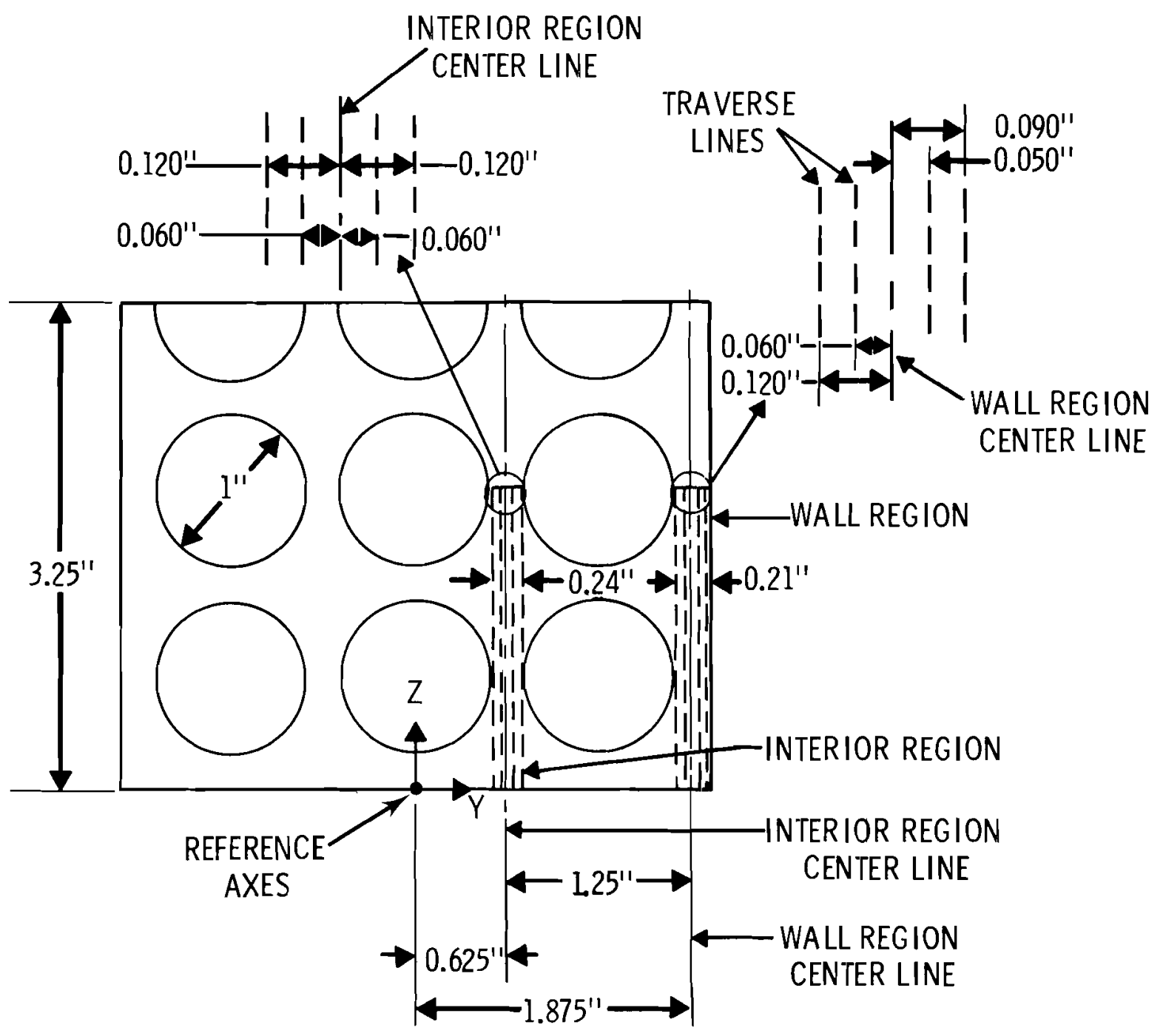

FIGURE 3.6 Data regions within data planes. 
coordinates, normalized values for the mean velocity, turbulent intensity and turbulent scale for each data point in the flow field. As in the previous study ${ }^{(2)}$ the turbulence scale estimates were obtained by fitting the correlation function plots to the equation

$$
R(\tau)=e^{\alpha_{1} \tau} \cos \alpha_{2} \tau
$$

By using the definition for Eulerian macro time scale

$$
T_{E}=\int_{0}^{\infty} R(\tau) d \tau
$$

and Taylor's hypothesis, the turbulence macro scale was calculated from the equation

$$
\Lambda=-\frac{\bar{u} \alpha_{1}}{\alpha_{1}^{2}+\alpha_{2}^{2}} .
$$




\subsection{EXPERIMENTAL RESULTS}

The results of this experimental study have provided new and somewhat surprizing information concerning the effect of a grid spacer on the turbulent flow structure in rod bundles. The most interesting observation from the data was that a region of rather quiet turbulent flow exists downstream of the grid spacer. Flow emerging from the grid spacers had rather high turbulence intensity in the axial direction but at only 14 inches downstream of the grid, the intensity decayed to a level that was lower than at the center of pipe flow. The turbulence intensity then increased to a high level downstream of this quiet region before eventually decaying to values typical of those obtained without the grid spacer.

The data presented in the following sections were obtained on four planes downstream from the first spacer and on one plane downstream from the second spacer. Data was acquired at each plane within the interior region and the wall region as shown in Figure 3.6. Data was taken at selected points within the interior region along transverse 1 ines located at \pm .600 inch and \pm .120 inch relative to the interior region center 1 ine as well as on the region center 1 ine. Data was taken at selected points in the wall region along 1 ines at -.120 inch, -.060 inch, .050 inch and .090 inch relative to the wall region center 1 ine and along the wall region center line.

The wall and interior regions 1 ie on a common plane which is perpendicular to the direction of flow. To facilitate the discussion of the experimental results, each downstream plane was assigned an identification number. The axial position of each plane is defined in Table 4.1. 
TABLE 4.1 Distance Downstream From Grid Spacer for Identified Plane
Plane 12.25 inches downstream first spacer
Plane $2 \quad 14.25$ inches downstream first spacer
Plane 326.25 inches downstream first spacer
Plane $4 \quad 38.25$ inches downstream first spacer
Plane $5 \quad 1.25$ inches downstream second spacer

The graphical presentation of the reduced data given in this chapter represents a significant portion of the entire data; however, complete tabulation of the reduced data is presented in Appendix A. A listing of the data reduction computer program is given in Reference 2.

\subsection{Interior Region Flow Structure}

The flow structure of the interior region was investigated and is presented in the following subsections. The results include mean velocity and turbulence intensity maps, macroscale along selected traverse lines and the effect of Reynolds number on both turbulence intensity and scale along the interior centerline.

\subsubsection{Mean Velocity}

Figures 4.1 through 4.5 give the mean velocity maps at the five measurement planes. Figure 4.1 shows the flow distribution at Plane 1 located at 2.25 inches downstream of the first spacer. The flow redistribution caused by the spacer can be determined by comparing this map with the map for nearly developed flow at Plane 4 given in Figure 4.4 . The comparison shows that the mean velocity has decreased locally in the wake of the 
BNWL-1757

19

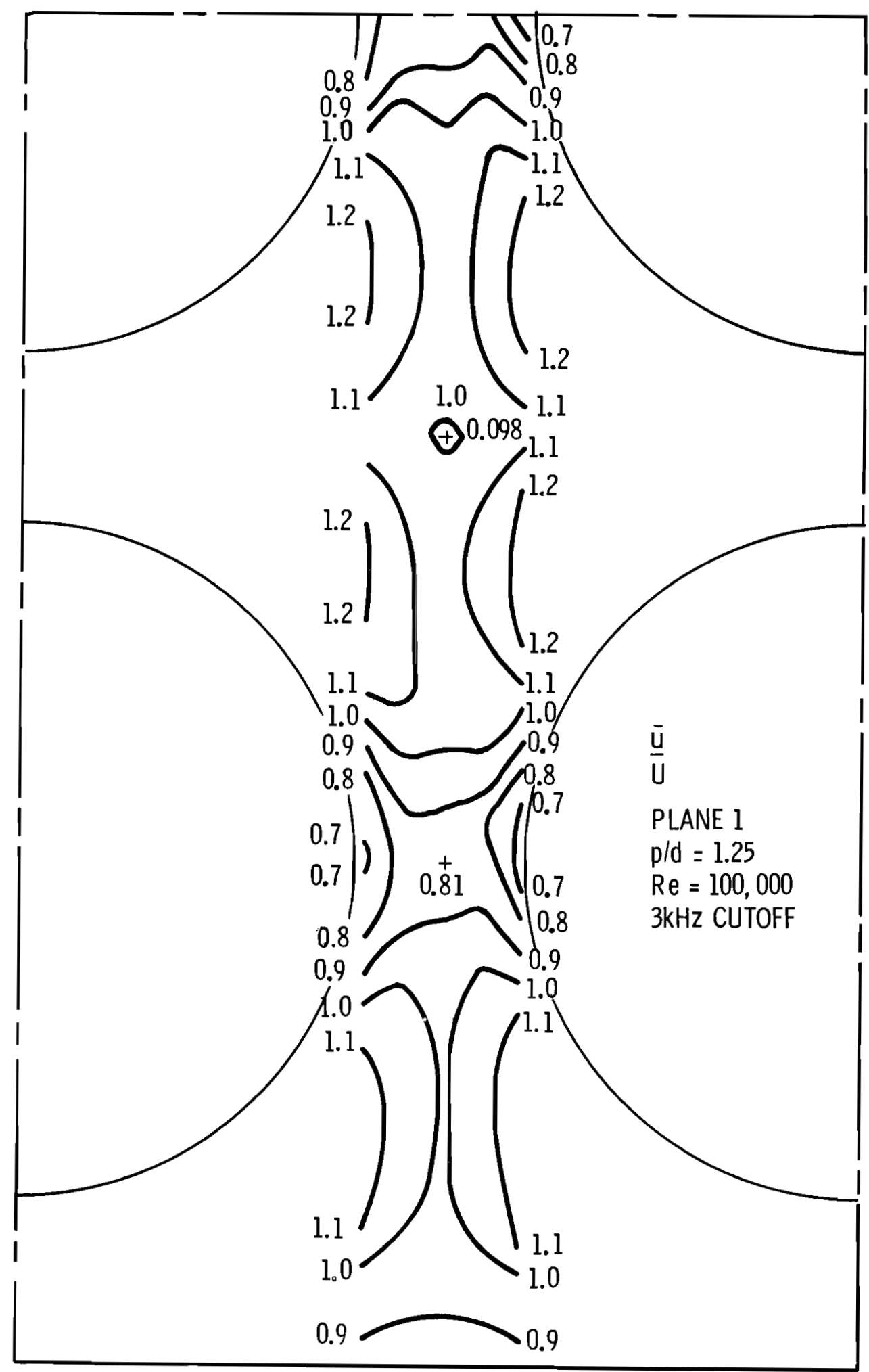

FIGURE 4.1 Axial velocity $\left(\frac{\bar{u}}{U}\right)$ map, interior region, Plane 1. 
BNWL-1757

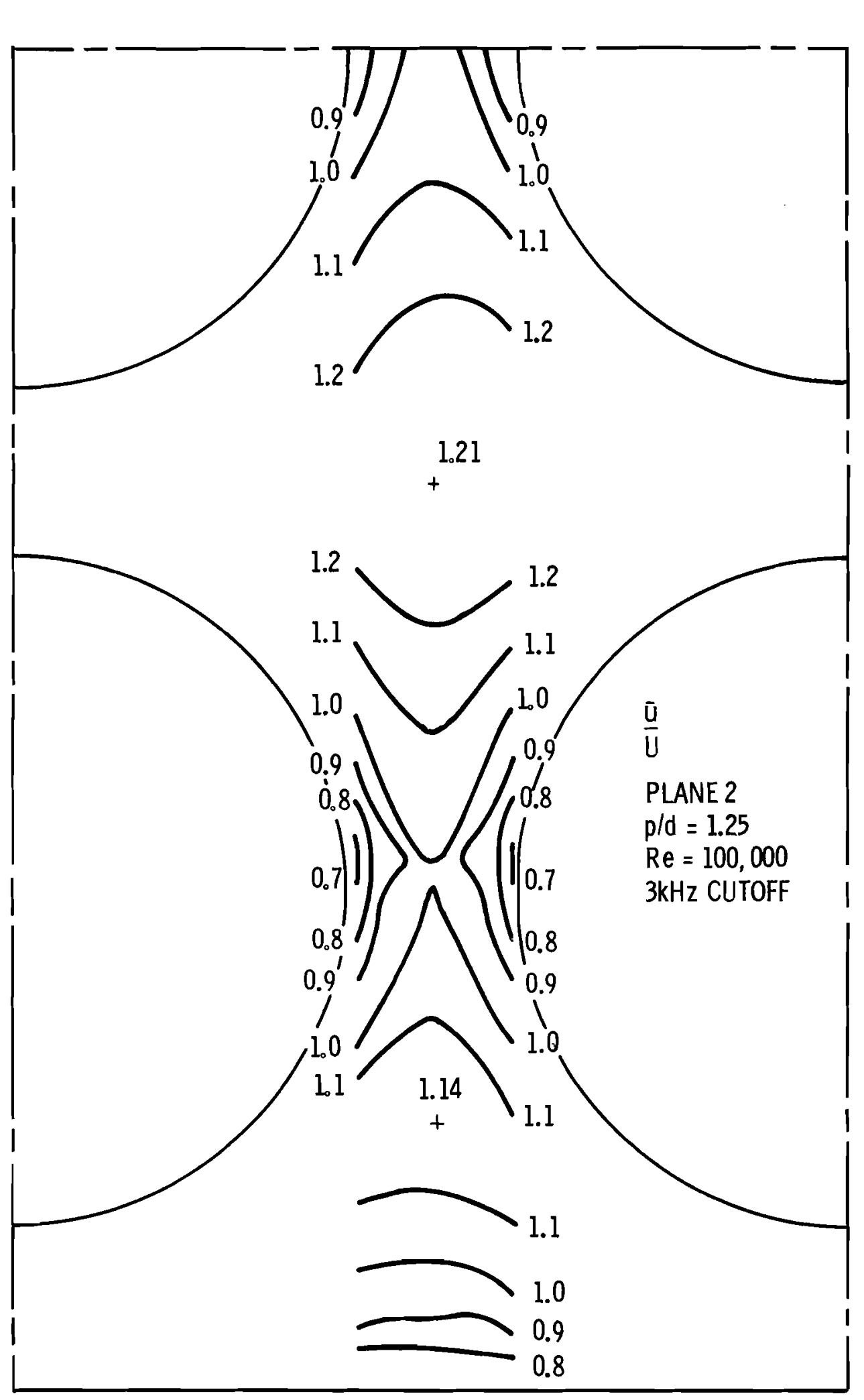

20

FIGURE 4.2 Axial yelocity $\left(\frac{\bar{u}}{U}\right)$ map, interior region, Plane 2. 


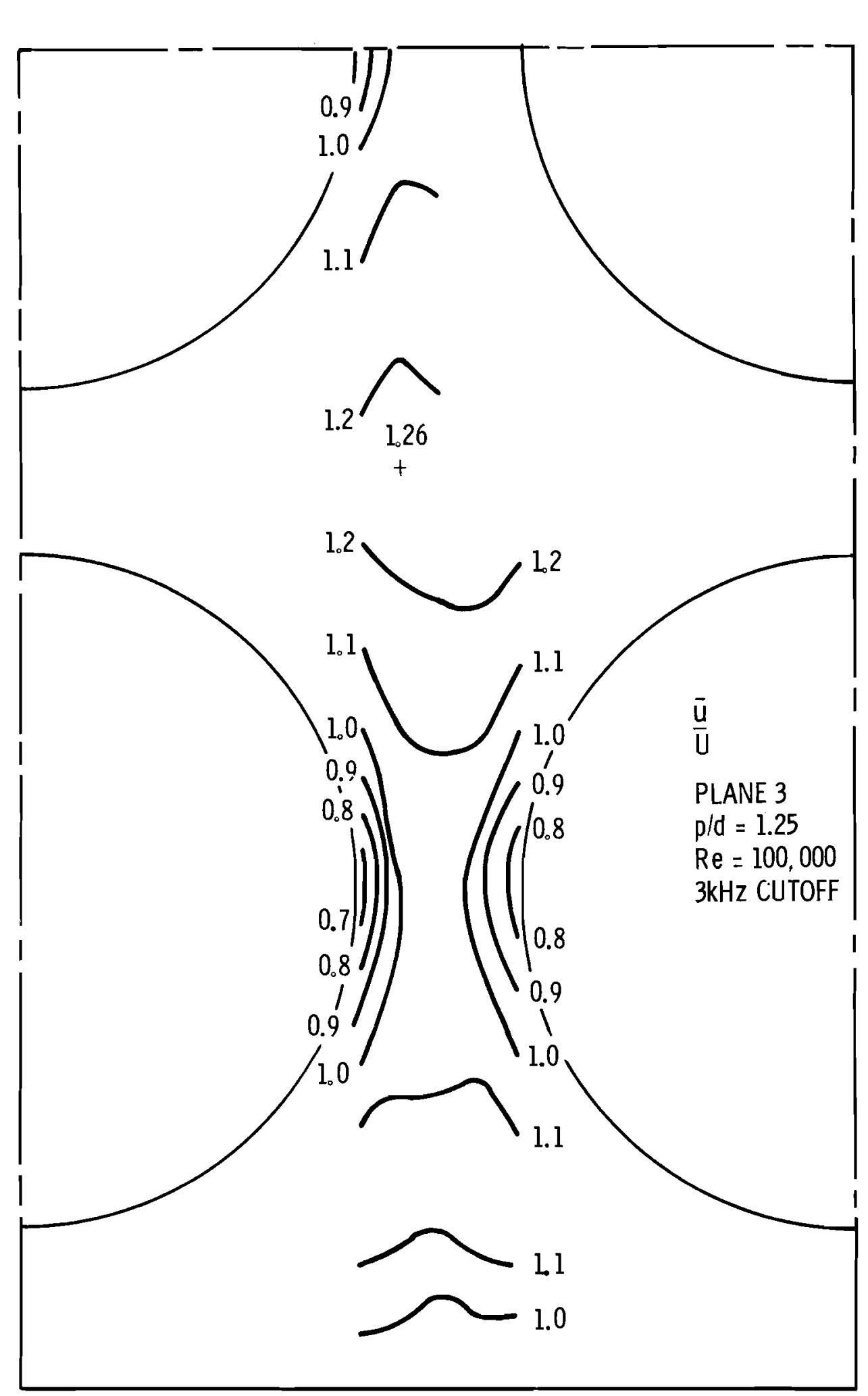

FIGURE 4.3 Axial velocity $\left(\frac{\bar{U}}{U}\right)$ map, interior region, Plane 3. 
BNWL-1757

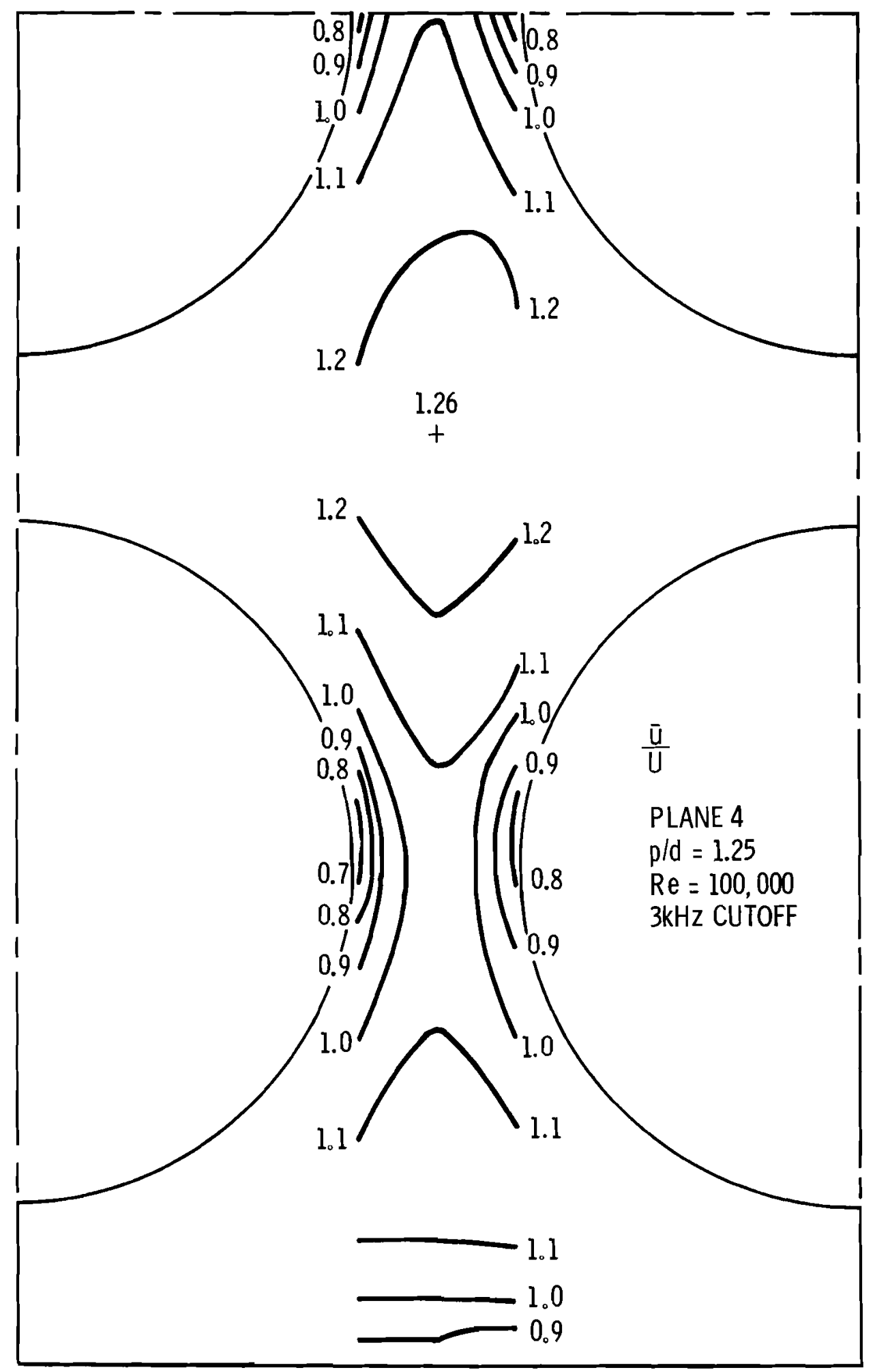

FIGURE 4.4 Axial veloctiy $\left(\frac{\bar{U}}{U}\right)$ map, interior region, Plane 4. 
BNWL-1757

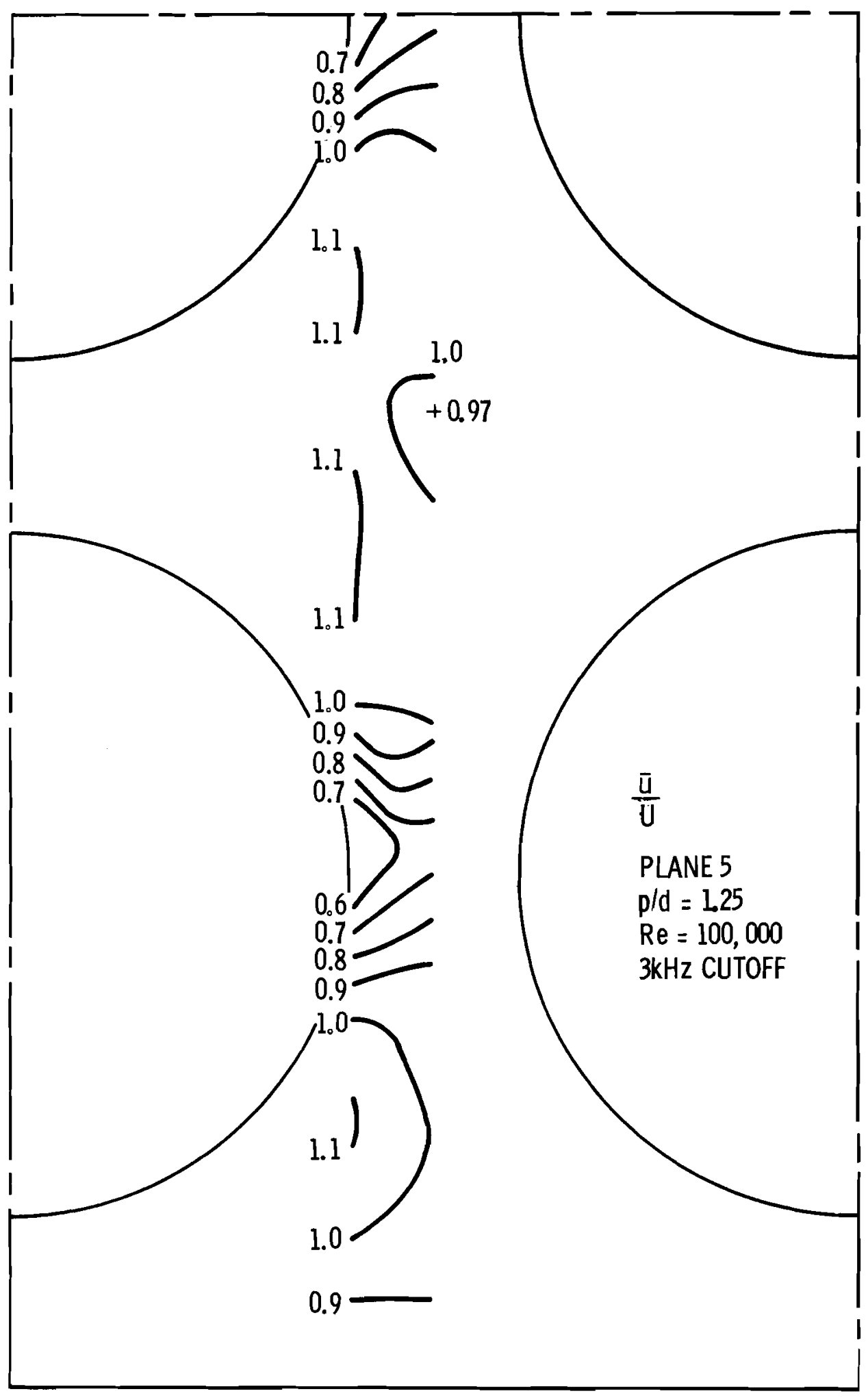

FIGURE 4.5 Axial velocity $\left(\frac{\bar{u}}{U}\right)$ map, interior region, Plane 5 . 
grid plate. The position of maximum velocity has been shifted from the center of the interior subchannel to the centers of the four symmetric quadrants of the interior subchannel. The asymmetry of the isovels (1ines of constant mean velocity) about the region centerline indicate how the flow is adjusting toward the fully developed condition.

Figure 4.2 presents the mean velocity map at Plane 2 located 14.25 inches downstream of the first grid spacer. The form and near symmetry of the isovels suggests that the flow is nearly developed; however, when compared with the results for nearly developed flow given in Figure 4.4, it is observed that the flow near the gap has not recovered. Plane 2 has higher velocity gradients in the gap region than does Plane 4. Except for this difference the map at Plane 2 shows close similarity to the map at P1ane 4.

The velocity contour map for Plane 3 located 26.25 inches downstream of the first grid spacer is given in Figure 4.3. The velocity gradient at Plane 3 is nearly fully developed. The noticeable change which has occurred between Plane 2 and Plane 3 is the isovel distortion in both the wall and interior subchannels. The distortion could be attributed to crossflow into the gaps. Near the subchannel centers the velocity gradients are sma11; therefore, smal1 changes in local velocity would result in relatively large shifts in the isovels. Thus, isovel distortions near the subchannel centers do not represent significant changes in velocity.

Figure 4.6 presents a velocity map for fully developed flow obtained in the previous study ${ }^{(2)}$ A comparison with the map at Plane 4 shows somewhat 
BNWL-1757

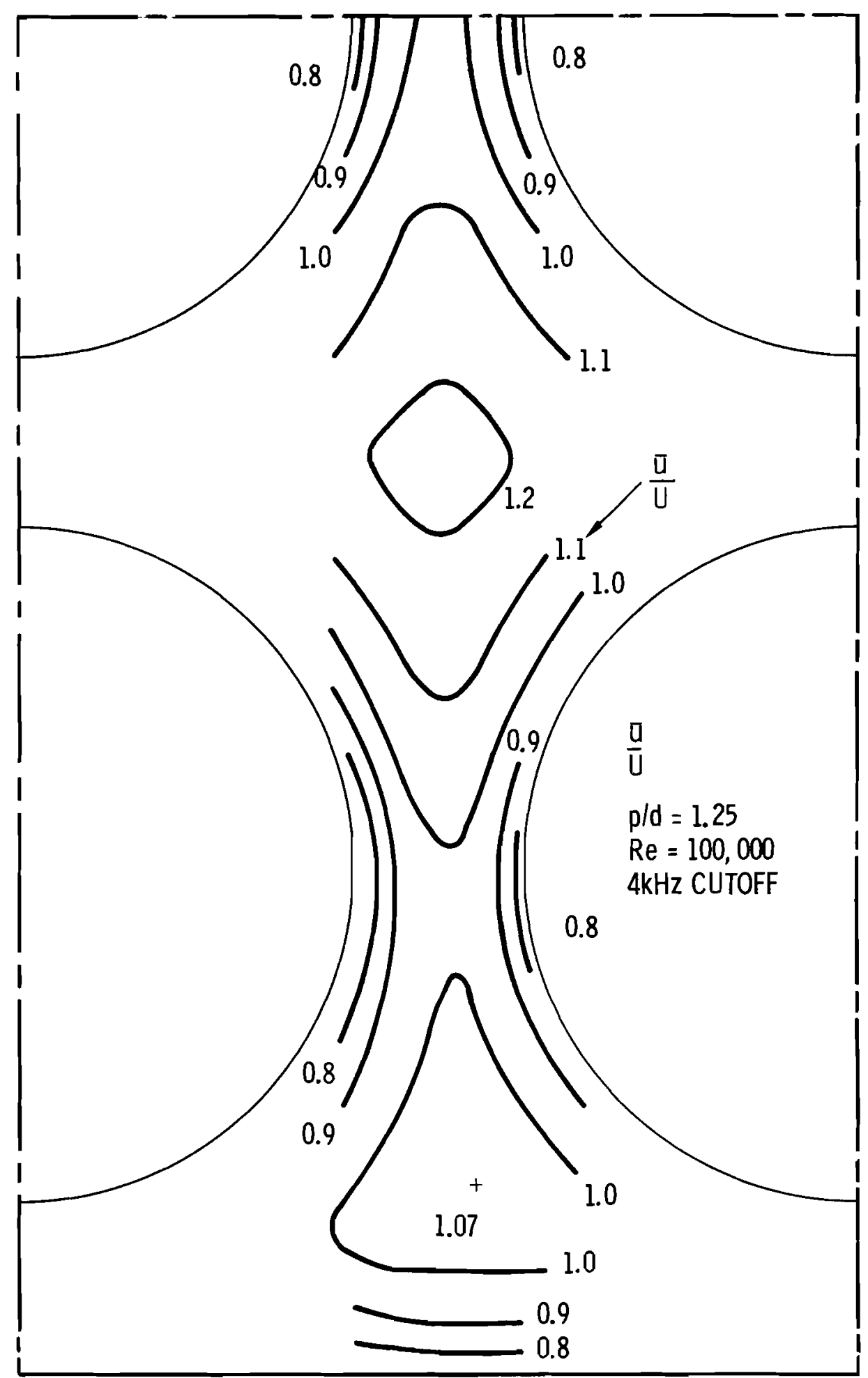

FIGURE 4.6 Axial velocity ( $\left.\frac{\bar{u}}{\bar{U}}\right)$ (map, interior region, fully developed flow no grid spacer (2). 
BNWL -1757

higher velocity in the present study. The reason for this discrepancy is believed to be caused by a small null offset found in the LDV electronics subsequent to the present experiments. The discrepancy between the two data sets are caused by the offsets being in the opposite directions for the two electronic readout channels available in the LDV system. In the first study all data was taken using one of the electronic channels. In the present study it was necessary to use a portion of the other electronic channel because of an electrical component failure early in the experimental program. This change was used through the remainder of the study. Aside from the noted discrepancy in the magnitude, the form of the velocity contours at Plane 4 compares favorably with the previous study.

Figure 4.5 presents the mean velocity map at Plane 5 which is 1.25 inches downstream from the second grid spacer. When the maps for Plane 1 and Plane 5 are compared, larger velocity reductions are observed at Plane 5. This was anticipated since Plane 5 is 1 inch closer to the grid. Assuming that the development of the mean velocity is independent of the spacer, the data indicate a rapid recovery of the local flow perturbation between $1.25^{\prime \prime}$ and $2.25^{\prime \prime}$ downstream from the spacers. The recovery in the rod gap is most rapid.

\subsubsection{Turbulence Intensity}

The axial turbulence intensity along the interior centerline at the four positions downstream the first spacer is given in Figure 4.7. The turbulence intensity at the four positions roughly exhibit the same form. Relative maxima occur midway between the gap center and the subchannel 
BNWL-1757
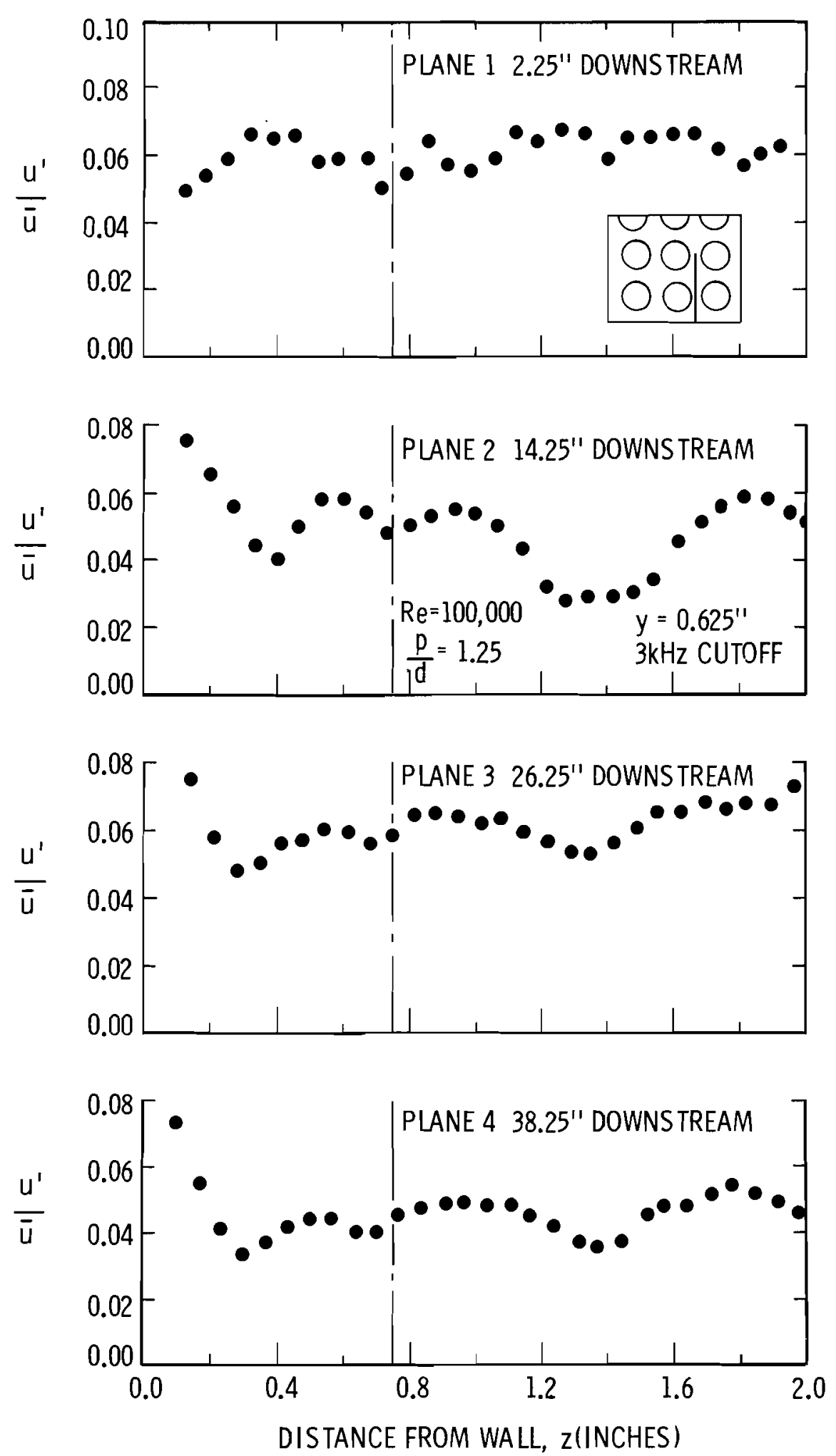

FIGURE 4.7 Axial intensity $\left(\frac{u^{\prime}}{\bar{u}}\right)$ along interior center line. 
centers and relative minima occur at the gap and the subchannel centers. The most interesting feature is the change in the turbulence intensity with distance downstream from the grid spacer. The change with downstream position is most pronounced around the interior subchannel center. The intensity at the subchannel center at the first position downstream from the grid spacer is 0.058 . A general increase in turbulence intensity was expected due to the passage of the flow through the grid spacer. However, the general decrease of axial turbulence intensity at only 14.25" downstream from the spacer was a surprise. The level of intensity of 0.028 found at Plane 2 is less than at the center of fully developed pipe flow. It is also below the level of intensity found for the same rod bundle without grid spacers. Between Plane 2 and Plane 3 the intensity increased nearly to the level observed at Plane 1. Further downstream at Plane 4 , the intensity has decayed and has finally approached values typical of a fully developed condition.

Figures 4.8 through 4.11 present the axial turbulence intensity maps for the interior regions at the planes downstream the first spacer. Figure 4.12 gives the intensity map for one-half of the interior region 1.25 inches downstream from the second spacer. These figures provide a vivid general picture of turbulence intensity within the rod bundle geometry.

The turbulence intensity map for Plane 1 is given in Figure 4.8 . The change in the axial intensity map due to the flow passing through the grid spacer can be determined by contrasting Plane 1 to Plane 4 


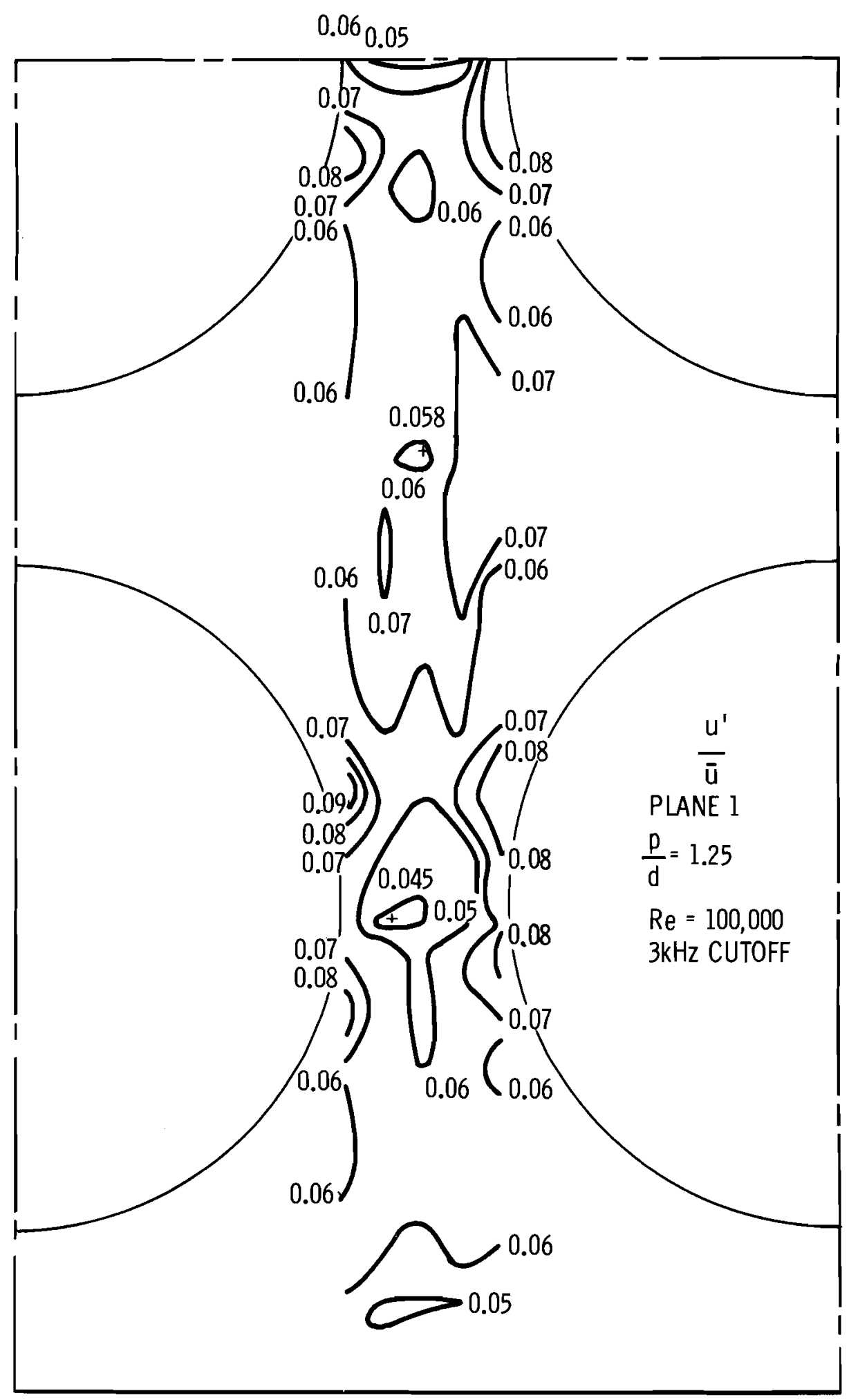

29

FIGURE 4.8 Axial intensity $\left(\frac{u^{\prime}}{\bar{u}}\right)$ map, interior region, Plane 1. 
BNWL-1757

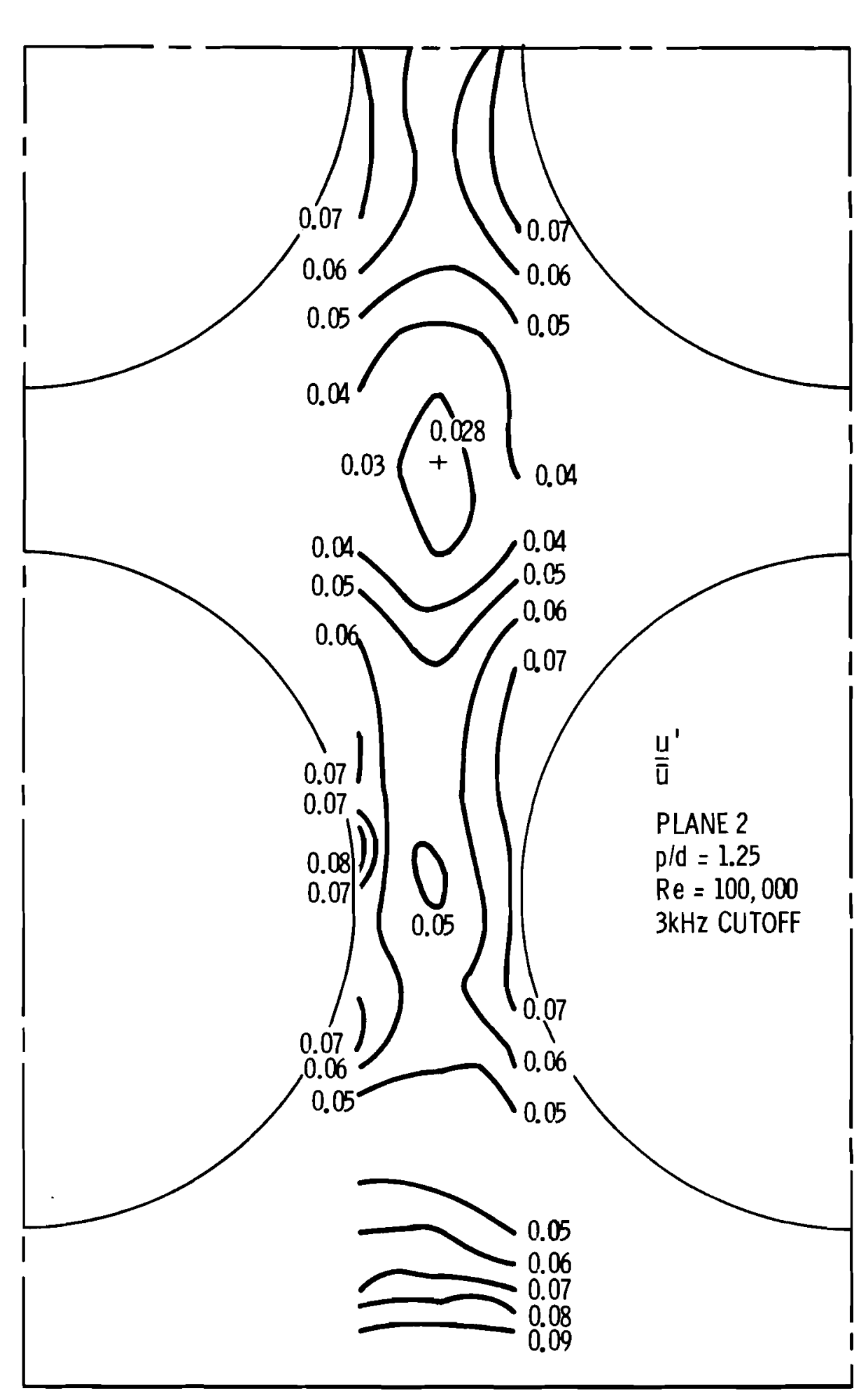

FIGURE 4.9 Axial intensity ( $\left.\frac{u^{\prime}}{\bar{u}}\right)$ map, interior region, Plane 2. 
BNWL-1757

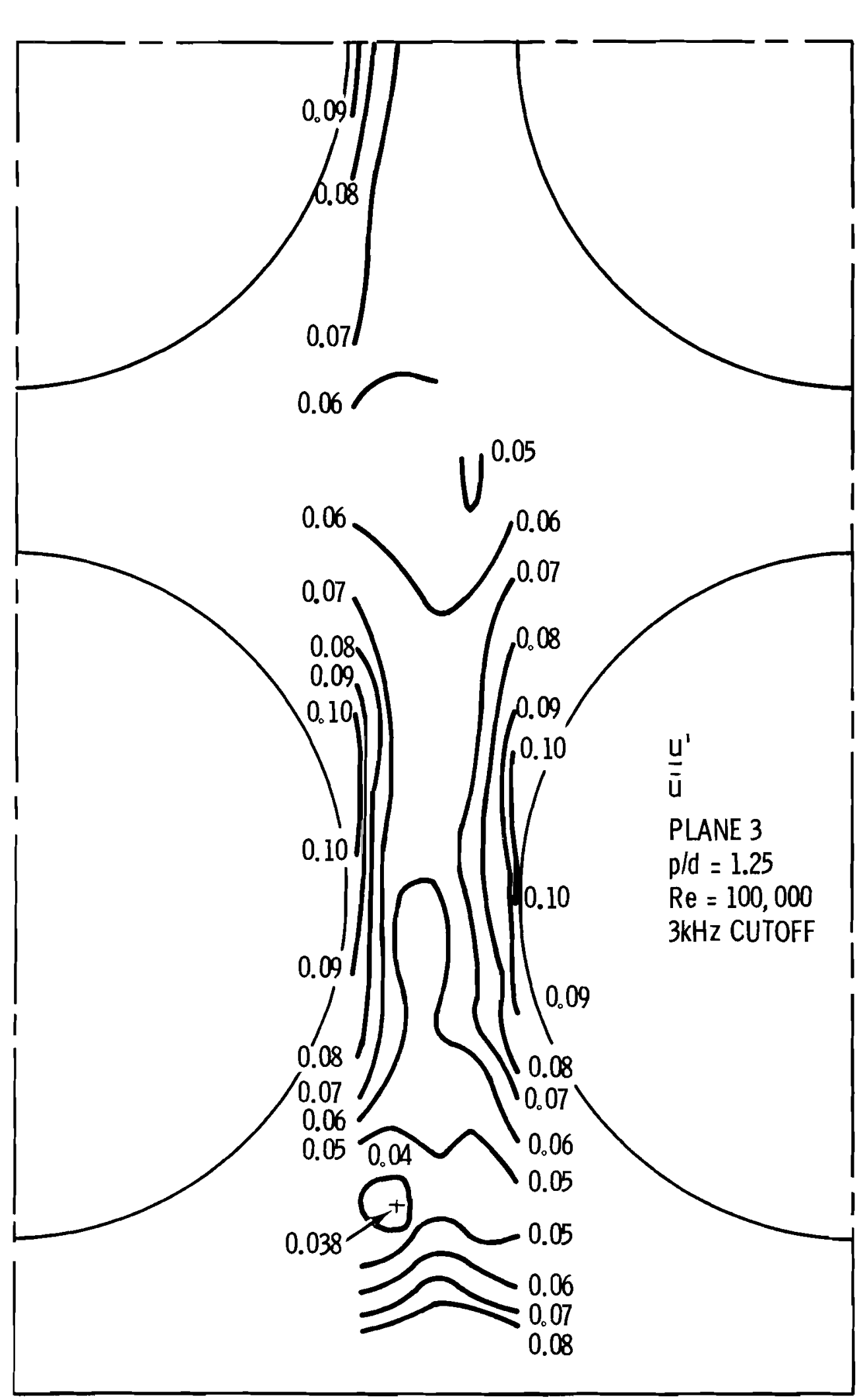

FIGURE 4.10 Axial intensity $\left(\frac{u^{\prime}}{\bar{u}}\right)$ map, interior region, Plane 3. 
BNWL-1757

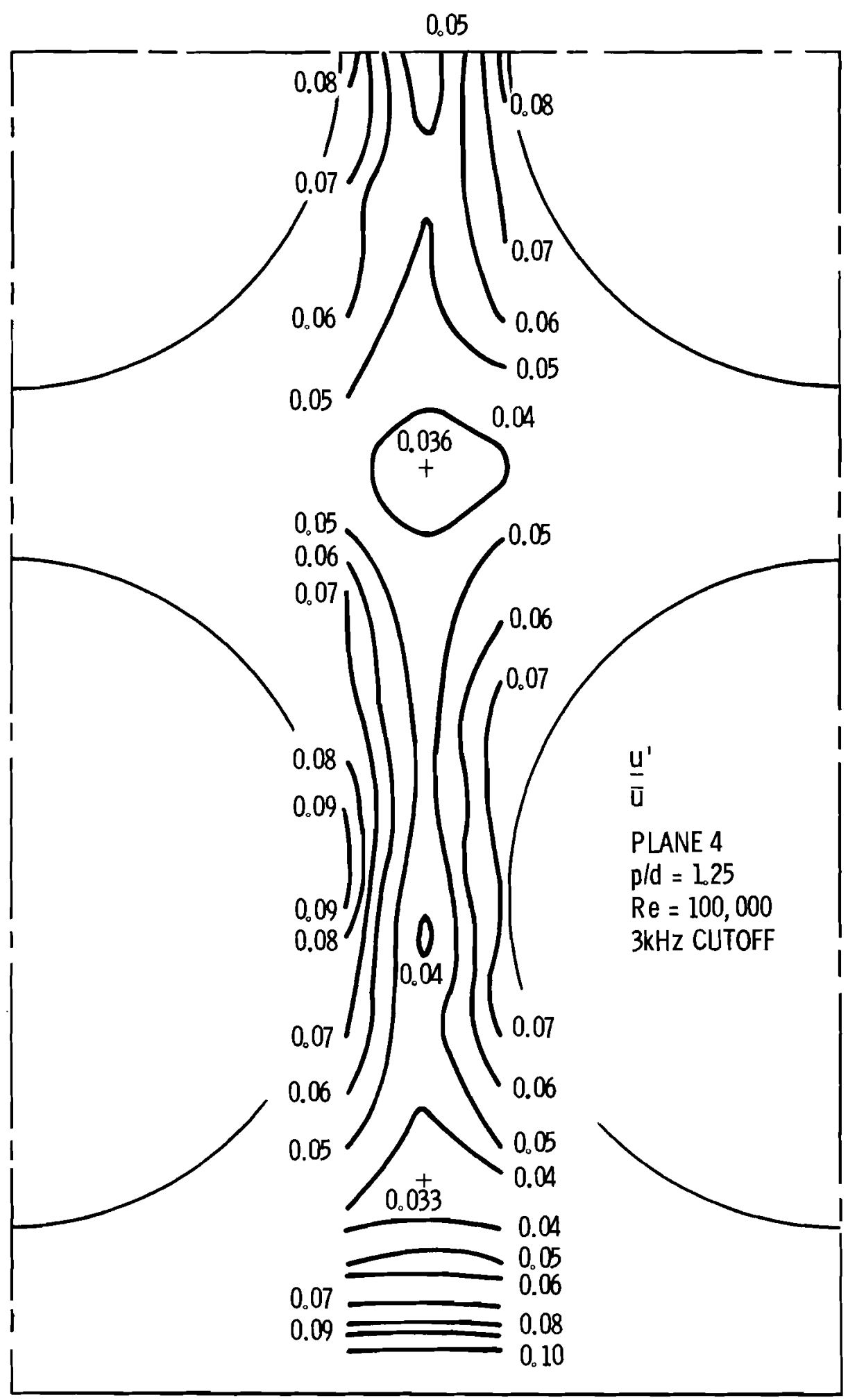

32

FIGURE 4.11 Axial intensity ( $\left.\frac{u^{\prime}}{\bar{u}}\right)$ map, interior region, Plane 4. 
BNWL-1757

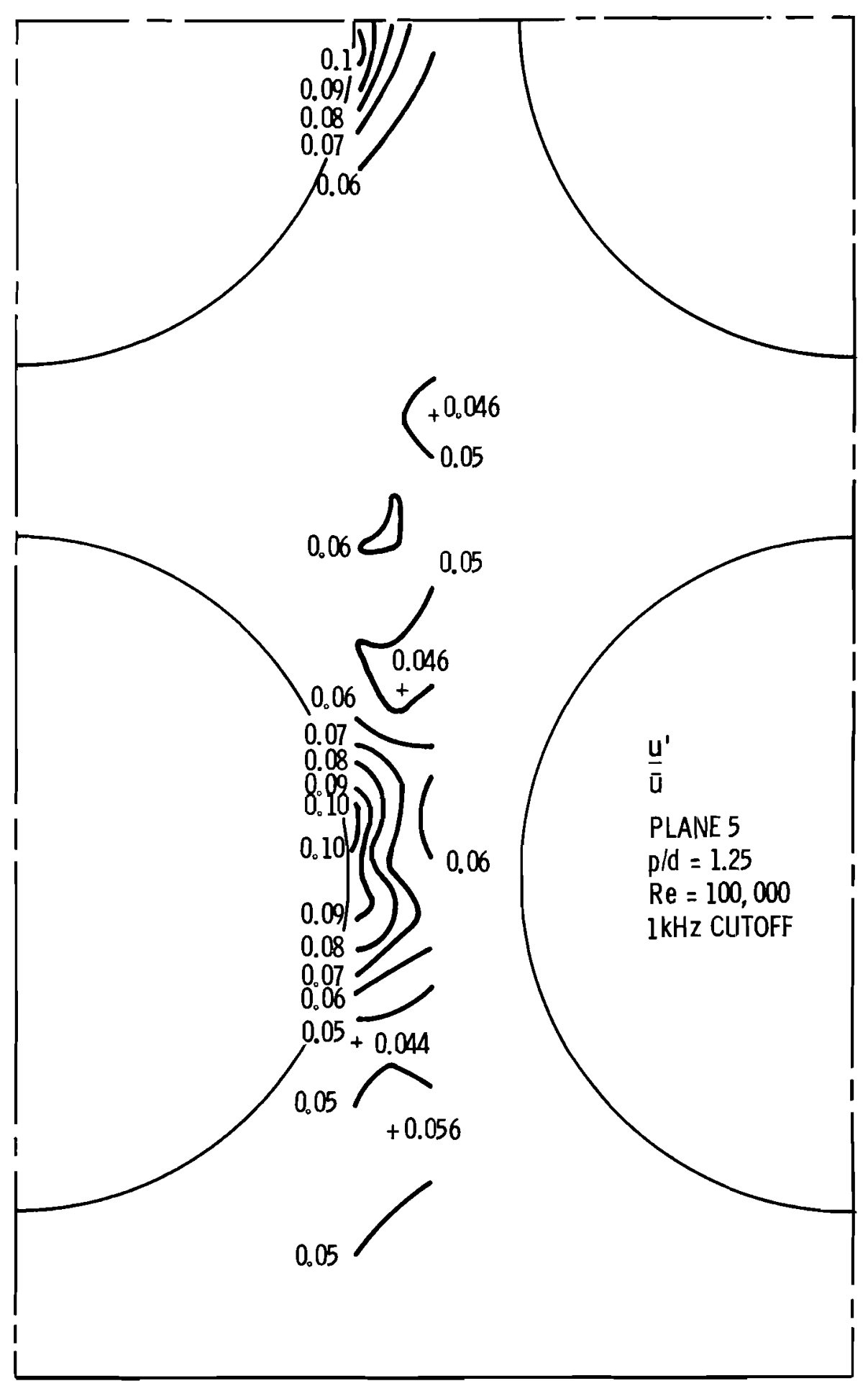

FIGURE 4.12 Axial intensity $\left(\frac{u^{\prime}}{0}\right)$ map, interior region, Plane 5. 
(Figure 4.11) for nearly developed flow. The comparison shows that the intensity in the interior region has increased with the largest increase occurring about the interior subchannel center. Passage through the spacer has caused a scrambling of the intensity contours. Another noticable difference between the maps for Plane 1 and Plane 4 is the zones of high intensity gradients in Plane 1 at the rod surfaces near the rod gap centers.

At Plane 2 (Figure 4.9) the level of intensity has experienced a general drop particularly about both the wall and interior subchannel centers. The axial intensity about the interior subchannel center has decreased over $50 \%$ from the intensity observed at Plane 1 . When Plane 2 is compared to the nearly developed condition at Plane 4 , it is seen that the intensity around the interior subchannel center is lower at Plane 2. The comparison also shows that the form of the intensity contours at Plane 2 are similar to Plane 4. The localized high intensity zones observed at Plane 1 near the rod gap centers have almost vanished at Plane 2.

Only 12 inches downstream from Plane 2 at Plane 3 , the leve1 of intensity in the interior subchannel has increased nearly $50 \%$. High intensity gradients have developed normal to the region centerline and rod surfaces. At Plane 4 the level of intensity has decayed and the intensity gradients have decreased. The intensity map is very similar to the one obtained in the previous study for fully developed flow (Figure 4.13); however, the values in the present study are about $15 \%$ lower. This is believed to be caused by the lower cutoff frequency of $3 \mathrm{kH}_{\mathrm{z}}$ as compared to $4 \mathrm{kH}_{\mathrm{z}}$ in the previous study. Figure 4.14 presents a comparison of data along the interior center line at Plane 4 with the data from the previous experiment with a $3 \mathrm{kH}_{z}$ cutoff. The agreement is excellent. 


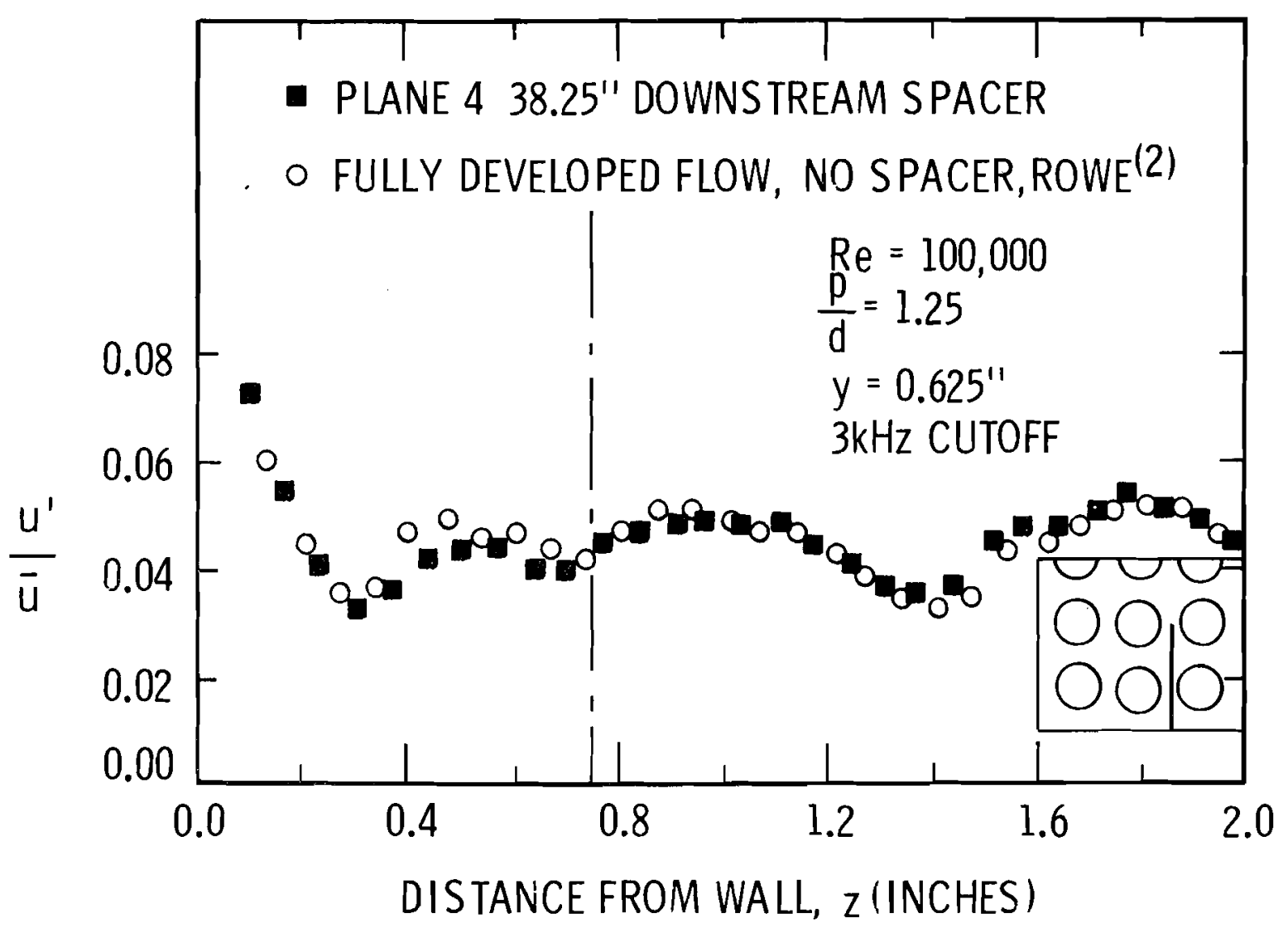

FIGURE 4.14 Axial intensity $\left(\frac{u^{\prime}}{u^{\prime}}\right)$ along interior center line. 
BNWL-1757

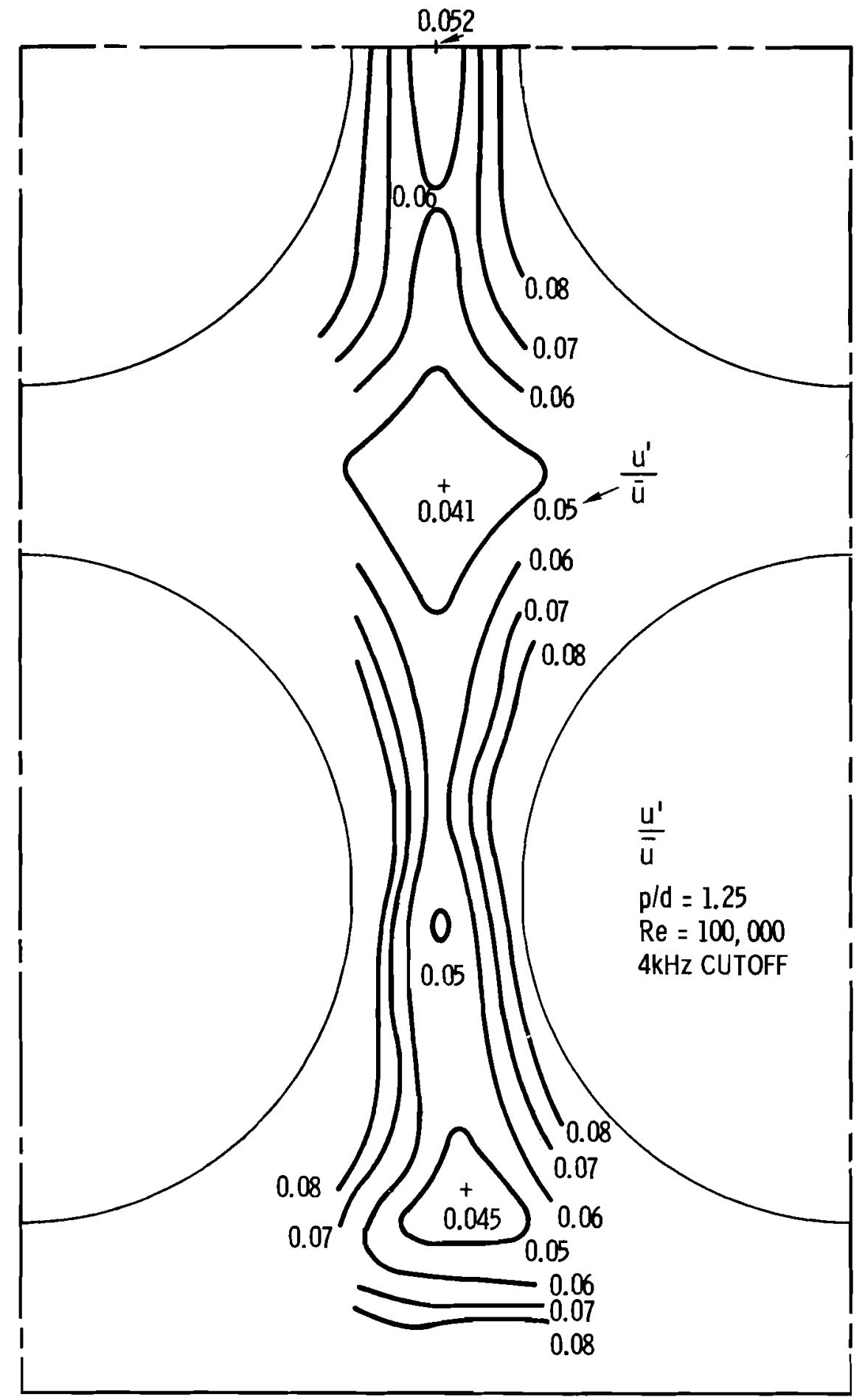

FIGURE 4.13 Axial intensity $\left(\frac{u^{\prime}}{\bar{u}}\right)$ map, interior region, fully developed flow, no grid spacer. (2) 
The turbulence intensity map 1.25 inches downstream of the second grid spacer (Plane 5) is shown in Figure 4.12. A comparison of this map with the map for Plane 1 at 2.25 inches downstream from the first spacer shows several similarities. The intensity contours for both maps are scrambled particularly about the subchannel centers. The high intensity gradients at the rod gap centers noted at Plane 1 are even more pronounced at Plane 5. However, the level of intensity at Plane 5 around the interior subchannel center is seen to be lower than the intensity at Plane 1. This discrepancy can again be attributed to the different cutoff frequences since data at Plane 5 was taken with a $1 \mathrm{kH}_{\mathrm{z}}$ cutoff and data at Plane 1 was taken with a $3 \mathrm{kH}_{\mathrm{z}}$ cutoff.

Review of the intensity maps downstream from the first grid spacer shows the general trend noted for only the interior center lines, particularly around the interior subchannel center. First, the flow emerges from the spacer with high axial intensity, then after decreasing rapidly to a low level of intensity, the intensity increases to high level before decaying to the nearly developed condition.

\subsubsection{Turbulence Scale}

Figure 4.15 shows the axial macroscale of turbulence as estimated by Taylor's hypothesis in the interior region at the various downstream planes. At the different planes the macroscale along lines $-.120^{\prime \prime}$ and $-.060^{\prime \prime}$ offset from the interior centerline as well as on the interior centerline are given. Comparison of the macroscale data found at the different downstream planes shows a general increase in scale with increasing distance downstream from the grid spacer. Generally, the scale also increases as 
BNWL-1757
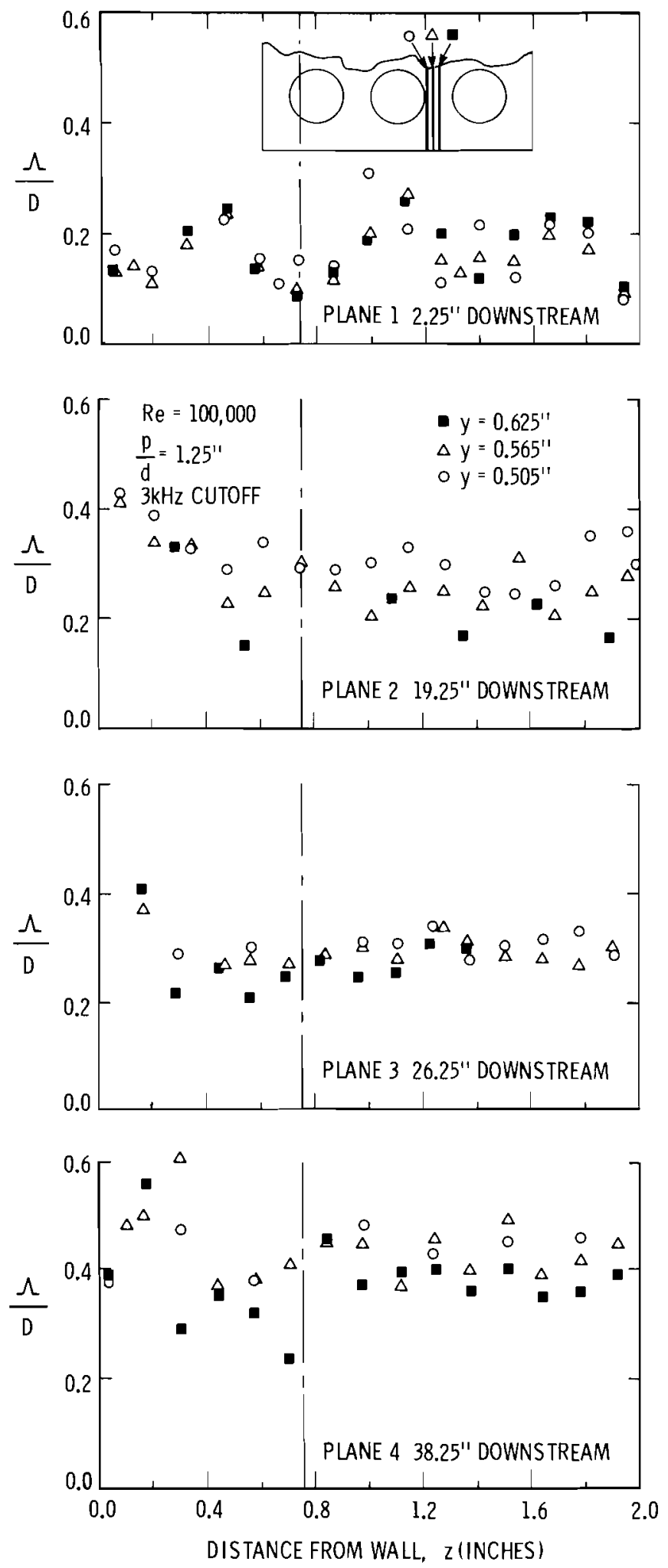

FIGURE 4.15 Axial scale $(\Lambda / D)$ for interior region. 
the distance from a boundary decreases. However, exceptions to this trend are found particularly at Plane 1. These exceptions found at Plane 1 may be due to the lingering influence of the grid spacer.

The turbulence scale at Plane 5 along the centerline is presented in Figure 4.16. The results at Plane 1 are included for comparison. The scale at Plane 5 is observed to be smaller between the wall and rod gap, but show close similarity in the interior subchannel. The results for the two planes immediately downstrean from the two grid spacers indicate that the axial macroscale experiences a marked reduction during passage through the grid spacers. Comparison between plane 4 for nearly developed flow and Plane 1 or Plane 5 shows that this reduction is about $50 \%$. Figure 4.17 compares the macroscale found at Plane 4 with the macroscale found in fully developed flow of the previous study. The results are very nearly the same.

\subsubsection{Effect of Reynolds Number}

A11 experimenta 1 data were taken at a nominal Reynolds number of 100,000 with the exception of some centerline traverses. The influence of different Reynolds numbers on the turbulence intensities are shown in Figure 4.18. The data indicate that the turbulence intensity decreases slightly with increasing Reynolds number. The largest influence of Reynolds number on intensity is observed at plane 2. At Plane 4 , the influence of Reynolds number on the intensity is small. These results are consistent with the results of the previous study.

Figure 4.19 shows the macroscale along the interior centerline at Planes 1, 2, and 4 at three different Reynolds numbers. The effect of Reynolds number on scale is weak. However, the results at Plane 1 
BNWL-1757

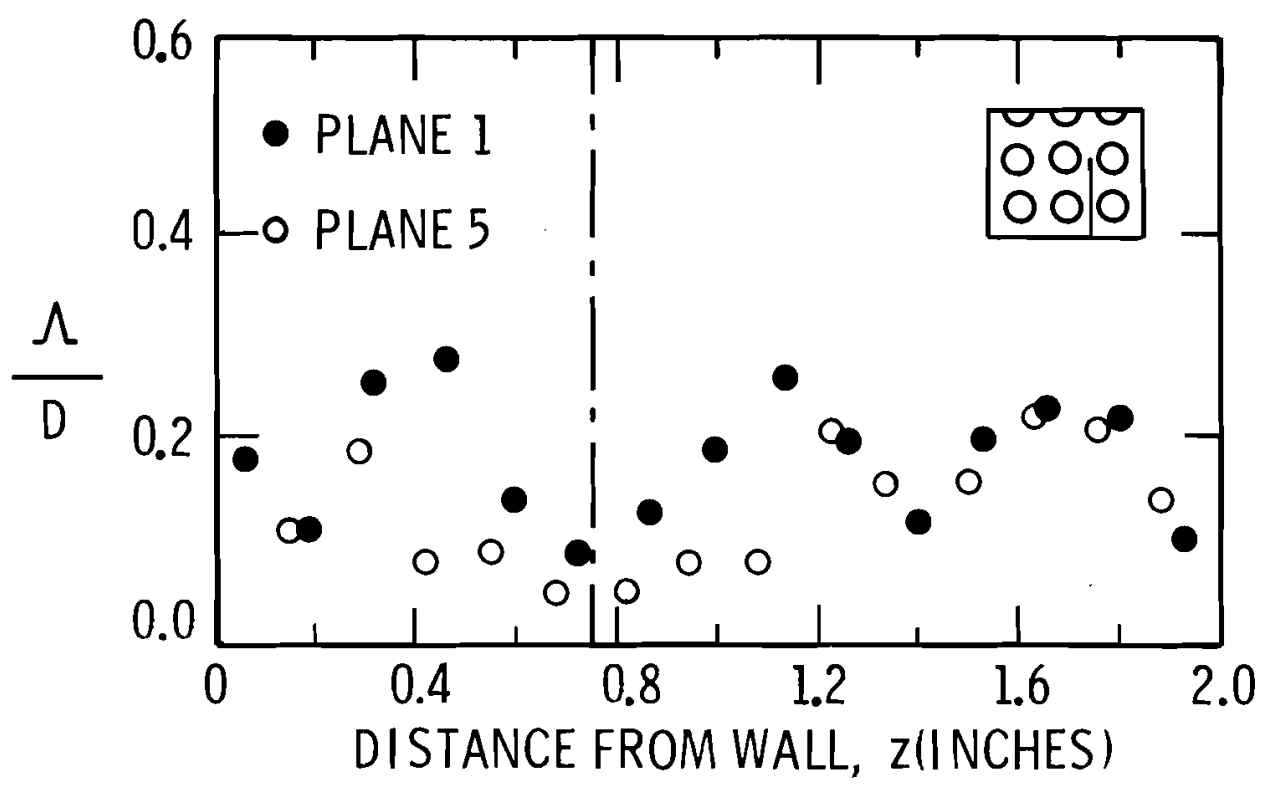

FIGURE 4.16. Axial Scale $(\Lambda / D)$ Along Interior Center Line for Plane 1 and Plane 5

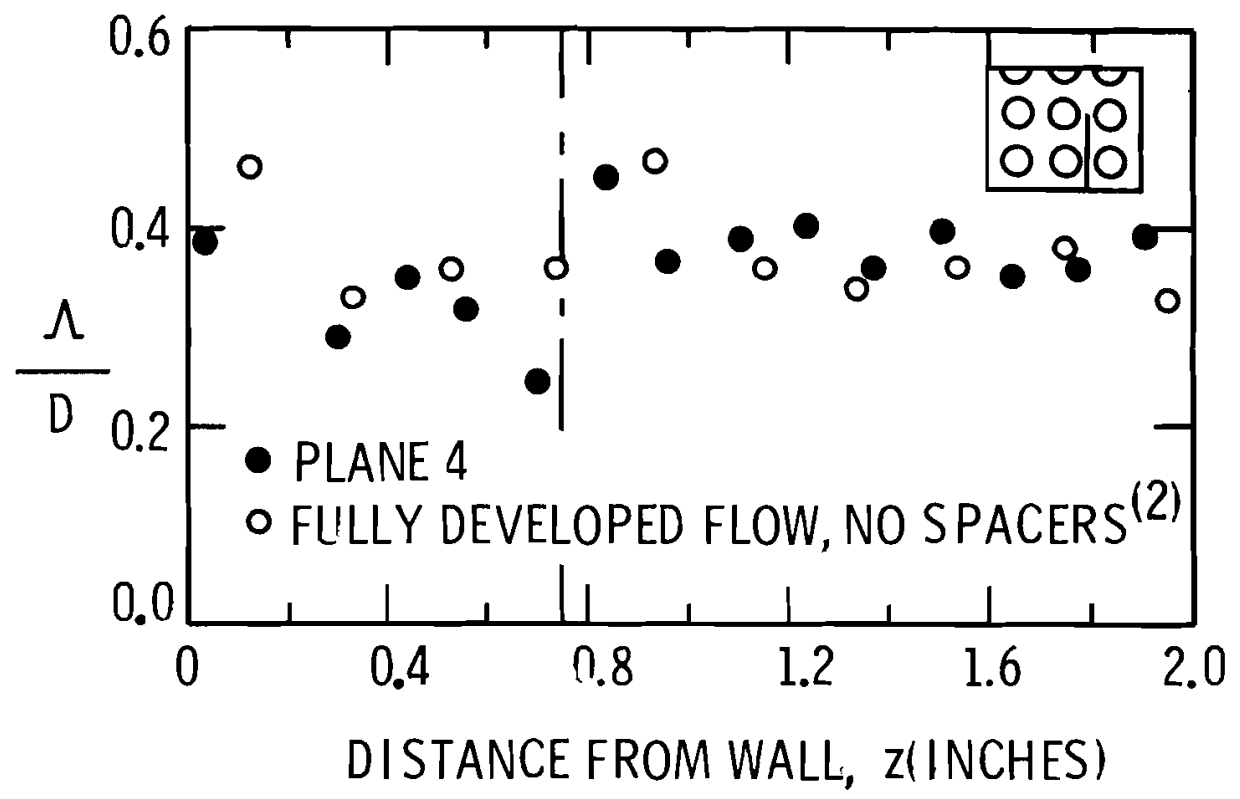

FIGURE 4.17. Axial Scale ( $\Lambda / D)$ Along Interior Center Line for Plane 4 and Fully Developed Flow 

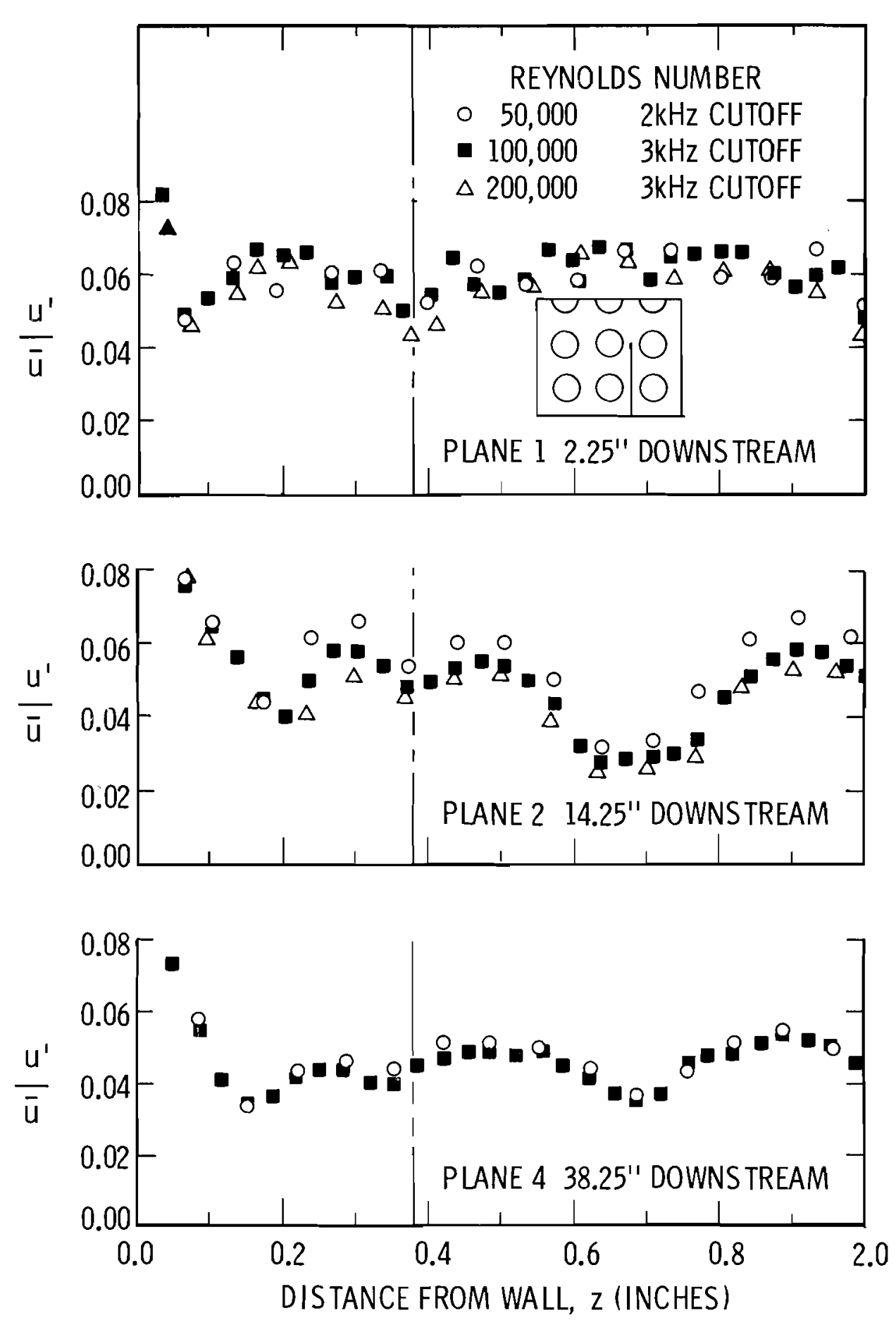

FIGURE 4.18. Axial Intensity $\left(\frac{u^{\prime}}{\bar{u}}\right)$ Along Interior Centerline for Different Reynolds Numbers 
BNWL-1757
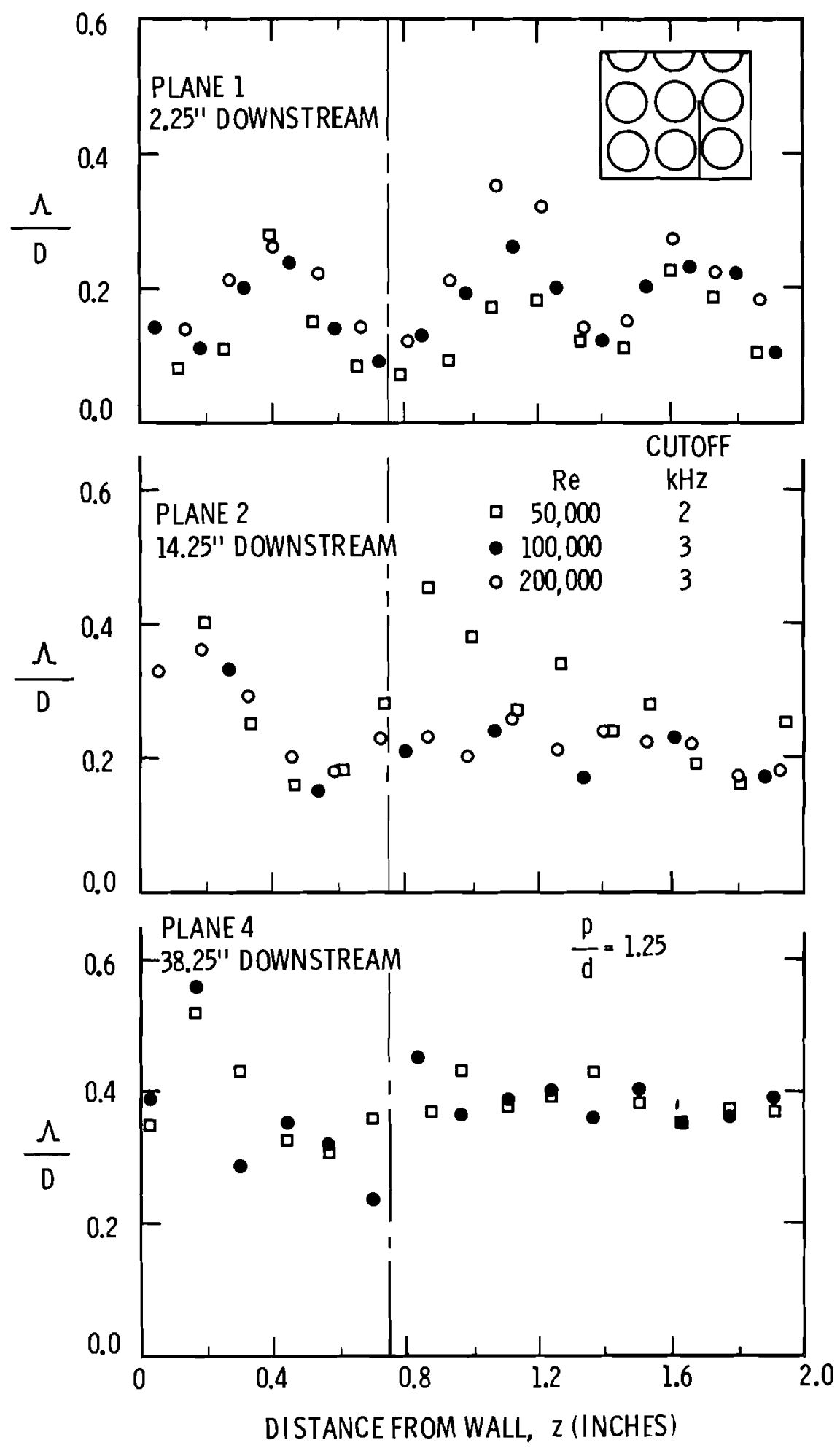

FIGURE 4.19. Axial Turbulence Scale ( $N / D)$ Along Interior Centerline for Different Reynolds Numbers 
indicate a slight increase in scale with a increase in Reynolds number. As the distance from the spacer increases, the effect of Reynolds number essentially vanishes. Thus, the effect of increasing Reynolds number causes a slight decrease in turbulence intensity and a slight increase in turbulence scale. The influence of Reynolds number on both intensity and scale diminishes rapidly with distance downstream from the grid.

\subsection{Wall Region Flow Structure}

The following results are for the side wall region which was defined in Figure 3.6. Data within this region were limited to Planes 1, 2, and 4 . The flow structure within the wall region is described by mean velocity maps, turbulence intensity maps and macroscale plots for three planes downstream from the first grid spacer.

\subsubsection{Mean Velocity Maps}

Figures 4.20 through 4.23 give mean velocity maps for the wal1 region at Planes 1, 2, 4 and for fully developed flow with no grid spacer. (2) Except for the apparent velocity peaks on both sides of the wall subchannel center, it may not be immediately obvious that the flow has passed through the spacer. When the map for Plane 1 (Figure 4.20) is contrasted with the map for Plane 4 (Figure 4.22), other flow changes are recognized, in particular the reduced velocity downstream of the cylindrical spacer in the rod gap. Note the general increase in the mean velocity in the corner subchannel, implying increased flow in the corner subchannel immediately downstream of the spacer. 


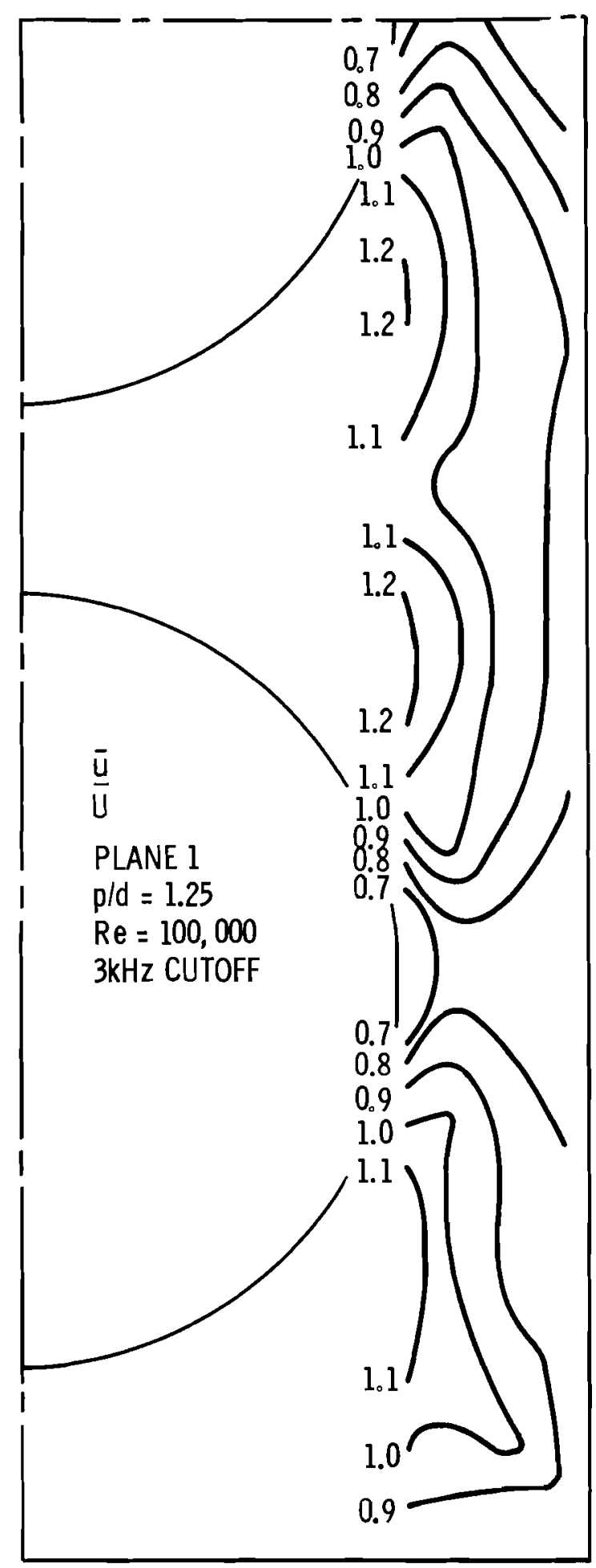

FIGURE 4.20. Axial Velocity $\left(\frac{\bar{u}}{U}\right)$ Map, Wa11 Region, Plane 1

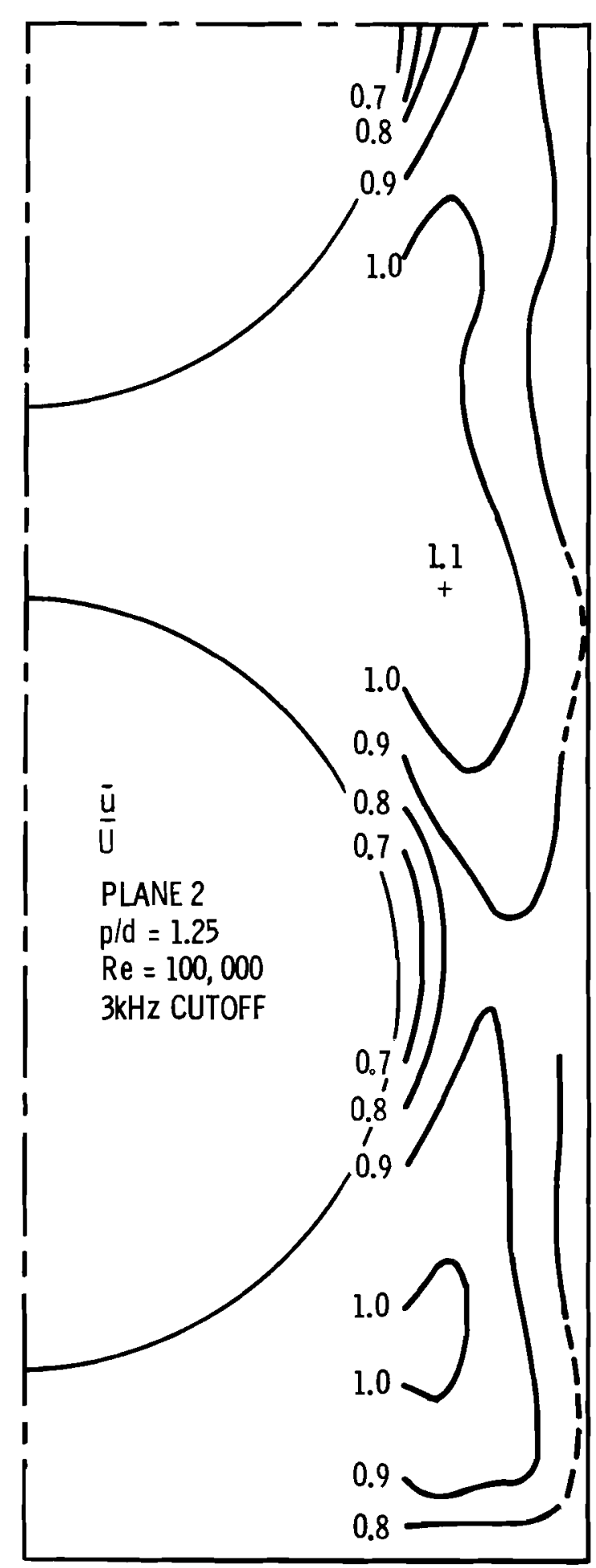

FIGURE 4.21. Axial Velocity $\left(\frac{\bar{u}}{U}\right)$ Map, Wa11 Region, Plane 2 
BNWL-1757

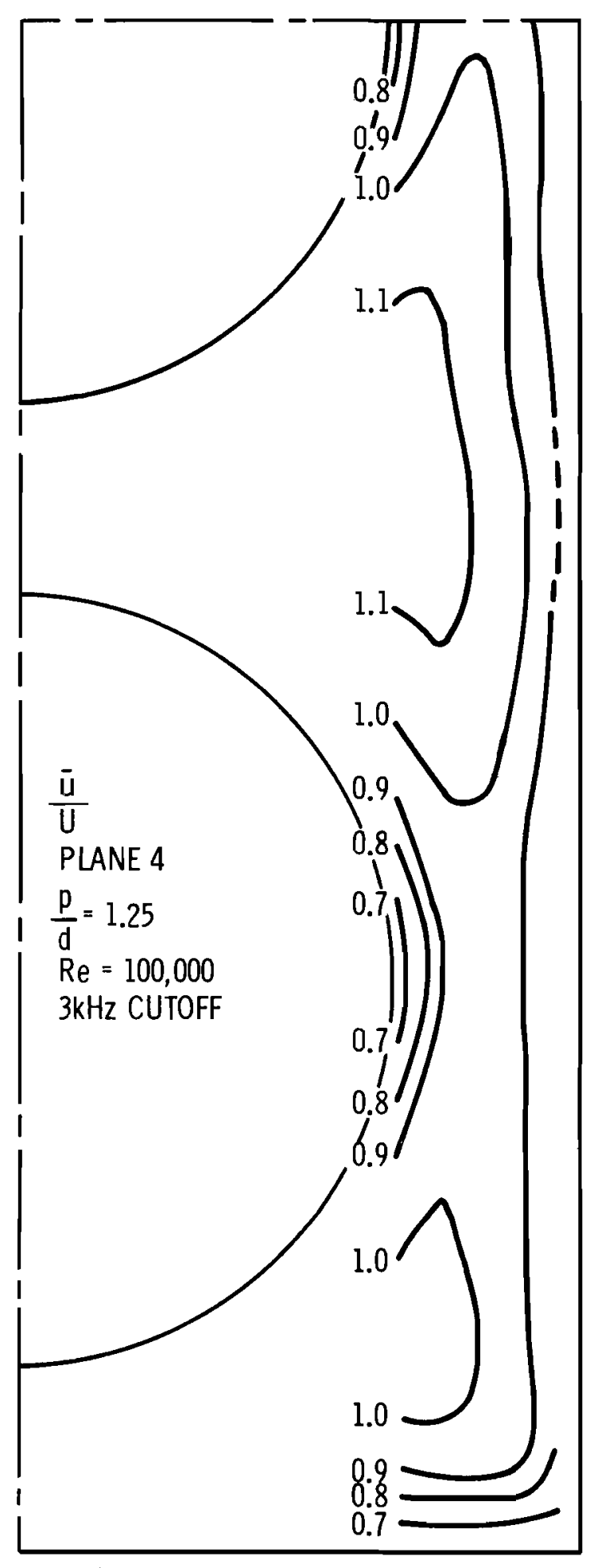

FIGURE 4.22. Axial Velocity $\left(\frac{\bar{u}}{U}\right)$ Map, Wall Region, Plane 4

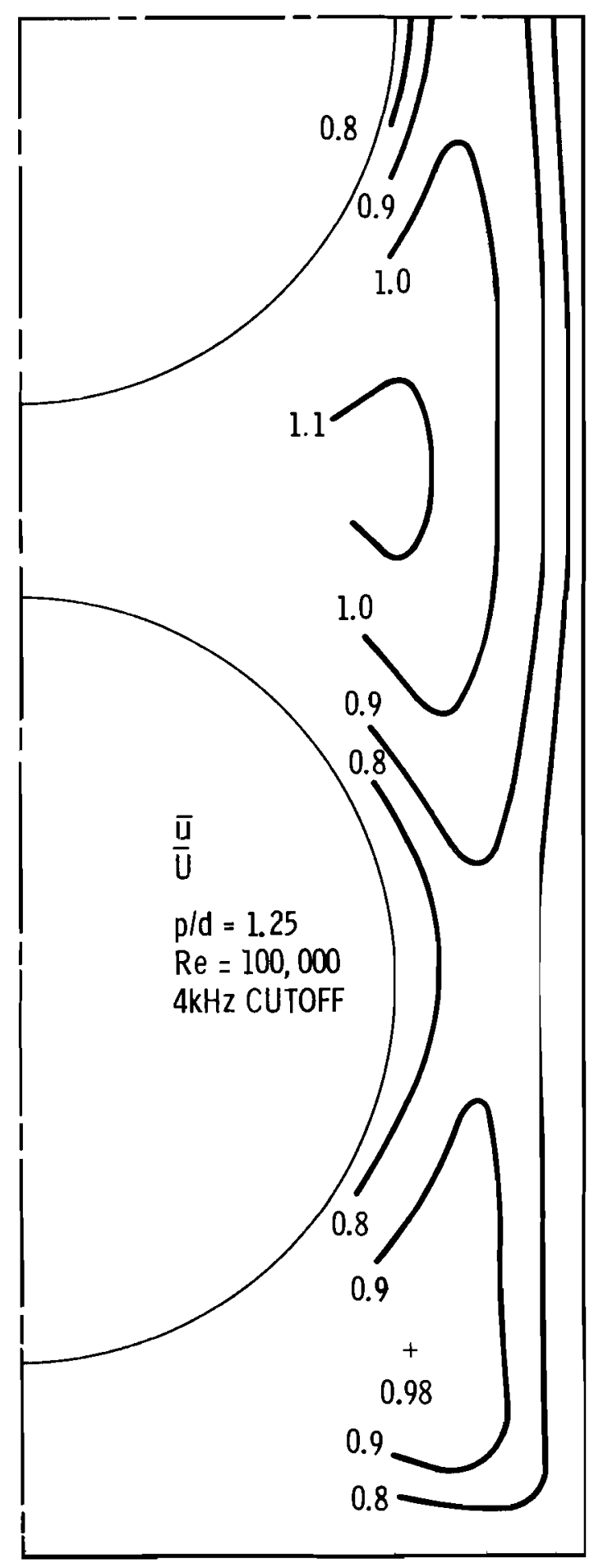

FIGURE 4.23. Axial Velocity $\left(\frac{\bar{u}}{4}\right)$ Map, Wall Region, Fulty Developed Flow, No Grid Spacers (2) 
BNWL- 1757

The velocity map shows only a modest change in velocity downstream from the grid plate which parallels the channel wall. The largest change in mean velocity below a grid plate occurred about the wall subchannel center. It is interesting to note that the orientation of the grid plate relative to the isovels has an apparent influence on the recovery rate of the mean velocity. When the grid plate is parallel to the isovels, the flow redevelops rapidly. The greatest change in velocity distribution occurs in a zone where the grid plate is normal to the isovels. Comparing the recovery of the mean velocity in the wall and interior regions, it appears that the wall region shows more rapid development toward the fully developed condition than the interior region.

Figure 4.21 presents the mean velocity map for Plane 2 . This map shows similarity to the map for nearly developed flow at Plane 4 (Figure 4.22). The isovel contours have established the form of fully developed flow except for the distortions near the wall in the wall subchannel. These distortions indicate the presence of secondary flows. Figure 4.22 presents the map for nearly fully developed flow at Plane 4. The isovels exhibit close similarity to the fully developed flow condition in Figure 4.23 except for moderate distortion near the channel wa11 in the wall subchannel. As for the interior region data discussed earlier, the wall channel dimensionless velocity is somewhat higher than the fully developed velocity measured in the previous study.

\subsubsection{Turbulence Intensity}

Figures 4.24 through 4.26 give turbulence intensity maps for three positions downstream the first grid spacer in the wal1 region. Figure 4.27 
BNWL-1757

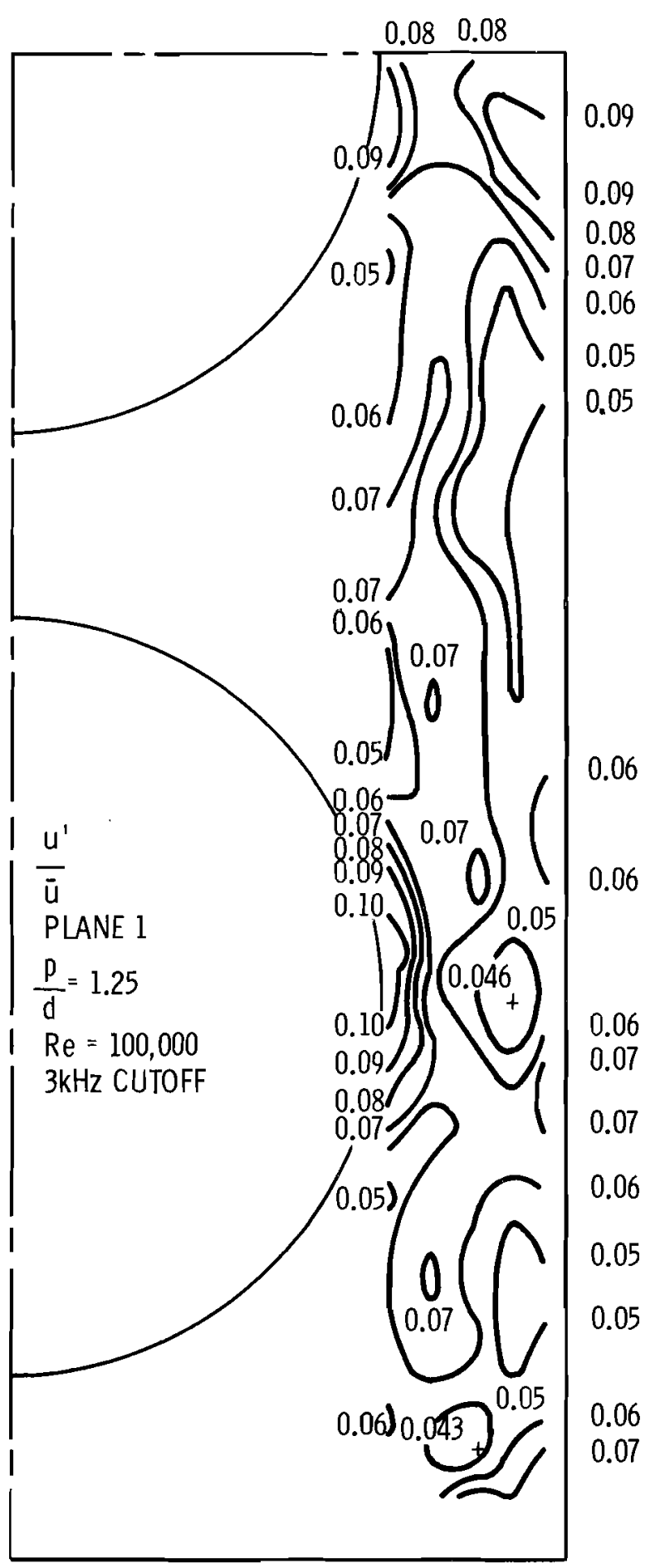

FIGURE 4.24. Axial Intensity $\left(\frac{\mathrm{U}^{\prime}}{\overline{\mathrm{u}}}\right)$ Map, Wall Region, Plane 1

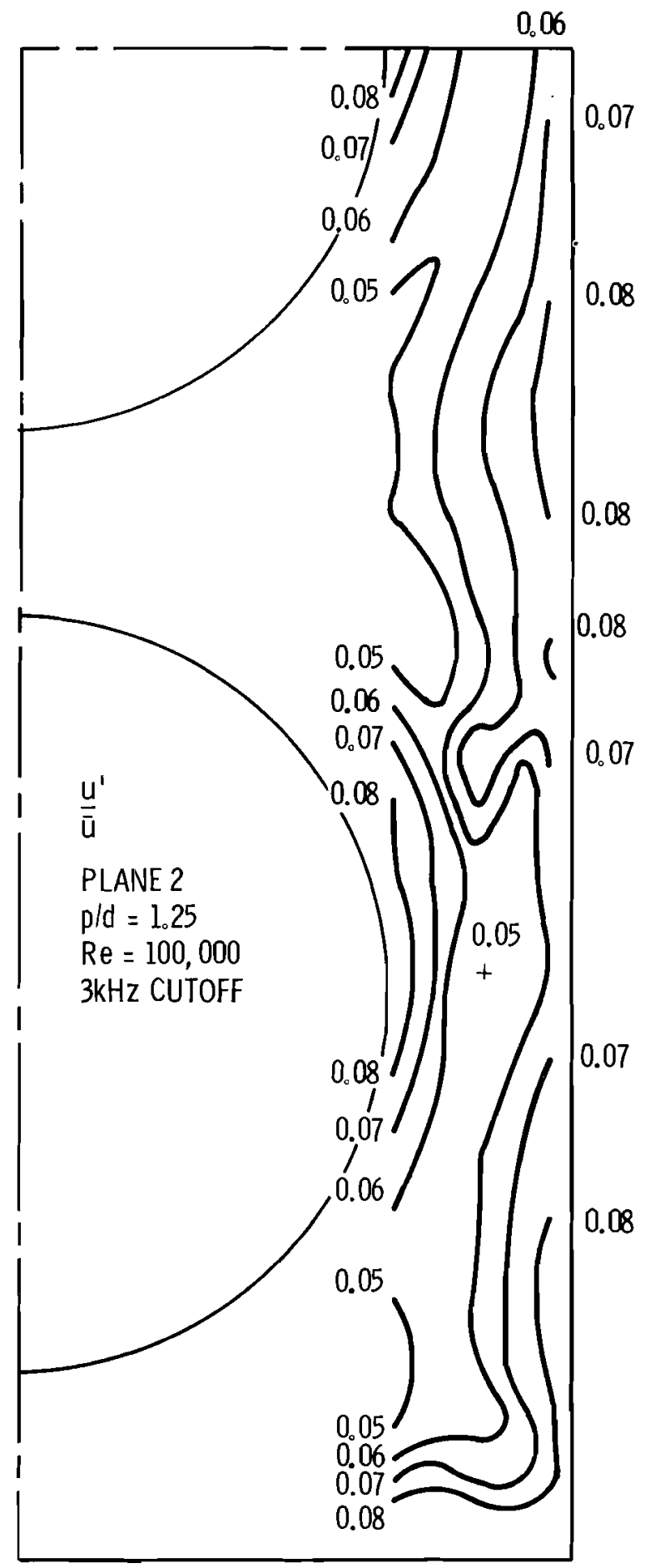

FIGURE 4.25. Axial Intensity $\left(\frac{\mathrm{u}^{\prime}}{\overline{\mathrm{u}}}\right)$ Map, Wall Region, Plane 2 
BNWL-1757

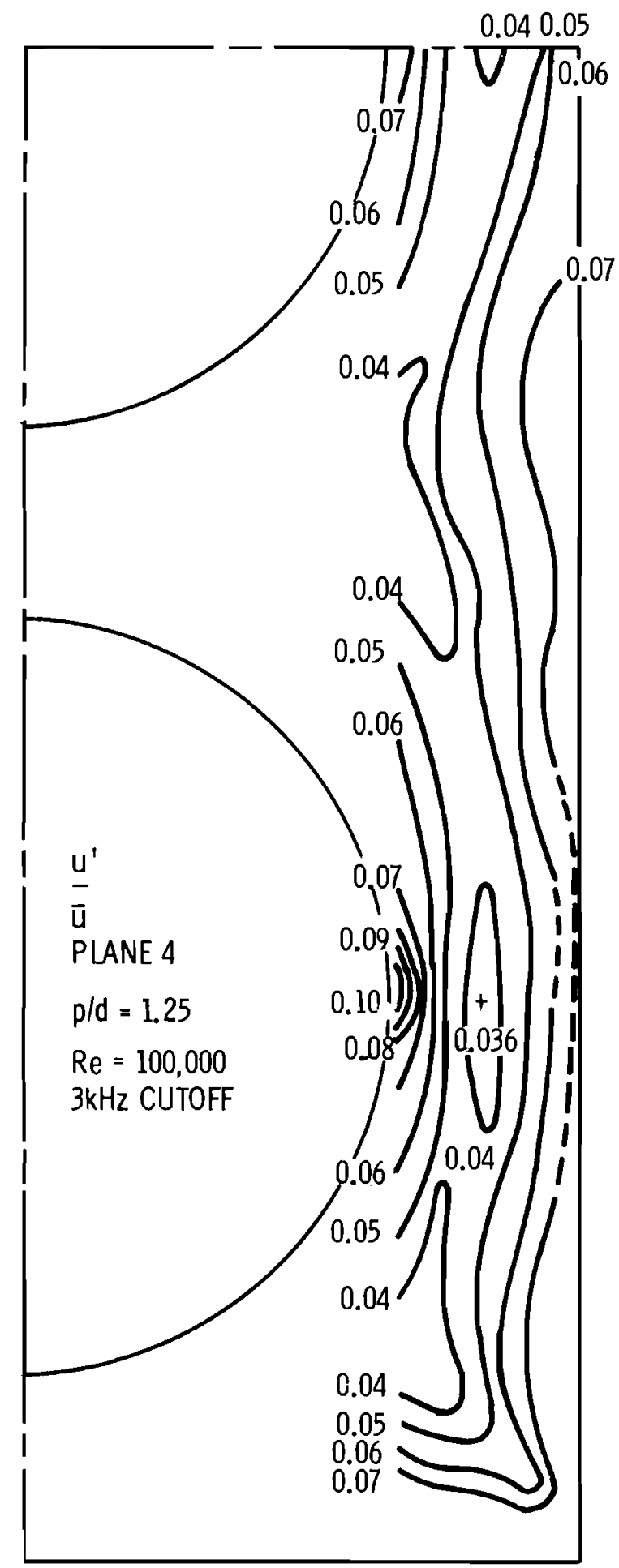

48

FIGURE 4.26. Axial Intensity $\left(\frac{u^{\prime}}{\bar{u}}\right)$ Map, Wall Region, Plane 4 
is the intensity map for fully developed flow as reported in the previous study. (2) The influence of the grid spacer on the turbulence intensity field can be observed by comparing the map for nearly developed flow (Figure 4.26) to the map at Plane 1 (Figure 4.24). Although the intensity contours have experienced untrackable distortions, the change in magnitude of turbulence intensity exhibit certain characteristics. The level of intensity in the area nearest the wall in the wall subchannel has decreased. A similar reduction in intensity is observed in the corner subchannel midway between the rod gap and the corner. Referring to the mean velocity map for this plane, it is noted that these areas of reduced intensity correspond to areas least affected by the grid plate. Areas about the wall and corner subchannel centers have experienced a marked increase in intensity. Again referring to the isovel map for Plane 1, these areas correspond to areas of high isovel distortion. The areas of greatest isovel distortion closely correspond to areas of increased turbulent intensity, notably in the rod-wall gap area.

The axial intensity map for Plane 2 is given in Figure 4.25. The large drop in intensity observed for the interior subchannel at this plane does not appear in the wall region. When the map for Plane 2 is compared to the map for nearly fully developed flow, a strong similarity in the shape of the intensity contours is seen. The noticeable exception between the two maps is found near the rod gap adjacent the corner. The erruption of high turbulence intensity off the wall toward the rod gap center correlates closely to the isovel distortion associated with an implied 
secondary flow observed in the mean velocity map for this plane. The level of intensity has decreased about the wall and corner subchannel center between Plane 1 and Plane 2 .

The axial intensity map at Plane 4 is presented in Figure 4.26.

For fully developed flow the intensity map is given in Figure 4.27. Comparison shows close correlation. The generally higher level of intensity for the fully developed intensity map from the previous study may be due, in part, to the $4 \mathrm{kH}_{z}$ cutoff frequency. The cutoff frequency for the present study was maintained at $3 \mathrm{kH}_{z}$. However, the difference may be due to the fact that the intensity field has not reached a fully developed condition.

\subsubsection{Turbulence Scale}

The turbulence macroscale in the wall region at Planes 1,2 , and 4 is given in Figure 4.28. The general trend of increasing macroscale with increasing distance downstream from the grid spacer is again observed. Comparison with the results for the interior region given in Figure 4.15, show that the macroscale is roughly of the same magnitude at each of the corresponding planes. 
BNWL-1757

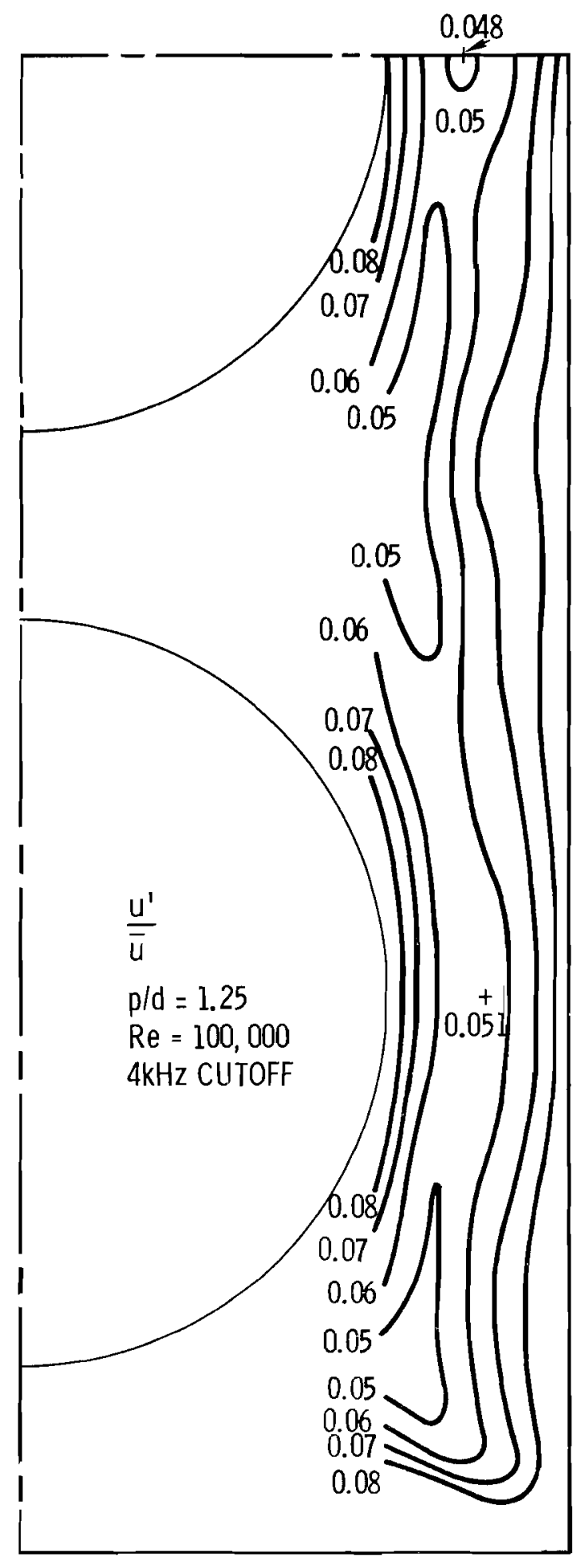

51

FIGURE 4.27. Axial Intensity $\left(\frac{u^{\prime}}{a}\right)$ Map, Wall Region, Fully Developed F] ow
No Grid Spacers 
BNWL -1757
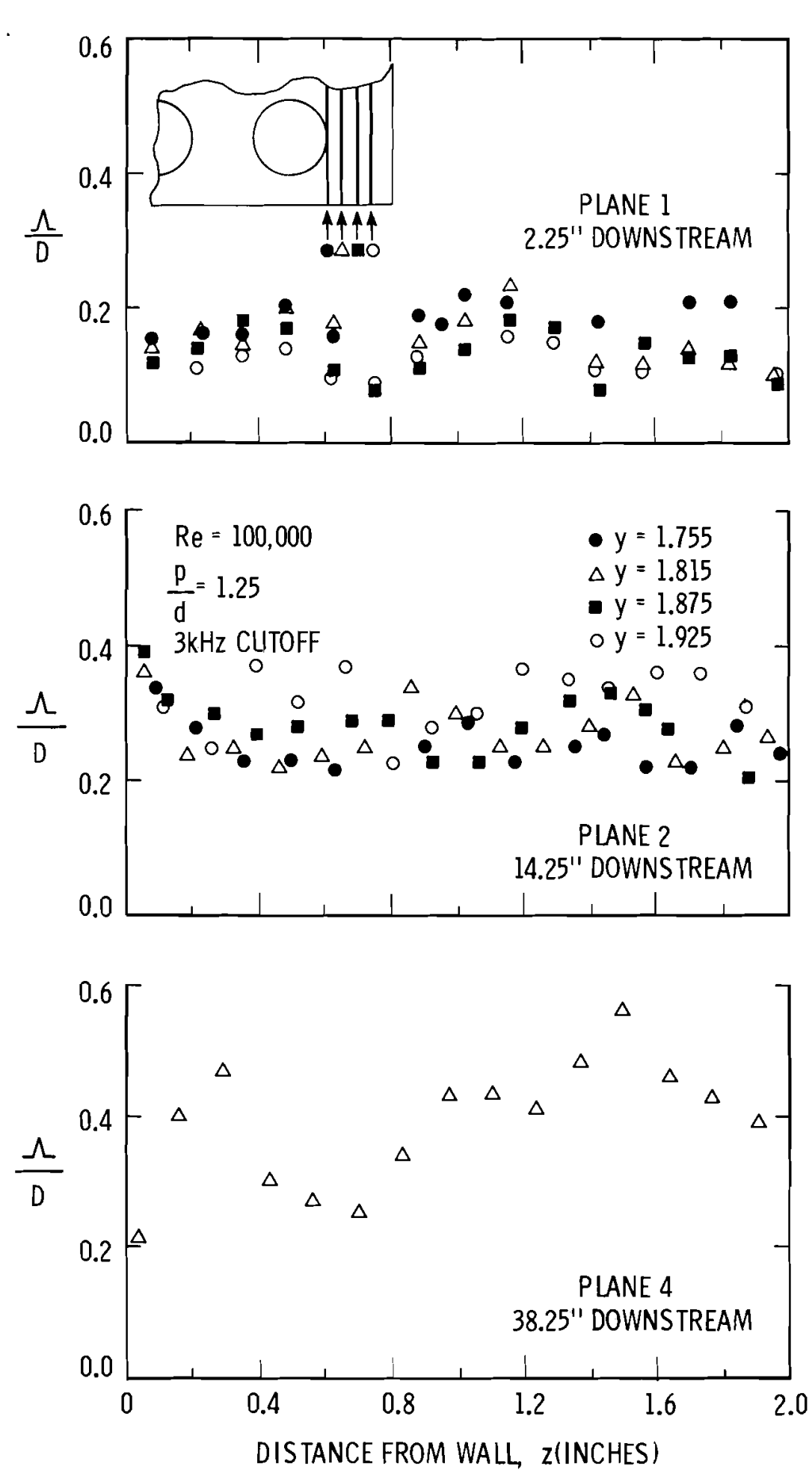

FIGURE 4.28. Axial Scale ( $N / D)$ for Wa11 Region 
BNWL-1757

\subsection{DISCUSSION OF RESULTS}

The experimental data have shown some interesting behavior concerning turbulent flow in rod bundle flow channels containing a simple grid spacer. Of particular interest is the reduction of turbulence intensity at an intermediate position between the two grid spacers, where the turbulence intensity was lower than the intensity for fully developed flow in rod bundles or in round tubes. Although a firm explanation for this behavoir is not available, considerable insight concerning the possible mechanisms that could produce it are available from a theoretical treatment of nonisotropic turbulence. The following discussion reviews the more significant terms of the theoretical equations governing the production and decay of turbulence. The second section contair.s a brief discussion of the results of this study as it could apply to the crossflow mixing processes downstream of grid spacers.

\subsection{Production and Decay of Turbulence}

The axial component of turbulence intensity was the primary turbulence parameter measured in this study. It is but one component of several used to characterize a turbulent flow field. More generally, the intensity is the square root of single point correlation $\overline{u_{1}^{2}}$ normalized to the local velocity. $\overline{u_{1}^{2}}$ is also a single component of the more general correlation $\overline{u_{i} u_{j}}$ where $i$ and $j$ refer to the three cartesian coordinate directions. The term $-\rho \overline{u_{i} u_{j}}$ is recognized as being the turbulent shear stress tensor. Starting with the equations of motion for each velocity component, assuming uniform density and uniform viscosity, the dynamic equations $(3)$ for $\overline{u_{i} u_{j}}$ can be written as 


$$
\begin{aligned}
& \frac{D}{D t} \overline{u_{i} u_{j}}=-\overline{u_{j} u_{k}} \frac{\partial \bar{u}_{j}}{\partial x_{k}}-\overline{u_{j} u_{k}} \frac{\partial \bar{U}_{j}}{\partial x_{k}} \\
& -\frac{\partial}{\partial x_{k}} \overline{u_{i} u_{j} u_{k}} \\
& -\frac{1}{\rho}\left(\frac{\partial}{\partial x_{i}} \overline{p u_{j}}+\frac{\partial}{\partial x_{j}} \overline{p u_{i}}\right) \\
& +\frac{1}{\rho} p \overline{\left(\frac{\partial u_{j}}{\partial x_{i}}+\frac{\partial u_{i}}{\partial x_{j}}\right)} \\
& +v \frac{\partial^{2} \overline{u_{j} u_{j}}}{\partial x_{\ell} \partial x_{\ell}}-2 v \frac{\partial \overline{u_{j}}}{\partial x_{\ell}} \frac{\partial u_{j}}{\partial x_{\ell}}
\end{aligned}
$$

A contraction of these equations gives a scalar equation for the kinetic energy $\left(q^{2} / 2\right)$ of turbulence where

$$
\overline{\frac{q^{2}}{2}} \equiv \frac{1}{2}{\overline{u_{i}}}^{2}=\frac{1}{2}\left(\overline{u_{1}^{2}}+\overline{u_{2}^{2}}+\overline{u_{3}^{2}}\right)
$$

The equation can be written as

$$
\text { (I) } \begin{aligned}
\frac{D\left(\overline{q^{2}}\right)}{D t}= & -\bar{u}_{i} u_{k} \frac{\partial \bar{U}_{j}}{\partial x_{k}} \\
& -\frac{\partial}{\partial x_{k}} \overline{\left(\frac{p}{\rho}+\frac{q^{2}}{2}\right) u_{k}}
\end{aligned}
$$




$$
\begin{gathered}
+v \frac{\partial^{2}}{\partial x_{\ell} \partial x_{l}}\left(\overline{\frac{q^{2}}{2}}\right) \\
-v \frac{\partial u_{i}}{\partial x_{\ell}} \frac{\partial u_{i}}{\partial x_{l}}
\end{gathered}
$$

Physical significance and importance can be given to each of the terms in the above equation.

The first term (I) represents the gain or loss of turbulence energy as the flow moves along the flow channel. It includes both the temporal and spatial changes of energy along a streamline.

The second term is called the production term since it represents the extraction of mean flow energy into turbulence energy. Because this term is the only source of turbulence energy, the integral of it over the entire extent of a flow field is essentially positive. However, this fact does not preclude the possibility that this term can be negative in part of the flow field. In regions where this term is negative, turbulence energy is returned to the mean flow.

The third term is the convective diffusion by turbulence of the turbulence energy. According to Hinze ${ }^{(3)}$ and Bradshaw ${ }^{(4)}$ the pressure component of this term represents a "scrambling" of the turbulence by the pressure and tends to make the turbulence more nearly isotropic and reduces the turbulence shear stress.

The fourth and fifth terms in combination represent the work done per unit mass and of time by the viscous shear stresses of the turbulent 
motion plus the dissipation per unit of mass by the turbulent motion. In the following discussion these terms will be referred to by the symbol $\varepsilon_{i j}$

In the present study only the axial component of turbulence $\overline{u_{1}^{2}}$ was measured and it changed significantly downstream of a grid spacer in the interior regions of the bundle. To help explain why this occurred it is worthwhile to review the dynamic equations for $\overline{u_{i} u_{j}}$. To simplify the discussion the equations are written for the case of turbulent flow between infinite, plane, parallel walls. For this case assume that the axial velocity $\bar{U}_{1}$ is a function of the axial and lateral coordinates $x_{1}$ and $x_{2}$ and the velocity component $\bar{U}_{3}$ is zero. Because of the uniformity of flow in the $x_{3}$ direction the derivatives with respect to $x_{3}$ are zero as are all correlations involving $\overline{u_{1} u_{3}}$ and $\overline{u_{2} u_{3}}$. While these approximations are not entirely valid for the three dimensional flow in rod bundles, they would apply roughly in a direction normal to a wall in a developing flow field. Consider then, $x_{2}$ to be the lateral distance from the wall and $x_{1}$ to be in the direction of flow. The axial velocity gradient in the $x_{2}$ direction would, therefore, be much larger than in the $x_{1}$ direction. With the above simplifications the equations are

$$
\begin{aligned}
\frac{D}{D t}\left(\overline{u_{1}^{2}}\right)= & -2 \overline{u_{1}^{2}} \frac{\partial \bar{U}_{1}}{\partial x_{1}}-2 \overline{u_{1} \bar{u}_{2}} \frac{\partial \overline{U_{1}}}{\partial x_{2}} \\
& -\frac{\partial}{\partial x_{1}} \overline{u_{1}^{3}}-\frac{\partial}{\partial x_{2}} \overline{u_{1}^{2} u_{2}} \\
& -\frac{2}{\rho} \frac{\partial}{\partial x_{1}} \overline{u_{1}}+\frac{2}{\rho} p \frac{\partial \bar{u}_{1}}{\partial x_{1}}-\varepsilon_{11}
\end{aligned}
$$


BNWL-1757

$$
\begin{aligned}
\frac{D}{D t}\left(\overline{u_{2}^{2}}\right)= & -2 \overline{u_{2} u_{1}} \frac{\partial \bar{U}}{\partial x_{1}}-2 \overline{u_{2} u_{2}} \frac{\partial \bar{U}}{\partial x_{2}} \\
& -\frac{\partial}{\partial x_{1}} \overline{u_{2}^{2} u_{1}}-\frac{\partial}{\partial x_{2}} \overline{u_{2}^{3}} \\
& -\frac{2}{\rho} \frac{\partial \bar{p} u_{2}}{\partial x_{2}}+\frac{2}{\rho} p \overline{\frac{\partial u_{2}}{\partial x_{2}}}-\varepsilon_{22}
\end{aligned}
$$

$$
\begin{aligned}
\frac{D\left(\overline{u_{3}^{2}}\right)=}{D t}=-\frac{\partial}{\partial x_{1}} \overline{u_{3}^{2} u_{1}}-\frac{\partial \overline{u_{3}^{2}} u_{2}}{\partial x_{2}} \\
\\
-\frac{2}{\rho} \frac{\partial}{\partial x_{3}} \overline{p u_{3}}+\frac{2}{\rho} p \frac{\overline{\partial u_{3}}}{\partial x_{3}}-\varepsilon_{33}
\end{aligned}
$$

$$
\begin{aligned}
\frac{D\left(\overline{u_{1} u_{2}}\right)}{D t}= & -\overline{u_{1} u_{2}} \frac{\partial \bar{u}}{\partial x_{1}}-\overline{u_{2}^{2}} \frac{\partial \bar{u}}{\partial x_{2}} \\
& -\overline{u_{1} u_{1}} \frac{\partial \bar{u}_{2}}{\partial x_{1}}-\overline{u_{1} u_{2}} \frac{\partial \bar{u}}{\partial x_{2}} \\
& -\frac{\partial}{\partial x_{1}} \overline{u_{1}^{2} u_{2}}-\frac{\partial}{\partial x_{2}} \overline{u_{1}^{2}} \\
& -\frac{1}{\rho}\left(\frac{\partial}{\partial x_{1}} \overline{p u_{2}}+\frac{\partial}{\partial x_{2}} \overline{p u_{1}}\right) \\
& +\frac{1}{\rho} p\left(\frac{\partial u_{2}}{\partial x_{1}}+\frac{\partial u_{1}}{\partial x_{2}}-\varepsilon_{12}\right.
\end{aligned}
$$


There are several interesting features of the above equations that are related to the results of the present experiments. First, consider the case of fully developed flow where the derivatives of $\bar{U}_{2}$ and derivatives with respect to $x_{1}$ are zero. For this case, only the expressions for

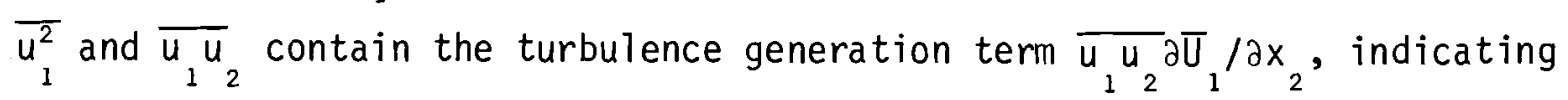
that the turbulence is strongly nonisotropic in the axial direction particularly in regions of high shear stress. The only way the other components $\left(\overline{u_{2}^{2}}, \overline{u_{3}^{2}}\right)$ gain turbulence energy is through the turbulence and pressure diffusion terms. Thus, turbulence energy is generated in the axial direction and then is passed on to the other components.

For the case of developing flow, the derivatives of $\bar{U}_{2}$ and derivatives in the $x_{1}$ direction are not zero and additional turbulence generation terms are present in the equations for $\bar{u}_{2}^{2}$ and $\bar{u}_{1} u_{2}$ but not in the equation for $\overline{u_{3}^{2}}$. Normaliy, the turbulence generation terms are positive. However, in certain regions of the flow field the production terms may result in a net reduction in turbulence energy. Consider the term $-\bar{u}_{1}^{2} \partial \bar{u}_{1} / \partial x_{1}$. When the flow is accelerating in the axial direction, this term would be negative and would cause a reduction in turbulence energy of $\overline{u_{1}^{2}}$. The use of a contracting section upstream from a working section to reduce turbulence has been known empirically for many years and almost wholly eliminates undesirable turbulent fluctuations. (5) The experimental results given by MacPail ${ }^{(6)}$ show the strong influence of accelerating flow on the reduction of axial intensity. By using the continuity equation the term $-\overline{u_{2}^{2}} \partial \bar{U}_{2} / \partial x_{2}$ in the equation for $\overline{u_{2}^{2}}$ can be written as $+\overline{u_{2}^{2}} \partial \bar{U}_{1} / \partial x_{1}$ which is positive for an accelerating flow in the $x_{1}$ direction. Turbulence $\left(\overline{u_{2}^{2}}\right)$ is 
BNWL-1757

therefore generated in the $x_{2}$ direction from this term in an axially accelerating flow. Batcheior and Proudman ${ }^{(7)}$ have shown theoretically that an accelerating flow causes a reduction in axial intensity and an increase in the lateral intensities. The experimental data of MacPail verify this to be the case. The term $\overline{u_{2} u_{1}} \partial \bar{U}_{2} / \partial x_{1}$ is similar to the term $\overline{u_{1} u_{2}} \partial \bar{U}_{1} / \partial x_{2}$. Their importance depends upon the location in the flow field. Near the center of the flow channel they are both small because of the small shear stress and velocity gradients. Near the wall, they would have more importance. The former would usually be smaller, however, because $\partial \bar{U}_{2} / \partial x_{1}$ is less than $\partial \bar{U}_{1} / \partial x_{2}$ for most cases.

The interaction between the shear stress and the lateral axial velocity gradient, $-\bar{u}_{2} \bar{u}_{2} \frac{\partial \bar{U}_{1}}{\partial x_{2}}$ may also result in a negative production of turbulence energy or energy reversal. When a turbulent eddy with positive shear stress $\left(-\overline{u_{1} u_{2}}>0\right)$ errupts into a zone of negative mean velocity gradient, energy reversal will occur and the eddy will be rapidly attenuated. Similarly, when a eddy with negative shear stress $\left(-\overline{u_{1} u_{2}}<0\right)$ migrates into a positive velocity gradient, energy reversal will occur. Bradshaw $(4)$ and Eskinozi and Erian ${ }^{(8)}$ give examples of developed flows in which energy reversal occurs. Bradshaw also discusses the likelihood of energy reversal at the meeting of boundary layers in developing flows. In a region of energy reversal some of the turbulence energy is returned to the mean flow and the loss is made up by diffusion from adjacent zones. Eskinazi and Erian ${ }^{(8)}$ noted this higher diffusion in their experimental work. 
For this study regions of energy reversal could be present in the wake of the grid spacer. The accelerating flow and the adjacent but opposite shear-velocity gradients in the wake of the spacer would indicate a region of possible energy reversal. This phenomena is believed to contribute, in part, to the reduction of axial turbulence intensity in the velocity recovery region behind the grid, but does not explain the general reduction of intensity found at Plane 2 .

The viscous effect, denoted by $\varepsilon_{11}, \varepsilon_{22}, \varepsilon_{33}$, and $\varepsilon_{12}$ above causes a negative contribution and is more significant with increasing intensity. It damps out the greater intensity components at a higher rate than the smaller ones; thus, it tends to equalize the components. The effect is greater for smaller eddies since they are closer in size to the dissipation scale of turbulence. The passage of the flow through the spacer causes a reduction in scale of turbulence. This implies that a larger number of turbulent eddies are closer to the dissipation scale. Dissipation of the smaller eddies by the viscous stresses would result in an increase in the macroscale since the smaller eddies would be eliminated from the turbulent eddy "population". This effect of increasing macroscale with increasing distance downstream from the spacer was observed in the experiments.

The rapid decay of turbulence intensity between PTane 1 and Plane 2 might be attributed to viscous dissipation. However, the average size of the eddies at the spacer's trailing edge is nearly two orders of magnitude greater than the size of the dissipating eddies. Thus it would require greater downstream distance (time) than 14 inches for the eddies to be dissipated. 
BNWL-1757

The marked decrease in scale experienced by the flow due to passage through the grid has some interesting implications. Since the diffusive action of turbulence is determined mainly by the larger eddies, the reduction in scale would imply decreased diffusion of turbulence energy from the rod surfaces. For rod bundles without spacers, the diffusion from the wall is the primary source of turbulent energy at the interior of the subchannel. For developing flow in a pipe with wire gauge transition, Shárón ${ }^{(9)}$ presents the radial distribution of axial intensity at a number of positions downstream from the entrance. At an axial position of $18 \mathrm{X} / \mathrm{D}$, the results show little increase of intensity about the center due to diffusion of turbulence energy from the wall. Between 20 and 40 $X / D$ the axial intensity develops to nearly the fully developed intensity distribution. If the interior subchannel of the present study is thought to be analogous to pipe flow, turbulence energy diffusion from the wall would not be significant until Plane 3 . The increase of intensity observed at Plane 3 thus may be due, in part, to the increased influence of turbulent diffusion from the wall.

It is somewhat difficult to assess the importance of the remaining terms of the above equations; however, there does appear to be a concensus $(3,4)$ that they tend to make the turbulence more isotropic. As mentioned previously for the flow field under discussion the turbulence is primarily generated in the axial direction and is transferred to the lateral components by turbulence and pressure diffusion.

For the case of developed flow and $\overline{u_{1}^{2}}>\overline{u_{2}^{2}}+\overline{u_{3}^{2}}$, Hinze discusses the pressure velocity-gradient correlation (pressure-velocity diffusion) to 
show that it decreases $\overline{u_{1}^{2}}$ and $\overline{u_{1} u_{2}}$ but increases $\overline{u_{2}^{2}}$ and $\overline{u_{3}^{2}}$. The general direction is toward isotropy. This term would be the strongest in regions of significant pressure fluctuations and, according to Hinze, in the smaller scale range of turbulence. This term is believed to provide a major contribution to the observed reduction in axial component turbulence intensity in the present experiments. The reduction is believed to be a transfer of energy from the axial to the lateral components of turbulence. Within the grid the turbulence would be highly nonisotropic in the axial direction with added generation of turbulence due to the shear on the grid plates.

Then in the smaller scale turbulent flow and pressure pulsations of the wake region the energy is "scrambled" or transferred to the lateral components. This would tend toward isotropy which would reduce $\overline{u_{1}^{2}}$. Farther downstream the transfer of turbulence from the axial component would become weaker due to the reduction of pressure pulsations. The flow would then revert back to its normal nonisotropic state and gradually achieve its fully developed profile.

To show that the magnitude of such a transfer is consistent with the observed experimental results, consider the reasonable case where $\overline{u_{1}^{2}}$ is four times $\overline{u_{2}^{2}}$ and $\overline{u_{3}^{2}}$. The turbulence energy is therefore,

$$
\frac{q^{\overline{2}}}{2}=\frac{u^{2}}{2}\left(1+\frac{1}{4}+\frac{1}{4}\right)=\frac{3}{4} u_{1}^{\overline{2}}
$$

For isotropy with the same turbulence energy,

$$
\frac{\overline{q^{2}}}{2}=\frac{\left(\overline{u^{2}}\right)}{2} \text { iso }_{2}(1+1+1)=\frac{3}{2}\left(\overline{u_{1}^{2}}\right)_{\text {iso }} \text {; }
$$


therefore, $\overline{u_{1}^{2}}$ for isotropy is one half that for the nonisotropic case. When stated in terms of intensity this is $\sqrt{2}$ change which is consistent with the magnitude of change observed downstream of the grid spacer. Additional factors which are probably also involved in the reduction of $\overline{u^{2}}$ behind the grid are energy reversal and viscosity effects. These would not be as important in the region where $\overline{u_{1}^{2}}$ recovers because the turbulence scale is larger and the velocity profiles have recovered to near those of fully developed flow.

Although the above discussion is somewhat speculative because complete data are not available, it is consistent with the experimental observations. In summary, consider the description of turbulent flow behind the grid spacer presented in Figure 5.1. The axial component intensity increases when passing through the grid spacer because of the added shear stress and velocity gradient interaction. The flow emerges with generally increased intensity, reduced macroscale and significant velocity distortions (wake). Following the grid spacer, the axial component intensity decreases most probably by transfer of turbulence energy to the lateral velocity components by action of the pressure-velocity correlations in the wake. This decrease would also be assisted by increased dissipation associated with the smaller macroscale and possibly assisted by local "energy-reversal" in the immediate wake of the grid strap. This decrease could be rather general as indicated by the reduced intensity throughout the flow field as shown in Figure 4.9. Following the reduction, $\overline{u_{1}^{2}}$ again increases but now due to the reduced dissipation and reduced transfer to isotropy. Wall shear stress is again important and begins to develop nonisotropic turbulence in the axial direction. 


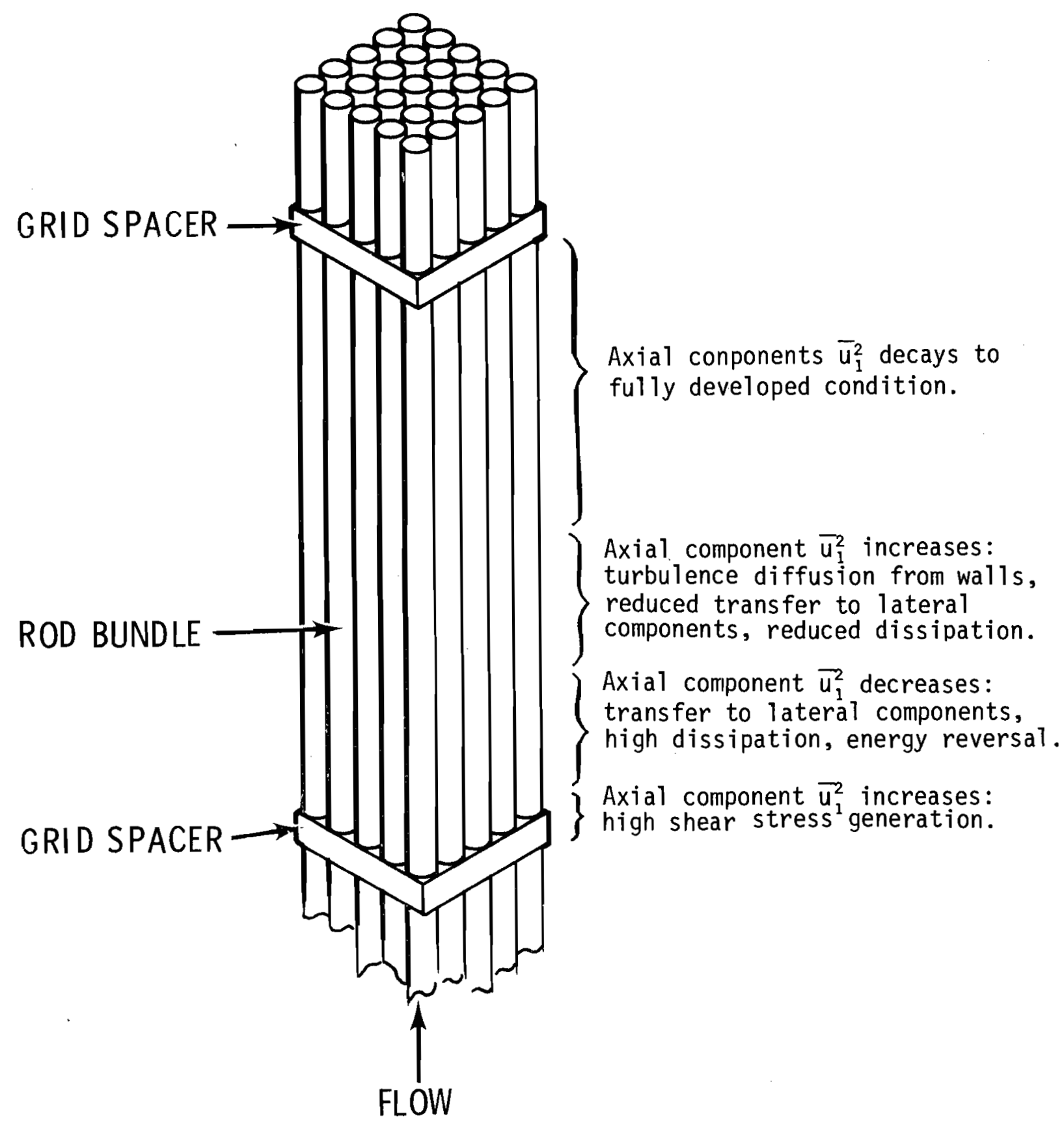

Figure 5.1. Production and dissipation of axial turbulence intensity. 
The turbulence diffusion and pressure-velocity correlation carries the turbulence to the central part of the channel. The flow continues in this manner toward a fully developed flow field which is essentially achieved prior to entering the second grid spacer.

It is natural to wonder if the phenomena observed in the present experiments would occur in rod bundles with grid spacers used for nuclear power reactors. It probably would, but would be dependent upon the design of the grid spacer. The tendency toward increased intensity and reduced scale upon emerging from a grid could be expected but the magnitudes would depend upon the design features of the grid. The tendency toward isotropy should also exist with a tendency for reduced axial component intensity and increased lateral component intensity. The recovery of the flow from the grid perturbation should also occur; however, the length over which this would occur is uncertain. The present experiments show the axial component intensity distribution to be rather insensitive to Reynolds number; however, the data do not show that the distances can be scaled to some dimension like hydraulic diameter. Experimentation in bundles of different size would help to determine the scaling parameters.

\subsection{Implications Regarding Crossflow Mixing}

An estimate for rod bundle crossflow mixing was made in the previous study ${ }^{(2)}$ by assuming that the product of axial component intensity and macroscale, as estimated by Taylor's hypothesis, could be used to approximate the eddy diffusion coefficient

$$
\varepsilon \approx u_{1}^{\prime} \Lambda
$$


The crossflow mixing was written as

$$
\frac{W^{\prime}}{G D} \propto\left(\frac{u^{\prime}}{\bar{u}}\right)\left(\frac{\bar{u}}{U}\right)\left(\frac{\Lambda}{D}\right)\left(\frac{S}{\Delta y}\right) .
$$

The implication of this equation is that crossflow mixing is dependent upon turbulence intensity, scale and a diffusion related geometric parameter. The results of this study taken at face value would suggest that mixing decreased behind the grid spacer because of reduced intensity and scale. This, however, may not be the case. An important assumption in Equation (5.10) is the factor of proportionality which includes at least the ratios $v^{\prime} / u_{1}^{\prime}$ and $\Lambda_{L} / \Lambda$. These are the ratio of lateral Lagrangian fluctuating velocity component to the axial Eulerian component and the ratio of Lagrangian lateral macroscale to the axial Eulerian macroscale. Values of these ratios are not known; however, they would not necessarily be constants in the wake region of the grid spacer.

The ratio $v^{\prime} / u_{1}^{\prime}$ could increase in the region of reduced $u_{1}^{\prime}$ if the previous discussion concerning the change to isotropy is valid. For the simple example considered previously, the reduction of $\overline{u_{1}^{2}}$ by a factor of two would correspond to a factor of two increase each in $\overline{u_{2}^{2}}$ and $\overline{u_{3}^{2}}$. This would correspond to a $\sqrt{2}$ increase in $\bar{v}^{\prime}$ if $\bar{v}^{\prime} \approx \bar{u}_{2}^{\prime}$.

The ratio $\Lambda_{L} / \Lambda$ could also be larger behind the grid than in fully developed flow. Axial scale $\Lambda$ is normally larger than the scale in the lateral direction. With the tendency toward isotropy in the wake of the grid, the axial scale could interact in such a way that, while the total scale may be reduced, the lateral scale could be increased. 
The net effect is that the crossflow mixing would probably not be decreased in the wake of the grid, but it is not possible to state that the mixing is higher behind the grid. It could be that, with the rather simple grid considered in this study, there might not have been a significant change in mixing even though the turbulent structure changed drastically. A mixing experiment with and without the grids would certainly help to determine how the flow structure changes affect crossflow mixing. 
BNWL-1757

\subsection{CONCLUSIONS AND RECOMMENDATIONS}

The present experimental study has yielded some new and interesting information concerning the turbulent flow structure in a rod bundle with grid spacers. The presence of the grid spacer in a rod bundle results in significant changes in axial mean velocity, turbulence intensity and turbulence scale. The influence of the grid spacer on the flow structure can be readily observed as far downstream from the spacer as $32 x / D$. The following conclusion can be made regarding the experimental results:

1. Fully developed turbulent flow passing through a grid spacer emerges with increased axial intensity and decreased axial macroscale.

2. The velocity perturbations caused by the spacer are most significant in the interior subchannel and least significant in the corner subchannel. Local velocity perturbations in the wake of the grid spacer recover in a rather short distance $218 \times / D$. The large flow redistributions caused by the spacer require $\checkmark 47 X / D$ to return to the nearly developed condition.

3. For an interior subchannel the axial intensity varies significantly with position downstream from the grid spacer: First emerging from the spacer with high intensity, then after decreasing rapidly to a low level of intensity, the intensity again increases to a high level before decaying to the nearly fully developed condition. The intermediate, "quiet", downstream position is believed to be due to the transfer of turbulence energy from the axial component to the lateral components. 
4. For a wall subchannel the high intensity near the trailing edge of the spacer decays monotonically downstream of the spacer toward the fully developed condition.

5. The axial macroscale increases monotonically from $20.15 \mathrm{D}$ near the trailing edge of the spacer ( $3 X / D)$ to $\sim 0.4 \mathrm{D}$ for nearly developed flow $(47 X / D)$ in the interior subchannel.

6. The effect of the grid spacer on the axial intensity, scale and mean velocity is weakly dependent upon Reynolds Number.

As a result of this study the following recommendations are offered for future studies:

- Obtain additional data at more planes downstream from the spacer including the measurement of the lateral component of turbulence. This could help identify the cause for the "quiet" region downstream of the grid observed in the present study. Perform an adjunct scaler mixing experiment with the turbulent flow measurements. This would lead to a better understanding of the cross flow mixing mechanism in rod bundles with grid spacers.

- Evaluate the effect of spacer design by using different model spacers in the rod bundle. This would indicate the influence of spacer design on downstream turbulence structure. 
A

d

D

G

$i, j, k, \ell$

$\mathrm{P}$

$\mathrm{p}$

PW

$q^{2}$

$\mathrm{Re}$

$R(\tau)$

s

$t$

$T_{E}$

$u^{\prime}$

$u^{\prime}{ }_{i}$

$u_{i}$

$u_{1}, u_{2}, u_{3}$

$\bar{u}$

U

$\bar{U}_{i}$

$\overline{\mathrm{U}}_{1}, \overline{\mathrm{U}}_{2}, \overline{\mathrm{U}}_{3}$

$\bar{u}_{i} u_{j}$

$v^{\prime}$

Flow area

Rod diameter

Hydraulic diameter $(4 \mathrm{~A} / \mathrm{PW})$

Mass flux $(\rho U)$

Tensor indices for coordinate directions

Rod pitch

Fluctuating pressure

Wetted perimeter

Kinetic energy of turbulence

Reynolds number, channel average (UD/v)

Eulerian time correlation function

Rod gap spacing

time

Eulerian macro time scale

"rms" of fluctuating velocity in $x$ direction

"rms" of fluctuating velocity in i direction

Fluctuating velocity in $i$ direction, $i=1,2,3$

Fluctuating velocity in the $x, y$, and $z$ directions

Local mean velocity in $x$ direction

Channel average velocity

Average velocity in $i$ direction

Average velocity in the $x, y$, and $z$ directions

Turbulent shear stress tensor

"rms" of Lagrangian fluctuating velocity in lateral

direction 


$\begin{array}{ll}w^{\prime} & \text { Turbulent crossflow per unit length } \\ x & \text { Coordinate direction parallel to flow } \\ x_{i} & \text { Coordinate in i direction } \\ x^{\prime} & \text { Distance from trailing edge of spacer } \\ y & \text { Coordinate direction parallel to window surface } \\ \Delta y & \text { Centroid or "mixing" distance between subchannels } \\ z & \text { Coordinate direction perpendicular to window surface } \\ \alpha_{1}, \alpha_{1}, & \text { Function fit parameters } \\ \varepsilon & \text { Eddy diffusivity } \\ \varepsilon_{i j} & \text { Combined viscosity terms of turbulent energy equa- } \\ \lambda & \text { tion } \\ \Lambda & \text { Wavelength of light } \\ \Lambda_{L} & \text { Eulerian longitudinal space macroscale as estimated } \\ \nu & \text { by Taylor's hypothesis } \\ \rho & \text { Lagrangian space macroscale } \\ \sigma & \text { Kinematic viscosity } \\ \sigma & \text { Fluid density } \\ & \text { Standard deviation } \\ & \text { Time delay }\end{array}$


BNWL-1757

\subsection{BIBLIOGRAPHY}

1. Yeh, Y. and H. Z. Cummins. Localized fluid flow measurements with a $\mathrm{H}_{\mathrm{e}}-\mathrm{N}_{\mathrm{e}}$ laser spectrometer. Applied Physics Letters 4:176-178. 1964.

2. Rowe, D. S. Measurement of turbulent velocity, intensity and scale in rod bundle flow channels. 1973. 222 p. (Battelle Memorial Institute. Pacific Northwest Laboratories. BNWL-1736).

3. Hinze, J. 0. Turbulence. New York, McGraw-Hi11, 1959. 586 p.

4. Bradshaw, P. An Introduction to Turbulence and its Measurement. New York, Pergamon Press, 1971. $218 \mathrm{p}$.

5. Batchelor, G. K. The Theory of Homogeneous Turbulence. London, Cambridge University Press, 1953. 197 p.

6. MacPai1, D. C. Turbulence changes in centracting and distorted passages. Rep. No. Aero. 1928, British R.A.E.

7. Batchelor, G. K. and I. Proudman. The effect of rapid distortion of a fluid in turbulent motion. Quarterly Journal of Mechanics and Applied Mathematics, Vol. VII, Pt. 1, 1954.

8. Eskinazi, S. and F. F. Erian. Energy reversal in turbulent flows. Physics of Fluids 10:1988-1998. 1969.

9. Shàrèn, V. KR. An experimental investigation of naturally developing turbulent flow and flow with fixed transition in a parallel pipe. American Society of Mechanical Engineers, ASME Paper 72-WA/FE-38. 
APPENDIX A

Tabulation of Reduced Data 


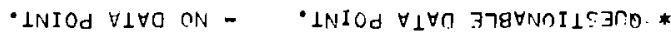

\begin{tabular}{|c|c|c|c|c|c|c|c|c|c|c|c|c|c|c|}
\hline & & & 03 & 11 & $S I=n$ & $7 \cdot 1$ & $073 \wedge$ & $\begin{aligned} \cdot 11 \\
\exists 9 \forall 8\end{aligned}$ & 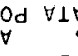 & $\begin{array}{l}\forall 0 \text { ON - } \\
-5 \exists H O N I\end{array}$ & โ T $8^{\circ}$ & $\begin{array}{l}\text { Od } \forall \perp \forall \\
0 \cdot \forall 31\end{array}$ & $\begin{array}{l}0 \text { 3าgषNn } \\
3 W \forall I 0 \quad \text { I }\end{array}$ & $\begin{array}{l}3 \cap 0 \\
\text { yกरㅐ }\end{array}$ \\
\hline - & - & - & $00^{\circ} \mathrm{E}$ & - & - & - & $T \angle 0^{\circ}$ & - & $80 \cdot 1$ & $8^{\circ} 91$ & sog. & $89 \pi^{\circ} \cdot \tau$ & - QSOTUT & $\varepsilon+\varepsilon$ \\
\hline - & - & - & $0 U^{\circ} \varepsilon$ & - & - & - & $\tau \angle 0^{\circ}$ & - & $\pi I \cdot \tau$ & $L \bullet \angle T$ & so. & $\angle 6 S \cdot T$ & -8SOTUT & ¿L \\
\hline - & - & - & $00^{\circ} \varepsilon$ & - & - & - & $+90^{\circ}$ & - & $2 I * T$ & $\eta^{\circ}<\tau$ & $599^{\circ}$ & $Z \varepsilon L \cdot \tau$ & - Bsotut & $T<\varepsilon^{\circ}$ \\
\hline - & - & - & $00 \cdot \varepsilon$ & - & - & - & $890^{\circ}$ & - & $20 \cdot \tau$ & $6^{\circ} 51$ & S.9. & $990^{\circ} \mathrm{T}$ & - BSOTUT & $2 \varepsilon s$ \\
\hline - & - & - & $00^{\circ} \varepsilon$ & - & - & - & $850^{\circ}$ & - & $28^{\circ}$ & $8 \cdot 51$ & SP9. & $000 \cdot 2$ & - BSOTUT & \\
\hline $610^{\circ}$ & $\cdot 0$ & $\angle T^{\circ}$ & $00^{\circ} \varepsilon$ & - & - & - & $2 \angle 0^{\circ}$ & - & $69^{\circ}$ & $8^{\circ} \mathrm{CI}$ & sns. & $\angle 90^{\circ} \mathrm{z}$ & - ESOTET & $89 \varepsilon$ \\
\hline - & - & - & $00^{\circ} \varepsilon$ & - & - & - & $590^{\circ}$ & - & $89^{\circ}$ & $9 \cdot 0 \mathrm{I}$ & sos. & $000^{\circ} 2$ & • GSOTUT & $\angle 9 \varepsilon$ \\
\hline $8 \mathrm{IO}^{\bullet}$ & $\cdot 0$ & $60^{\circ}$ & $00^{\circ} \bar{\varepsilon}$ & - & - & - & $\angle 9^{\circ}$ & - & $\mathrm{SL} \cdot$ & $L \cdot I \mathrm{I}$ & sतis. & $\varepsilon \varepsilon \sigma^{\circ} \tau$ & - PGOTUT & $99 \varepsilon$ \\
\hline - & - & - & $00^{\circ} \bar{\varepsilon}$ & - & - & - & $060^{\circ}$ & - & $68^{\circ}$ & $8^{\circ} \varepsilon \mathrm{I}$ & şis. & $998^{\circ} \tau$ & - RSOTOT & 998 \\
\hline $220^{\circ}$ & $\cdot 0$ & $0 \iota^{*}$ & $00^{\circ} \varepsilon$ & - & - & - & $9 \angle 0^{\circ}$ & - & $\angle O^{\circ} \mathrm{I}$ & $g^{\circ} 9 \mathrm{I}$ & $\mathrm{s}^{\circ} \mathrm{S}^{\circ}$ & $66 L^{\circ} \cdot \tau$ & - PSOIUT & $+9 \varepsilon^{\circ}$ \\
\hline$\$ \rightarrow 0^{\circ}$ & $\cdot 0$ & टट• & $00^{\circ} \varepsilon$ & - & - & - & $+50^{\circ}$ & - & $I Z \cdot \tau$ & $g^{\circ} 8 \mathrm{I}$ & sns. & $\$ 99^{\circ} \tau$ & - PSOIOT & $\varepsilon^{\circ} \varepsilon$ \\
\hline $210^{\circ}$ & $\cdot 0$ & $2 T^{\circ}$ & $00^{\circ} \varepsilon$ & - & - & - & อง & - & $n{ }^{\circ} \mathrm{I}$ & $L \bullet 8 T$ & Sis. & $0 \& S \cdot T$ & -950IUT & $29 \varepsilon$ \\
\hline Oع $0^{\circ}$ & $\cdot 0$ & $22^{\circ}$ & $0 u^{\circ} \varepsilon$ & - & - & - & $990^{\circ}$ & - & $50^{\circ} \tau$ & $\varepsilon \cdot 9 T$ & $\mathrm{sOS}^{\circ}$ & $96 \varepsilon \cdot \tau$ & - BSOTOT & $a_{\varepsilon}$ \\
\hline$\angle \mathrm{TO} 0^{\circ}$ & $\cdot 0$ & T T. & $00 \cdot \bar{\varepsilon}$ & - & - & - & T90. & - & $6 I \cdot T$ & $S^{*} 8 \mathrm{~T}$ & $\mathrm{SOS}^{\circ}$ & $292^{\circ} \tau$ & - BSOIOT & $09 \varepsilon^{\circ}$ \\
\hline $\mathrm{T}+0^{\circ}$ & $\cdot 0$ & $\tau Z^{\bullet}$ & $00^{\circ} \bar{\varepsilon}$ & - & - & - & SSO० & - & $O Z \cdot \tau$ & $9^{\bullet} 8 \mathrm{~T}$ & cros. & $8 Z \mathrm{I} \cdot \mathrm{T}$ & - BSOTEt & $69 \varepsilon^{\prime}$ \\
\hline $0 \varepsilon 0^{\circ}$ & $\cdot 0$ & $\tau \varepsilon^{\bullet}$ & $00^{\circ} \varepsilon$ & - & - & - & $\angle 90^{\circ}$ & - & $60^{\circ} \mathrm{I}$ & $6 \cdot 91$ & $\operatorname{sos}$. & $\varepsilon 66^{\circ}$ & - BSOICI & QS' \\
\hline - & - & - & $00^{\circ} \varepsilon$ & - & - & - & $960^{\circ}$ & - & $16^{\circ}$ & $\tau \cdot n \tau$ & sis. & $926^{\circ}$ & • QSGIUT & $\angle S \varepsilon^{C}$ \\
\hline STO & $\cdot 0$ & $n \tau^{\circ}$ & $00^{\circ} \varepsilon$ & - & - & - & $080^{\circ}$ & - & SL. & $g \cdot$ โ T & sns. & $658^{\circ}$ & - gGOtút & $99^{c}$ \\
\hline - & - & - & $00^{\circ} \varepsilon$ & - & - & - & $990^{\circ}$ & - & $O L^{\circ}$ & $6^{\circ} 01$ & SOS. & $26 L^{\circ}$ & - GSOLOT & GS $\varepsilon^{\prime}$ \\
\hline $910^{\circ}$ & $\cdot 0$ & $\mathrm{SI} \cdot$ & $00^{\circ} \varepsilon$ & - & - & - & S90. & - & $T L^{\circ}$ & $\tau \cdot \tau T$ & sos. & SzL. & - gSotut & $\pi S$ \\
\hline $210^{\circ}$ & $\cdot 0$ & $\vec{\tau} \tau$ & $00 \cdot \bar{\varepsilon}$ & - & - & - & $0<0^{\circ}$ & - & $9 L^{\circ}$ & $8^{\circ}$ T T & sos. & $859^{\circ}$ & 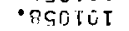 & 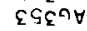 \\
\hline $920^{\circ}$ & $\cdot 0$ & $\mathrm{SI} \cdot$ & $00^{\circ} \varepsilon$ & - & - & - & $980^{\circ}$ & - & $88^{\circ}$ & $L^{\bullet} \varepsilon I$ & $\mathrm{SOS}^{\circ}$ & $165^{\circ}$ & - OSOTUT & $29 \varepsilon^{\prime}$ \\
\hline - & - & - & $00^{\circ} \varepsilon$ & - & - & - & $290^{\circ}$ & - & $9 T^{\circ} \cdot \tau$ & {$[\cdot 8 \mathrm{I}$} & sng. & $\csc \cdot$ & -8G0LOT & TS \\
\hline$\varepsilon \varepsilon \sigma^{\circ}$ & $\cdot 0$ & $\varepsilon \iota^{\bullet}$ & $00^{\circ} \varepsilon$ & - & - & - & $9 \mathrm{SO}^{\circ}$ & - & $\mathrm{ZI} \cdot \mathrm{I}$ & $S^{\circ} \angle T$ & $\vec{s} \cap \vec{c}_{3} \cdot$ & $9 \mathrm{GH}^{\circ}$ & - $850 \mathrm{~T}$ t & \\
\hline - & - & - & $00^{\circ} \varepsilon$ & - & - & - & $650^{\circ}$ & - & $6 \mathrm{I} \cdot \mathrm{T}$ & $g^{\circ} \mathrm{RI}$ & $\operatorname{sig} \mathrm{g}^{\circ}$ & टટદ. & - BSOTÚt & \\
\hline $\operatorname{se} 0^{\circ}$ & $\cdot 0$ & $\varepsilon \tau \bullet$ & $00 \cdot \varepsilon$ & - & - & - & $0<0^{\circ}$ & - & $\varepsilon 0^{\circ} \tau$ & $\therefore 9 \tau$ & GCS. & $88 T^{\circ}$ & - OSOTUL & \\
\hline $970^{\circ}$ & $\cdot 0$ & $\angle T^{\circ}$ & $00^{\circ} \varepsilon$ & - & - & - & $090^{\circ}$ & - & $06^{\circ}$ & $6^{\circ} \varepsilon \tau$ & grig. & $h S 0^{\circ}$ & - OGOIOT & $\angle t C$ \\
\hline ST $0^{\circ}$ & .69 & $\varepsilon I^{\bullet}$ & $00^{\circ} \varepsilon$ & - & - & - & $2 \angle 0^{\circ}$ & - & $98^{\circ}$ & $\varepsilon \cdot \varepsilon \tau$ & $g^{\circ}$ & tร. & - RG0โŨ & $9+$ \\
\hline$\varepsilon ट 0^{\circ}$ & $\cdot 0$ & $\pi I^{\circ}$ & $00^{\circ} \varepsilon$ & - & - & - & $8+0^{\circ}$ & - & $96^{\circ}$ & $6 \cdot+1$ & $\mathrm{~S}^{\circ} \mathrm{S}^{\circ}$ & โこI• & • QGOโUI & Gh \\
\hline- & - & - & $00^{\circ} \varepsilon$ & - & - & - & $990^{\circ}$ & - & $90^{\circ} \mathrm{I}$ & $t^{*} 9 I$ & $\mathrm{~S}^{\circ} \mathrm{S}^{\circ}$ & SSz ${ }^{\circ}$ & • 8GOLUT & 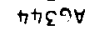 \\
\hline$\tau \tau \sigma^{\circ}$ & $\cdot 0$ & I T • & $00^{\circ} \varepsilon$ & - & - & - & $990^{\circ}$ & - & $00 \cdot \tau$ & $S^{\bullet} S I$ & $\mathrm{~g}^{n} \mathrm{~S}^{\circ}$ & $88 \mathrm{I}^{\circ}$ & - gSOLÚT & $\varepsilon^{n} \varepsilon^{c}$ \\
\hline $520^{\circ}$ & $\cdot 0$ & $8 \mathrm{I}^{\circ}$ & $00^{\circ} \varepsilon$ & - & - & - & $990^{\circ}$ & - & $\angle 0^{\circ} \mathrm{I}$ & $L \cdot 9 T$ & $\mathrm{~S}^{\circ} \mathrm{G}$. & ZZદ. & - BgOIÚt & टh \\
\hline$\angle \varepsilon 0^{\circ}$ & $\cdot 0$ & $\rightarrow 2^{\circ}$ & $00^{\circ} \bar{\varepsilon}$ & $=$ & - & - & $990^{\circ}$ & - & $90 \cdot \tau$ & $\mathrm{S}^{*} 9 \tau$ & $\mathrm{G}^{\circ} \mathrm{S}^{\circ}$ & $9 \mathrm{gt}$. & - PGOAOUT & \\
\hline 与 T $0^{\circ}$ & $\cdot 0$ & $n \tau^{\circ}$ & $00^{\circ} \varepsilon$ & - & - & - & $+90^{\circ}$ & - & $86^{\circ}$ & $\tau \cdot \mathrm{s} T$ & S9G. & $T_{6 S^{\circ}}$ & - RSOLET & on \\
\hline- & - & - & $00^{\circ} \bar{\varepsilon}$ & - & - & - & $+90^{\circ}$ & - & $88^{\circ}$ & $L \cdot \bar{\varepsilon} \tau$ & s9. & $85^{\circ}$ & - Bstatut & $6 \varepsilon$ \\
\hline - & - & - & $00^{*} \bar{E}$ & - & - & - & 9SO. & - & $58^{\circ}$ & $\sum \cdot \varepsilon T$ & $\mathrm{~s}^{9} \mathrm{~S}^{\circ}$ & $26 L^{\circ}$ & - OSOTuI & \\
\hline$\varepsilon \tau 0^{\circ}$ & $\cdot 0$ & OT * & $00^{\circ} \varepsilon$ & - & - & - & $\operatorname{sho} 0^{\circ}$ & - & $\varepsilon 8^{\circ}$ & $6^{\circ} 2 I$ & $\mathrm{~s}^{\circ} \mathrm{s}^{\circ}$ & $\mathrm{G} 2 \mathrm{~L}^{\circ}$ & - BGOLŨ T & $\angle \varepsilon$ \\
\hline โこ०⿰ & $\cdot 0$ & ZI* & $00^{\circ} \varepsilon$ & - & - & - & $990^{\circ}$ & - & $76^{\circ}$ & $S^{*}+\tau$ & $g^{a} g^{\circ}$ & $658^{\circ}$ & - BGDIUT & \\
\hline $020^{\circ}$ & .0 & $0 Z^{\circ}$ & $00^{\circ} \bar{\varepsilon}$ & - & - & - & $650^{\circ}$ & - & $O \tau^{\bullet} \tau$ & $\tau \cdot \angle \tau$ & $s^{n} \cdot$ & $\varepsilon 66^{\circ}$ & - 890T U I & \\
\hline 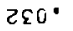 & $\cdot 0$ & $\angle Z^{\circ}$ & $00^{\circ} \varepsilon$ & - & - & - & $89 n$. & - & $\tau \tau \cdot \tau$ & $Z^{\cdot} \cdot L^{\top}$ & $\mathrm{s}^{a} \mathrm{~g}^{\circ}$ & AटI I I & - Bgoró I & $\rightarrow \varepsilon \varepsilon$ \\
\hline$=$ & - & - & $00^{\circ} \varepsilon$ & - & - & - & 990. & - & $80^{\circ} \tau$ & $L \cdot 9 I$ & $\mathrm{~S}^{\circ} \mathrm{S}^{\circ}$ & $\varepsilon 9 \boldsymbol{H}^{\circ} \mathrm{T}$ & • CGOLUT & cs. \\
\hline $920^{\circ}$ & $\cdot 0$ & $\mathrm{GI}^{\bullet}$ & $00^{\circ} \varepsilon$ & - & - & - & $\tau \angle 0^{\circ}$ & - & $O T \cdot \tau$ & $\tau \cdot L \tau$ & s9. & $292 \cdot 1$ & - Esกtút & \\
\hline $820^{\circ}$ & $\cdot 0$ & $\varepsilon I^{\circ}$ & $\mathrm{OU} \cdot \bar{\varepsilon}$ & - & - & - & $0 \angle 0^{\circ}$ & - & $90^{\circ} \mathrm{T}$ & $\pi^{\circ} \bar{\varphi} \tau$ & sog. & $62 \varepsilon \cdot 1$ & - مGotút & \\
\hline$\varepsilon 20^{\circ}$ & $\cdot 0$ & $9 T^{\circ}$ & $00 \cdot \varepsilon$ & - & - & - & $890^{\circ}$ & - & $20^{\circ} \tau$ & $6^{\circ} \subseteq \tau$ & $\mathrm{g}^{a} \mathrm{~g}^{\circ}$ & $965 \cdot 1$ & - ASOTOT & \\
\hline $870^{\circ}$ & $\cdot 0$ & $\mathrm{GI} \cdot$ & OL $\bar{\varepsilon}$ & - & - & - & $990^{\circ}$ & - & $Z T \cdot \tau$ & $n \cdot L \tau$ & $\mathrm{G}^{\circ} \mathrm{G}^{\circ}$ & $0 \varepsilon S^{\circ}$ & - ogกlú I & 6? \\
\hline $280^{\circ}$ & $\cdot 0$ & G2* & $00 \cdot \bar{\varepsilon}$ & - & - & - & $690^{\circ}$ & - & $2 \tau \cdot T$ & $7^{\circ}<T$ & sag. & $+99 \cdot 1$ & - RSOLUT & \\
\hline $020^{\circ}$ & $\cdot 0$ & $\angle T^{\circ}$ & $00^{\circ} \varepsilon$ & - & - & - & $290^{\circ}$ & - & $60^{\circ} T$ & $6 \cdot 97$ & $\overrightarrow{\mathrm{s}} \mathrm{G}^{\circ}$ & $6 G L \cdot T$ & - PSOLUT & \\
\hline- & - & - & $00^{\circ} \varepsilon$ & - & - & - & $\tau \angle 0^{\circ}$ & - & $00 \cdot \tau$ & $\mathrm{G}^{\circ} \mathrm{S} T$ & $\sin 5^{\circ}$ & $998 \cdot 1$ & - ogfílu I & \\
\hline nT $0^{\circ}$ & $\cdot 0$ & $60^{\circ}$ & $00 \cdot \varepsilon$ & - & - & - & $290^{\circ}$ & - & $88^{\circ}$ & $L \cdot \varepsilon \tau$ & $\mathrm{s}^{\mathrm{a}} \mathrm{S}^{\circ}$ & $\varepsilon \varepsilon \sigma \cdot I$ & - gsolut & \\
\hline- & - & - & $00^{\circ} \varepsilon$ & - & - & - & $9+0^{\circ}$ & - & $\varepsilon 8^{\circ}$ & $6^{\bullet} 2 T$ & $\mathrm{~s}^{0} \mathrm{~g}^{\circ}$ & $000 \cdot 2$ & -Rgolút & \\
\hline - & - & - & $00 \cdot \bar{\varepsilon}$ & - & - & - & $6+0^{\circ}$ & . & $28^{\circ}$ & $8 \cdot 21$ & $\mathrm{~s}>9^{\circ}$ & $000 \cdot 2$ & - RGOLÚT & $\varepsilon ?$ \\
\hline t $20^{\circ}$ & $\cdot 0$ & OT & $00^{\circ} \bar{\varepsilon}$ & - & - & - & $290^{\circ}$ & - & $68^{\circ}$ & $8^{\circ} \varepsilon T$ & s?9. & $\varepsilon \& 6^{\circ} \mathrm{I}$ & - RSOIÜT & \\
\hline- & - & - & $00 \cdot \bar{\varepsilon}$ & - & - & - & $090^{\circ}$ & - & $86^{\circ}$ & $I \cdot G I$ & $5>9^{\circ}$ & $998 * T$ & - RSOLOT & {$[2$} \\
\hline $520^{\circ}$ & $\cdot 0$ & $22^{\circ}$ & $00 \cdot \varepsilon$ & - & - & - & $\angle S 0^{\circ}$ & - & $20 \cdot 1$ & $6^{\circ} \mathrm{ST}$ & $5>9^{\circ}$ & $6 G L \cdot I$ & - ostrút & 02 \\
\hline - & - & - & $00 \cdot \varepsilon$ & - & - & - & I90. & - & $n 0^{\circ} \cdot \mathrm{T}$ & $z \cdot 9 \tau$ & $s>9^{\circ}$ & $2 \varepsilon L \cdot \tau$ & - osotut & \\
\hline $20^{\circ}$ & $\cdot G L$ & $\varepsilon 2^{\circ}$ & $00 \cdot \bar{\varepsilon}$ & - & - & - & $990^{\circ}$ & - & $90 \cdot T$ & $+9 T$ & s?9. & $799^{\circ} \mathrm{I}$ & - PGOLOT & \\
\hline - & - & - & $00^{\circ} \varepsilon$ & - & - & - & $990^{\circ}$ & - & $90^{\circ} \mathrm{T}$ & $c^{*} 9 \tau$ & $5>9^{\circ}$ & $265^{\circ} \mathrm{T}$ & - ogolut & \\
\hline +20 & $\cdot 0$ & $02^{\circ}$ & $00^{\circ} \varepsilon$ & - & - & - & $590^{\circ}$ & _ & $90^{\circ} \mathrm{T}$ & $c^{\circ} 9 T$ & $\cdot$ & $n_{\varepsilon} S \cdot I$ & 2BSOLUT & \\
\hline- & - & - & $00^{\circ} \varepsilon$ & - & - & - & $590^{\circ}$ & - & $\varepsilon 0^{\circ} \tau$ & $0^{\circ} 0 \mathrm{~T}$ & $s>9^{\circ}$ & Egh 1 & - sstj IÜT & \\
\hline $610^{\circ}$ & $\cdot 0$ & Zा• & $00^{\circ} \varepsilon$ & - & - & - & $890^{\circ}$ & - & $66^{\circ}$ & $\varepsilon^{\cdot} \varsigma \mathrm{T}$ & S?:. & $96 \varepsilon \cdot 1$ & - agOIÚT & \\
\hline - & - & - & $00^{\circ} \varepsilon$ & - & - & 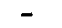 & $990^{\circ}$ & 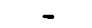 & $20^{\circ} \mathrm{T}$ & $8 \cdot \bar{S} T$ & $5>9^{\circ}$ & $625 \cdot 1$ & - SgOTút & \\
\hline $820^{\circ}$ & $\cdot 0$ & $0 z^{\circ}$ & $00^{\circ} \bar{\varepsilon}$ & - & - & - & $\angle 90^{\circ}$ & - & $90^{\circ} \tau$ & $\mathrm{G} \cdot 9 \mathrm{~T}$ & $a^{\circ}$ & $395 \cdot 1$ & - Bátút & \\
\hline- & - & - & $00^{\circ} \varepsilon$ & - & - & - & $790^{\circ}$ & - & $\angle O^{\circ} \mathrm{T}$ & $9 \cdot 9 \tau$ & $\mathrm{G} \geqslant 9^{\circ}$ & $S_{6} T \cdot \tau$ & - RSOIÚT & \\
\hline Sع $0^{\circ}$ & $\cdot \subseteq L$ & $92^{\circ}$ & $00 \cdot \varepsilon$ & - & - & - & $\angle 90^{\circ}$ & - & $90 \cdot \tau$ & $C \cdot 9 \tau$ & $5 \geq 9^{\circ}$ & $82 \mathrm{I} \cdot \mathrm{I}$ & - Bgolut & \\
\hline - & - & - & $0 D \cdot \varepsilon$ & - & - & 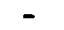 & $6 \mathrm{SO}^{\circ}$ & 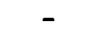 & $90 \cdot T$ & $S^{\circ} \cdot 9 \mathrm{~T}$ & $\cdot$ & $090^{\circ} \mathrm{\tau}$ & - QGOTŨ T & \\
\hline$\varepsilon 20^{\circ}$ & $\cdot 0$ & $6 I^{\circ}$ & $00^{\circ} \varepsilon$ & - & - & - & SGO & - & SO.'T & $\varepsilon^{\circ} \circ$ & c?9. & $866^{\circ}$ & - PSOLUT & \\
\hline - & - & - & $00 \cdot \varepsilon$ & - & - & - & $\angle S^{\circ}$ & 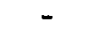 & To-T & $L \cdot G T$ & G? & $926^{\circ}$ & - QGDIUT & \\
\hline 2T0 & $\cdot n$ & $\varepsilon \mathrm{I} \cdot$ & $00 \cdot 8$ & - & - & - & $+90^{\circ}$ & - & n6. & $G \cdot+T$ & $s^{7} \cdot$ & $698^{\circ}$ & -RGDIUT & \\
\hline- & - & - & $00 \cdot 8$ & - & - & - & $\rightarrow S 0^{\circ}$ & - & $98^{\circ}$ & $Z^{\bullet} \varepsilon T$ & $S>9^{\circ}$ & $26 L^{\circ}$ & - QSaljút & \\
\hline $120^{\circ}$ & $\cdot 0$ & $60^{\circ}$ & $00^{\circ} \overline{8}$ & - & - & - & $950^{\circ}$ & - & $\varepsilon 8^{\circ}$ & $6 \cdot 2 \tau$ & $979^{\circ}$ & GटL. & - OgDfût & \\
\hline - & $=$ & - & $00^{\circ} \overline{8}$ & - & - & - & $60^{\circ}$ & - & $06^{\circ}$ & $6^{\circ} \varepsilon T$ & G?9. & RG & - QSOLÛ̃ & \\
\hline $\operatorname{te} 0^{\circ}$ & $\cdot 0$ & h厂 & $00 \cdot \bar{c}$ & - & - & - & $650^{\circ}$ & - & $96^{\circ}$ & $8 \cdot 7 \tau$ & $S \geq 9^{\circ}$ & T $6 S^{\circ}$ & - RSDIU T & \\
\hline- & - & - & $00^{\circ} \varepsilon$ & - & - & - & $850^{\circ}$ & - & $86^{\circ}$ & $\tau^{\circ} \mathrm{G} T$ & $9^{\circ}$ & EटS. & • 8SO I Ü T & \\
\hline $2 \varepsilon 0^{\circ}$ & •カ十 & $n 2^{\circ}$ & $00^{\circ} \varepsilon$ & - & - & - & $990^{\circ}$ & - & $66^{\circ}$ & $H^{\circ} \mathrm{ST}$ & G>9. & $9 S^{\circ}$ & - ogolú I & \\
\hline & - & & $00^{\circ} \bar{\varepsilon}$ & - & - & - & $590^{\circ}$ & 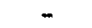 & $00 \cdot T$ & $\mathrm{~S}^{\cdot} \overline{\mathrm{S}} \mathrm{T}$ & $S>9^{\circ}$ & $688^{\circ}$ & - DSOTuT & \\
\hline $620^{\circ}$ & $\cdot 0$ & $02^{\circ}$ & $00^{\circ} \varepsilon$ & - & - & - & $\angle 90^{\circ}$ & - & $66^{\circ}$ & $\vec{\varepsilon} \cdot \overrightarrow{S T}$ & $\mathrm{~S}^{\circ}, 9^{\circ}$ & टटE. & - DSOTÚt & \\
\hline- & - & - & $00^{\circ} \bar{\varepsilon}$ & - & - & - & $6 \mathrm{SO} 0^{\circ}$ & - & $86^{\circ}$ & $Z \cdot S T$ & $\mathrm{G} \geqslant 9^{\circ}$ & SSZ. & - BGOLUT & $\angle G$ \\
\hline$\varepsilon 20^{\circ}$ & $\cdot 0$ & I I & $00^{\circ} \varepsilon$ & - & - & - & $+90^{\circ}$ & - & $96^{\circ}$ & $8 \cdot \hbar \tau$ & S>9. & $88 \mathrm{I}^{\circ}$ & - gsotút & \\
\hline- & - & - & $00^{\circ} \varepsilon$ & - & - & 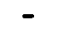 & $6+0^{\circ}$ & - & $\mathrm{SG}^{\circ}$ & $L \cdot n T$ & G.9. & โこТ. & - aş IUT & 56 \\
\hline T T0 $0^{\circ}$ & .0 & $n I^{\circ}$ & $00 \cdot \varepsilon$ & - & - & . & $280^{\circ}$ & 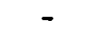 & $\varepsilon 8^{\circ}$ & $8^{\circ} 2 T$ & $929^{\circ}$ & h $0^{\circ}$ & - PGOTUT & \\
\hline D & $(2 H)\rfloor$ & $0 / V$ & $2 \pi A$ & & & & & & & $\exists S / 1 \exists$ & & - NI & \& $\exists$ WกN & \\
\hline 11$\rfloor$ & $\exists \wedge$ ヨักว & & $\exists \exists 01 \cap 0$ & $\ln$ & $\underline{n} / \wedge$ & חות ת* & {$[1 /, n$} & $1 / n$ & $n / n$ & $n$ & & $z$ & SCTond & Nก \\
\hline
\end{tabular}

OZt- h6Z NกY dVW yOIGJINI

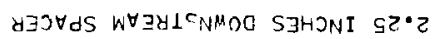

İn: 


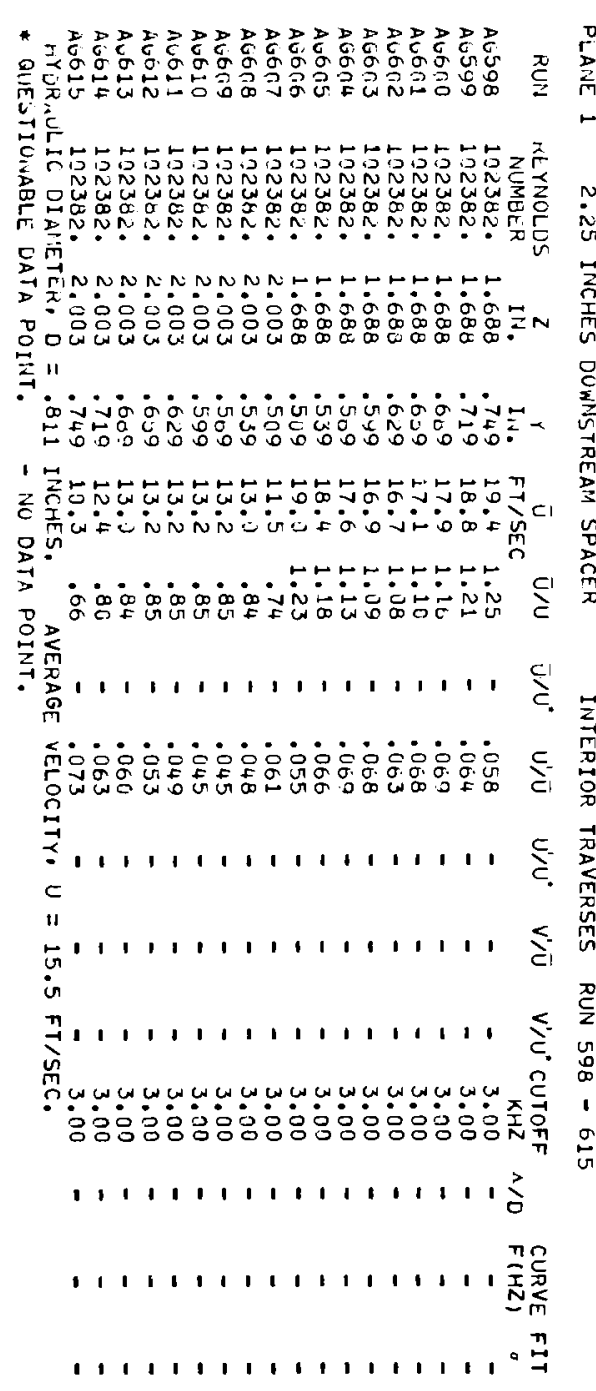

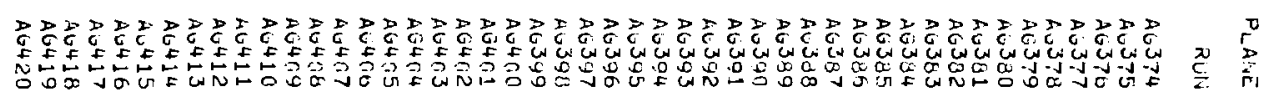

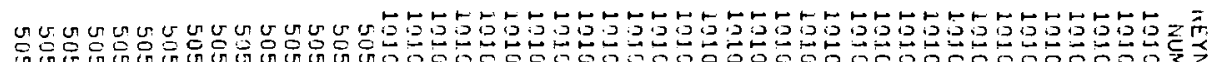

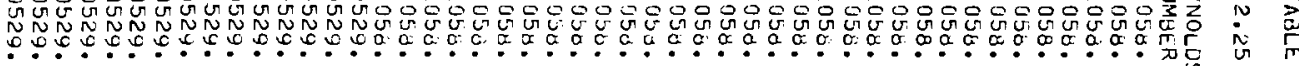

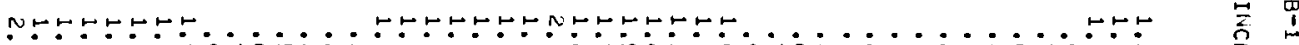

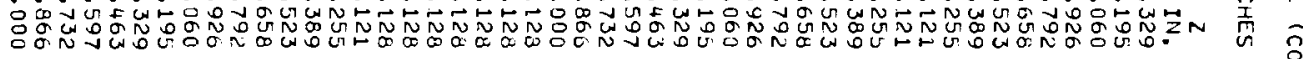

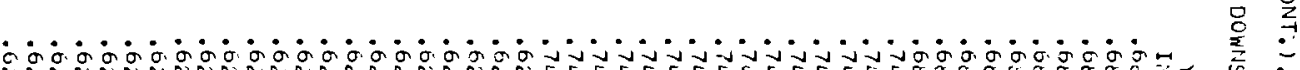

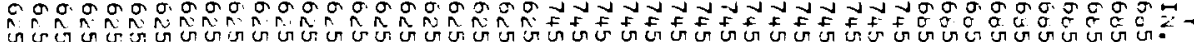

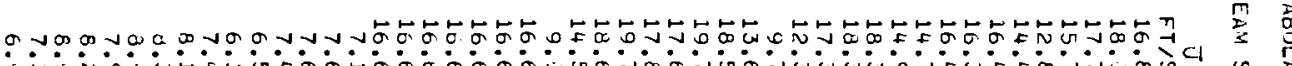

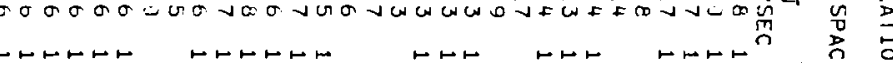

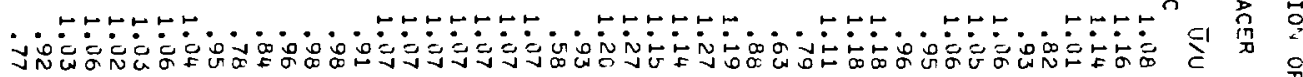

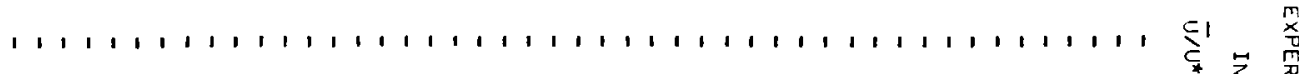

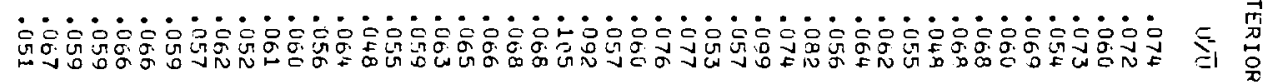

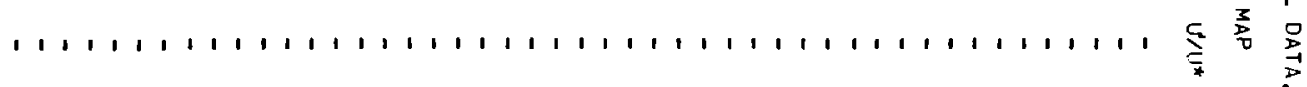
$1,1,1,1,1,1,1,1,1,1,1,1,1,1,1,1,1,1,1,1 \leqslant$

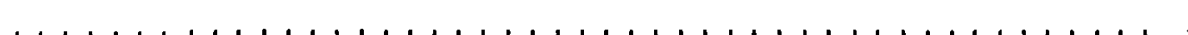

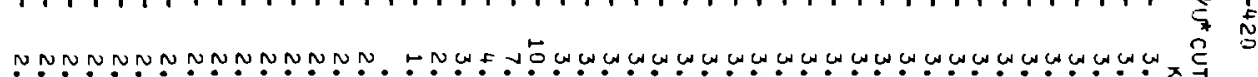

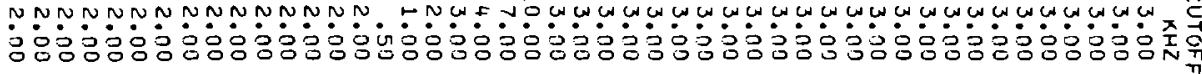

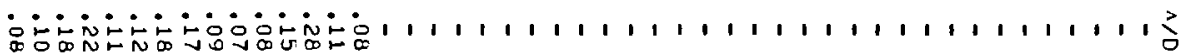

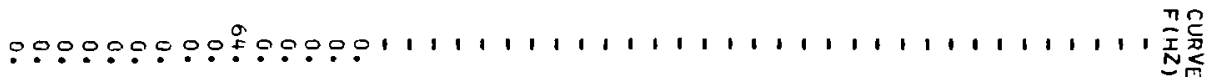

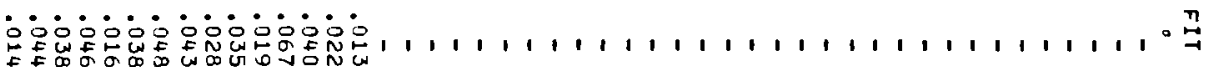


BNWL-1757

TABLE 3-1 (CONT.). TABULATION OF EXPER_MENTAL DATA.

\begin{tabular}{|c|c|c|c|c|c|c|c|c|c|c|c|c|c|}
\hline PLAliE & $2 \cdot 25$ & INCHES & DO. N'ST & $A M S$ & FR & WAL & L MAP & & UUN 4 & -597 & & & \\
\hline RUNi & $\begin{array}{l}\text { REYNOLDS } \\
\text { NV:JMBER }\end{array}$ & $\begin{array}{l}2 \\
I N\end{array}$ & $I_{1+.}^{r}$ & $\begin{array}{c}\bar{J} \\
F T / S E C\end{array}$ & $\bar{U} / U$ & $\overline{\mathrm{u}} / \mathrm{U}^{*}$ & $U^{\prime} / \bar{U}$ & $u^{\prime} U^{*}$ & $v^{\prime} / \bar{v}$ & $\begin{array}{c}\text { V'U" CUTOFF } \\
\text { KHZ }\end{array}$ & $A / D$ & $\begin{array}{l}\text { CURVE } \\
F(H Z)\end{array}$ & FI T \\
\hline$A_{0}, 447$ & 102382 & .081 & $1.7,5$ & 14.1 & .91 & - & .050 & - & - & 3.00 & .15 & 96. & .0 \\
\hline$A 6448$ & 122382 & .148 & $1.7,5$ & 15.5 & 1.00 & - & .059 & - & - & 3.00 & - & - & \\
\hline 40449 & 102382 . & .21 .5 & $1 \cdot 7\lrcorner 5$ & 17.1 & 1.10 & - & .059 & - & - & 3.00 & .17 & 0 . & .016 \\
\hline$A_{1}, 450$ & 172382 & .282 & $1.7,55$ & 17.8 & 1.15 & - & .053 & - & - & 3.00 & - & - & - \\
\hline A 0451 & 102382 . & .349 & $1.7 \jmath 5$ & 17.5 & 1.13 & - & .059 & - & - & 3.00 & .16 & 0. & .01 \\
\hline$A G 452$ & 102382. & .410 & 1.755 & 17.6 & 1.13 & - & .058 & - & - & 3.00 & - & - & - \\
\hline$A G 453$ & 122382 & .483 & 1.755 & 17.4 & 1.12 & - & .049 & - & - & 3.00 & .20 & 0 . & .022 \\
\hline$A 6454$ & 102382 & .550 & 1.705 & 16.3 & 1.05 & - & .061 & - & - & 3.00 & - & - & . \\
\hline 40455 & 122382 & .617 & $1.7 \supset 5$ & 13.8 & .89 & - & .082 & - & - & 3.00 & .16 & 60. & .015 \\
\hline Au 455 & 122382 . & .685 & $1.7=5$ & 10.8 & .69 & - & .093 & - & - & 3.00 & - & - & \\
\hline$A G 457$ & 1.2382 & .752 & 1.755 & - & - & - & - & - & - & - & - & - & - \\
\hline 46458 & 102382 & .819 & 1.705 & 8.1 & .52 & - & .151 & - & - & 3.00 & - & - & 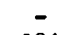 \\
\hline 40459 & 132382. & .886 & $1.7 \supset 5$ & 11.3 & .72 & - & .096 & - & - & 3.00 & .19 & 0. & .021 \\
\hline$A \cup 400$ & 132382 & .953 & $1.7 \cup 5$ & 14.5 & .94 & - & .089 & - & - & 3.00 & .18 & 0. & .020 \\
\hline$A 64$ '́1 & 132382 & 1.020 & $1.7,5$ & 17.3 & 1.11 & - & .059 & - & - & 3.00 & .22 & 0 . & .028 \\
\hline$A G 4 \div 2$ & 1.2382. & 1.037 & $1.7,5$ & 18.6 & 1.20 & - & .049 & - & - & 3.00 & - & - & - \\
\hline$A<463$ & $10<302$. & 1.154 & 1.755 & 19.2 & 1.24 & - & .046 & - & - & 3.00 & .21 & 0. & .044 \\
\hline 40464 & 102382 . & 1.221 & $1.7,5$ & 19,3 & 1.24 & - & .0140 & - & - & 3.00 & - & - & - \\
\hline$A \cup 465$ & $19238{ }^{\circ}$. & 1.288 & 1.755 & 10.1 & 1.16 & - & .071 & - & - & 3.00 & - & - & - \\
\hline$A 0466$ & $12238 \mathrm{c}$ & 1.356 & 1.705 & 16.3 & 1.05 & - & .074 & - & - & 3.00 & - & - & - \\
\hline 40467 & $1023 \mathrm{dz}$. & 1.423 & 1.7 J & 16.1 & 1.04 & - & .068 & - & - & 3.00 & .18 & 106. & .017 \\
\hline A6468 & $1 \cap 23 \mathrm{H}<$. & 1.490 & 1.755 & 17.7 & 1.14 & - & .069 & - & - & 3.00 & - & - & - \\
\hline$A 6469$ & $10238 \alpha$. & 1.557 & 1.755 & 18.8 & 1.21 & - & .058 & - & - & 3.00 & .12 & 0. & .009 \\
\hline Au 470 & i?2382. & 1.024 & 1.755 & 13.8 & 1.21 & - & .058 & - & - & 3.00 & - & - & (3) \\
\hline$A 04 ? 1$ & 132382 & 1.691 & 1.755 & 18.6 & 1.20 & - & .052 & - & - & 3.00 & .21 & 0. & .021 \\
\hline$A \cup 472$ & $1 ? 2382$. & 1.758 & 1.705 & 18.3 & 1.16 & - & .052 & - & - & 3.00 & - & - & - \\
\hline$A \cup 473$ & 122382. & 1.825 & $1.7=5$ & 16.3 & 1.05 & - & .073 & - & - & 3.00 & .21 & 0. & .013 \\
\hline$x<474$ & 122382 . & 1.392 & 1.705 & 13.6 & .87 & - & .099 & - & - & 3.00 & - & - & - \\
\hline A 475 & 122302 . & 1.960 & 1.755 & 10.6 & .69 & - & .097 & - & - & 3.00 & - & - & - \\
\hline$A 64 ? 6$ & +72382 & 2.927 & $1.7,35$ & 9.6 & .62 & - & .078 & - & - & 3.00 & - & - & - \\
\hline $464 ? 7$ & $10238<$. & 2.027 & 1.815 & 11.7 & .75 & - & .058 & - & - & 3.00 & - & - & - \\
\hline A $4 ? 3$ & 102382 . & 1.960 & $1.8 \geq 5$ & 12.7 & .82 & - & .087 & - & - & 3.00 & .10 & 151. & .009 \\
\hline$A \cup 479$ & 172382 . & 1.892 & 1.815 & 14.9 & .96 & - & .075 & - & - & 3.00 & - & - & - \\
\hline$A 0480$ & 122382. & 1.825 & 1.815 & 16.1 & 1.03 & - & .067 & - & - & 3.00 & .12 & 0. & .014 \\
\hline $204: 31$ & 172382. & 1.758 & 1.815 & 16.6 & 1.07 & - & .065 & - & - & 3.00 & - & - & 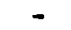 \\
\hline$A 6432$ & 122382 . & 1.691 & 1.815 & 16.9 & 1.09 & - & .066 & - & - & 3.00 & .14 & 109. & .014 \\
\hline 26483 & 102302 . & 1.557 & 1.815 & 16.7 & 1.08 & - & .072 & - & - & 3.00 & .12 & 0. & .013 \\
\hline$A 64$ is 4 & 102382 . & 1.490 & 1.815 & 16.2 & 1.04 & - & .070 & - & - & 3.00 & - & - & - \\
\hline$A \& 4 \leqslant 5$ & 102382. & 1.423 & 1.815 & 15.3 & .99 & - & .061 & - & - & 3.00 & .12 & 0. & .012 \\
\hline A4486 & +.92362 & 1.356 & 1.815 & 15.7 & 1.31 & - & .065 & - & - & 3.00 & - & - & - \\
\hline$A 0437$ & 191058. & 1.289 & 1.615 & 17.1 & 1.10 & - & .066 & - & - & $3.0 \%$ & - & - & - \\
\hline 40488 & 101058. & 1.221 & 1.815 & 17.8 & 1.15 & - & .068 & - & - & 3.00 & - & - & - \\
\hline$A 6409$ & 101058. & 1.154 & 1.815 & 17.6 & 1.13 & - & .071 & - & - & 3.00 & .23 & 16. & .008 \\
\hline A0490 & 101050. & 1.020 & 1.815 & 16.9 & 1.09 & - & .063 & - & 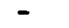 & 3.00 & .18 & 0. & .022 \\
\hline$A 0491$ & 101050. & .953 & 1.815 & $16 .:$ & 1.044 & - & .062 & - & - & 3.00 & - & - & - \\
\hline 10492 & 101050. & 1.087 & 1.815 & 17.1 & 1.10 & - & .068 & - & - & 3.00 & - & - & - \\
\hline A0493 & 121050. & .886 & 1.815 & 14.1 & .91 & - & .075 & - & - & 3.00 & .15 & 82 . & .010 \\
\hline$A 0494$ & 191058. & .819 & 1.815 & 12. & .77 & - & .067 & - & - & 3.00 & - & - & - \\
\hline AG495 & 101050. & .752 & 1.815 & 11.6 & .75 & - & .064 & - & - & 3.00 & .08 & 98 . & .017 \\
\hline Au496 & 191050. & .685 & 1.815 & 13.2 & .85 & - & .078 & - & - & 3.00 & - & - & - \\
\hline$A \cup 497$ & 101058. & .617 & 1.815 & 14.9 & .96 & - & .061 & - & - & 3.00 & .18 & 0. & .043 \\
\hline$A 6498$ & 12105. & .550 & 1.815 & 15.8 & 1.02 & - & .06 & - & - & 3.00 & - & - & - \\
\hline A6499 & 101058. & .483 & 1.815 & 16.9 & 1.03 & - & .066 & - & - & 3.00 & .20 & 0 . & .020 \\
\hline Aus 5,0 & 101050 . & .416 & 1.815 & 15.8 & 1.02 & - & .070 & - & - & 3.00 & - & - & - \\
\hline AGЈ 1 & 101058. & .349 & 1.815 & 15.7 & 1.01 & - & .070 & - & - & 3.00 & .15 & 0. & .011 \\
\hline$A G 5 \pi 2$ & 191058. & .282 & 1.815 & 16.9 & 1.03 & - & .066 & - & - & 3.00 & - & - & - \\
\hline$A 0503$ & 121058. & .21 .5 & 1.815 & 15.9 & 1.02 & - & .05 & - & - & 3.00 & .17 & 1. & .020 \\
\hline$A 050.4$ & 101058. & $.14 i$ & 1.815 & 15,2 & .98 & - & .04 & - & 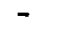 & 3.00 & - & - & - \\
\hline A6505 & 131050. & .081 & 1.815 & 14.01 & .90 & - & .05 & - & - & 3.00 & .14 & 0. & .00 \\
\hline A०5त6 & 121050. & $.0 B_{1}$ & 1.875 & 13.7 & .86 & - & .07 & - & - & 3.00 & .12 & 0. & .019 \\
\hline$A 656,7$ & 121050. & .148 & 1.875 & 15.7 & 1.31 & - & .043 & - & - & 3.00 & - & - & - \\
\hline$A \cup 5 r .8$ & 101050. & .215 & 1.875 & 15.2 & .96 & - & .050 & - & - & 3.00 & .14 & 0. & .011 \\
\hline$A 6569$ & 121.050. & .282 & 1.875 & 14.4 & .93 & - & .061 & - & - & 3.00 & - & - & 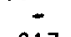 \\
\hline$A G 510$ & $12105 d$. & .349 & 1.875 & 14.1 & .91 & - & .05 & - & 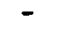 & 3.00 & .18 & 0. & .017 \\
\hline$A G 511$ & 101058. & .483 & 1.875 & 14.2 & .91 & - & .061 & - & - & 3.00 & .17 & 79. & .03 \\
\hline AG512 & 121050. & .617 & 1.875 & 13.2 & .85 & - & .06 & - & - & 3.00 & .11 & 0. & .01 \\
\hline$A \cup 513$ & 121058. & .685 & 1.875 & 12.4 & .80 & - & .06 & - & 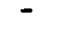 & 3.00 & $=$ & - & \\
\hline$A 6514$ & 101058. & .752 & 1,875 & 11.6 & .75 & - & .049 & - & - & 3.00 & .08 & 74. & .019 \\
\hline Ao5 515 & 101058. & .819 & 1.875 & 11.9 & .77 & - & . 1555 & - & - & 3.00 & - & - & \\
\hline$A G 516$ & 101050. & .886 & 1.875 & 13.4 & .86 & - & .070 & - & - & 3.00 & .11 & 97. & .00 \\
\hline$A G 517$ & 101058 . & 1.020 & 1.875 & 14.8 & .95 & - & .062 & - & 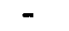 & 3.00 & .24 & 0. & .01 \\
\hline$A=518$ & 12.1050. & 1.154 & 1.875 & 15.4 & .99 & - & .066 & - & - & 3.00 & .18 & 88. & .025 \\
\hline$A 6519$ & 101058. & 1.289 & 1.875 & 15.4 & .99 & - & .064 & - & - & 3.00 & .17 & 0. & .019 \\
\hline$A 0520$ & 121058 . & 1.356 & 1.875 & 14.9 & .96 & - & .049 & - & - & 3.00 & - & - & - \\
\hline AG521 & 101058. & 1.423 & 1.875 & 15)$. & .96 & - & .046 & - & - & 3.00 & .08 & 0. & .010 \\
\hline$A \cup 522$ & 121050. & 1.499 & 1.875 & 15.1 & - & - & .052 & - & 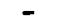 & 3.00 & - & - & . \\
\hline AGS23 & 101050. & 1.557 & 1.875 & $15 . ?$ & .97 & - & .054 & - & - & 3.00 & .15 & 0. & .012 \\
\hline AgS24 & 191058 . & 1.691 & 1.875 & 15.1 & .97 & - & .058 & - & - & 3.00 & .13 & 126. & .023 \\
\hline $\begin{array}{l}A 6525 \\
A \cup 526\end{array}$ & $\begin{array}{l}191058 . \\
101.058 .\end{array}$ & $\begin{array}{l}1.825 \\
1.960\end{array}$ & $\begin{array}{l}1.875 \\
1.875\end{array}$ & $\begin{array}{l}14.9 \\
11.9\end{array}$ & $\begin{array}{r}.90 \\
.77\end{array}$ & - & $\begin{array}{l}.072 \\
.083\end{array}$ & - & - & $\begin{array}{l}3.00 \\
3.00\end{array}$ & $\begin{array}{r}.13 \\
.09\end{array}$ & 98. & $\begin{array}{l}.015 \\
.006\end{array}$ \\
\hline
\end{tabular}

HYLR IULIC DIAMETER, D $=.811$ INCHES. AVERAGE VELOCITY, U $=15.5 \mathrm{FT} / \mathrm{SEC}$.

* guestivivable data puint. I nu data poin!t. 


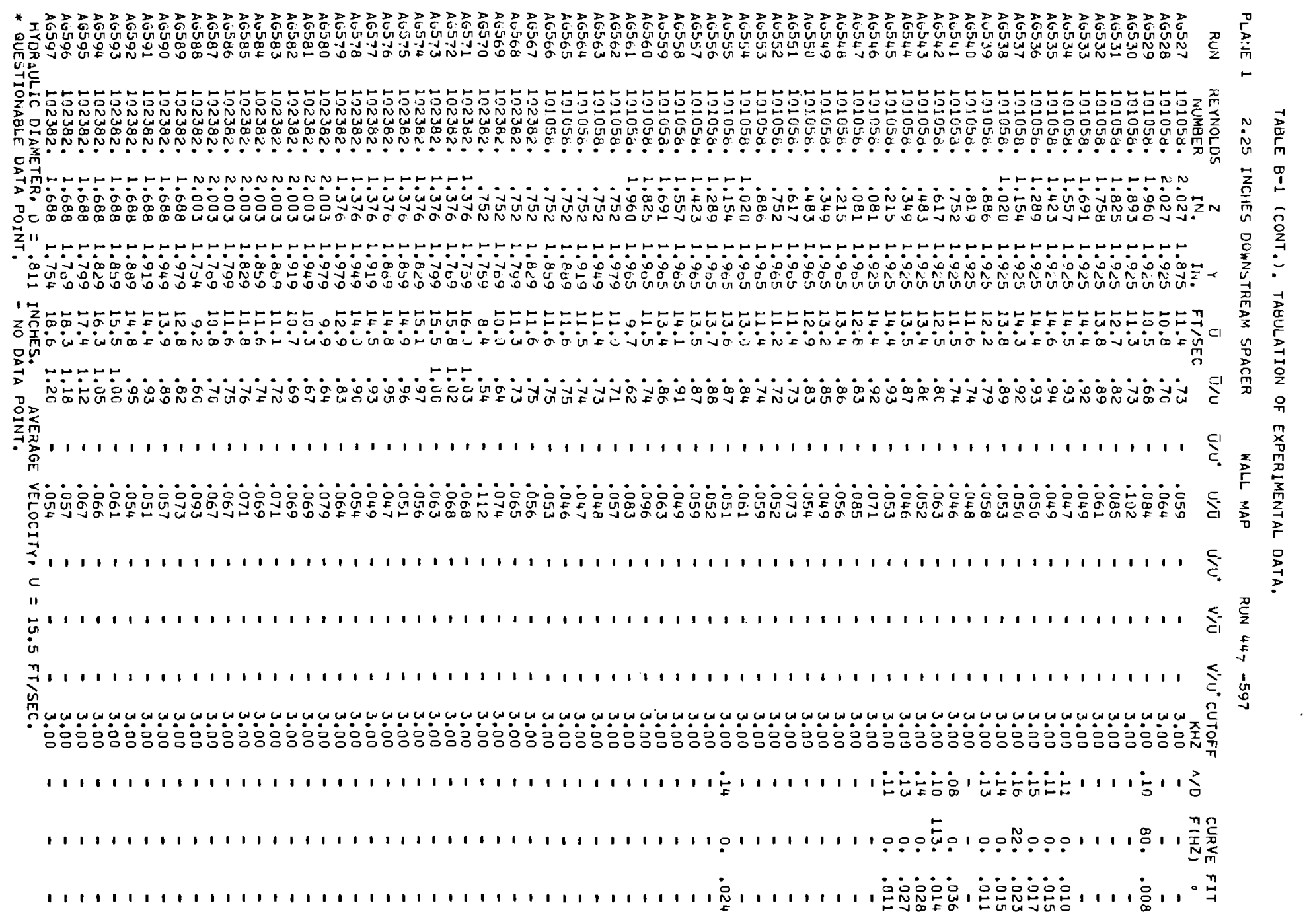


BNWL-1757

TAdLE B-1 (CONT.). TABULATION OF EXPEKIMENTAL DATA.

\begin{tabular}{|c|c|c|c|c|c|c|c|c|c|c|c|c|c|}
\hline \multirow{2}{*}{$\begin{array}{c}\text { PLA } \\
\text { RUN }\end{array}$} & \multicolumn{2}{|c|}{2.25 INCHES } & \multicolumn{3}{|c|}{ DOrNSTREAP SPACER } & \multicolumn{3}{|c|}{ IITIERIOR CL } & \multicolumn{3}{|c|}{ RUIJ $42.1-446 \quad 2 R E$} & \multirow[b]{2}{*}{$\begin{array}{l}\text { CURVE } \\
F(H Z)\end{array}$} & \multirow[b]{2}{*}{$\mathrm{FIT}$} \\
\hline & $\begin{array}{c}\text { KEYNOLOS } \\
\text { NUMGER }\end{array}$ & I ${ }^{Z}$ & I' & $F T / S E C$ & $c^{i} / U$ & $\overline{\mathrm{u}} / U^{*}$ & U'u & $u^{\prime} u^{*}$ & $v^{\prime} / \bar{u}$ & $\begin{array}{c}V^{\prime} / U^{*} \text { CUTOFF } \\
\text { KHZ }\end{array}$ & $\kappa / 0$ & & \\
\hline$A_{0} 421$ & 203479 & 2.010 & $.6<5$ & 15.6 & .88 & - & .045 & - & - & -3.00 & .11 & 0. & .016 \\
\hline 40422 & $<23479$. & 1.877 & $.6<5$ & 15.7 & 1.01 & - & .055 & - & 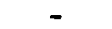 & 3.00 & .18 & 0. & \\
\hline$A 0423$ & $\angle 23479$, & 1.743 & $.6<5$ & 16.3 & 1.05 & - & . Utio & - & - & 3.00 & .22 & 0. & \\
\hline$A 6424$ & 203479. & 1.609 & .625 & 16.6 & 1.07 & - & .061 & - & - & 3.00 & .27 & 0. & \\
\hline Au 425 & $\therefore 23479$. & 1.476 & .625 & 15.8 & 1.02 & - & .059 & - & - & 3.00 & .15 & 0. & \\
\hline Aut:6 & 223479 , & 1.342 & $.6<^{5}$ & 15.9 & 1.02 & - & .063 & - & - & 3.00 & .14 & 0. & \\
\hline$A 64<7$ & $2 \cap 3479$. & 1.209 & $.0<5$ & 16.7 & 1.07 & - & .066 & - & - & 3.00 & .32 & 0 . & \\
\hline A. 428 & $2 n 3479$. & 1.075 & .625 & 16.5 & 1.06 & - & .057 & - & - & 3.00 & .35 & 0. & \\
\hline$A \cup 429$ & 273479. & .942 & $.0<5$ & 15.8 & 1.12 & - & .056 & - & - & 3.00 & .21 & 0 . & \\
\hline$A G 430$ & 203479 & .800 & $.6 \div 5$ & 13.7 & .88 & - & .046 & - & - & 3.00 & .12 & 0. & \\
\hline A 4431 & 203479. & .674 & $.6<5$ & 14.6 & .94 & - & .050 & - & - & 3.00 & .14 & 0. & \\
\hline 46432 & $\angle 03479$. & .541 & .625 & 15.4 & .99 & - & .052 & - & - & 3.00 & .22 & 0. & \\
\hline$A \cup 433$ & 203479 & .407 & $.6<5$ & 15.7 & 1.01 & - & .064 & - & - & 3.00 & .26 & 40. & \\
\hline$A \cup 434$ & $\angle 03479$. & .274 & $.0<5$ & 15.4 & .99 & - & .055 & - & - & 3.00 & .21 & 0 . & .0 \\
\hline$A \cup 435$ & 203479. & .140 & .025 & 15.1 & .97 & - & .046 & - & - & 3.00 & .14 & 0. & \\
\hline$A 0436$ & 233479. & .073 & $.6<5$ & 13.1 & .84 & - & .073 & - & - & 3.00 & - & - & - \\
\hline$A 0437$ & 293479. & .741 & .625 & 13.6 & .88 & - & .044 & - & - & 3.00 & - & - & \\
\hline$A \cup 436$ & 20347 . & .341 & $.0<5$ & 15.6 & 1.01 & - & .061 & - & - & 3.00 & - & - & \\
\hline $\mathrm{AO}^{4} 39$ & $\sin 3479$. & .341 & $.6<5$ & 15.6 & 1.01 & - & .064 & - & - & 10.00 & - & - & 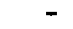 \\
\hline Av440 & $\angle 03479$. & .341 & $.6<5$ & 15.6 & 1.01 & - & .063 & - & - & 7.00 & - & - & 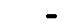 \\
\hline$A \cup 44]$ & 203479. & .341 & $.6<5$ & 15.6 & 1.01 & - & .063 & - & - & 5.00 & - & - & 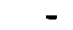 \\
\hline A0442 & 203479. & .341 & $.6 \angle 5$ & 15.6 & 1.01 & - & .062 & - & - & 4.00 & - & - & - \\
\hline$A 0443$ & 203479. & .341 & .625 & 15.6 & 1.01 & - & .051 & - & - & 3.00 & - & - & - \\
\hline $\mathrm{AC} 444$ & 203479. & .341 & $.0<5$ & 15.6 & 1.01 & - & .061 & - & - & 2.00 & - & - & \\
\hline Ao 445 & 203479 . & .341 & $.6<5$ & 15.6 & 1.01 & - & .058 & - & - & 1.00 & - & - & - \\
\hline$A 0440$ & $<03479$. & .341 & $.5<5$ & 15.6 & 1.01 & $n$ & .051 & - & - & .50 & - & - & \\
\hline LAI E 2 & $14.25 I$ & INCHES & DUNAST & 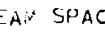 & $C[R$ & INI & E & $C L$ & RUN b3 $3_{4}$ & - 650 & & & \\
\hline Ruid & KEYNULJS & 2 & r & 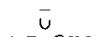 & $\bar{U}$ & $\bar{\Pi} / U^{\circ}$ & & $u^{\prime} u^{*}$ & $v^{\prime} / \bar{U}$ & V'UU' CUTOFF & & CURVE & FTT \\
\hline & IVUJMELTR & IN. & $I_{\text {ive }}$ & $F T / S E C$ & & & & & & $\mathrm{KHZ}$ & $\Lambda / D$ & $F(H Z)$ & $\sigma$ \\
\hline 0634 & 203479. & .060 & .625 & 11.9 & .76 & - & . cog & - & - & 3.00 & .33 & 0. & .02 \\
\hline 6075 & 203479. & .127 & $.6<j$ & 14.3 & .92 & - & .077 & - & - & 3.00 & - & - & 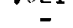 \\
\hline AG636 & $\angle 03479$. & .194 & $.6<5$ & 15.0 & 1.00 & - & .061 & - & - & 3.00 & .36 & 0. & .00 \\
\hline 4003? & $\operatorname{con} 347 y$. & .327 & .625 & 17.3 & $1.1 \mathrm{c}$ & - & .044 & - & - & 3.00 & .29 & 54. & .00 \\
\hline MU53 & $20347 \mathrm{~s}$. & .461 & $.0<5$ & 17.5 & 1.13 & - & .041 & - & - & 3.00 & .20 & 101. & .01 \\
\hline 40039 & <23475. & .594 & $.0<5$ & 16.5 & 1.00 & - & .051 & - & - & 3.00 & .18 & 97. & .02 \\
\hline 040 & c'1347y. & .728 & $.0<5$ & 15.7 & 1.01 & - & .045 & - & - & 3.00 & .23 & 76. & .01 \\
\hline Ang61 & co3479. & .861 & $.6<5$ & 16.3 & 1.03 & - & .050 & - & - & 3.00 & .23 & 81. & .02 \\
\hline Au 64 ? & 203479 & .995 & $.6 \angle 5$ & 17.2 & 1.11 & - & .051 & - & - & 3.00 & .20 & 92. & .02 \\
\hline A, 643 & $<03479$. & 1.129 & $.0<5$ & 10.4 & 1.19 & - & .039 & - & - & 3.00 & .26 & 82. & .01 \\
\hline inv644 & 203479. & 1.262 & $.6<5$ & 19.1 & 1.23 & - & .025 & - & - & 3.00 & .21 & 102. & .02 \\
\hline$A, 0645$ & 223479 . & 1.396 & .625 & 19.2 & 1.24 & - & .026 & - & - & 3.00 & .24 & 75. & .08 \\
\hline$M 0646$ & $\angle 03479$. & 1.529 & $.0<5$ & 19.9 & $1.2 c$ & - & .029 & - & - & 3.00 & .22 & 99. & .01 \\
\hline Av647 & $\angle 03479$. & 1.663 & $.0<5$ & 18.2 & 1.17 & - & .048 & - & - & 3.00 & .22 & 97. & .01 \\
\hline Au64a & $\therefore 03479$. & 1.796 & $.6<5$ & 17.2 & 1.10 & - & .053 & - & - & 3.00 & .17 & 101. & .01 \\
\hline$A 5649$ & $2 \cap 3479$. & 1.930 & $.6<5$ & 16.1 & 1.134 & - & .053 & - & - & 3.00 & .18 & 98. & .02 \\
\hline$A \cup 0,0$ & 203479. & 2.064 & .625 & 15.8 & 1.02 & - & .048 & - & - & 3.00 & .31 & 42 . & .01 \\
\hline
\end{tabular}

PLAINE 214.25 IIVCHES DONNTREAN SPACER INTERIOR CL RUN 651 - 667 .5RE

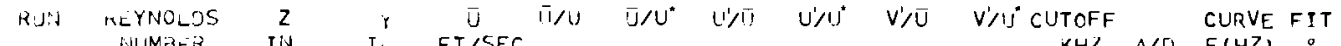

\begin{tabular}{|c|c|c|c|c|c|c|c|c|c|c|c|c|c|c|}
\hline 651 & $\begin{array}{l}\text { NuMaER } \\
\text { SOS2\%. }\end{array}$ & 2.08i & $\begin{array}{c}y \\
I_{1 \cdots} \\
.6<5\end{array}$ & $\begin{array}{c}\mathrm{FT} / \mathrm{SEC} \\
7.7\end{array}$ & .99 & - & .061 & - & - & - & $\begin{array}{r}\mathrm{KH} 2 \\
2.00\end{array}$ & $\begin{array}{l}1 / 0 \\
.28\end{array}$ & $\begin{array}{c}F(H Z) \\
29 .\end{array}$ & .014 \\
\hline 40652 & $5052 y$. & 1.946 & $.6<5$ & 7.7 & .99 & - & .052 & - & - & - & 2.00 & .25 & 36. & 029 \\
\hline 10653 & 50529. & 1.812 & $.6<5$ & 8.2 & 1.06 & - & .067 & - & - & - & 2.00 & .16 & 49. & .022 \\
\hline 40654 & 50529. & $1.67 \mathrm{~d}$ & $.6<5$ & 8.9 & 1.14 & - & .061 & - & $=$ & - & 2.00 & .19 & 48. & 17 \\
\hline $66>5$ & $5052 y$. & 1.544 & $.0<5$ & 9.4 & 1.21 & - & .047 & - & - & - & 2.00 & .28 & 39. & \\
\hline 656 & 50529. & 1.409 & .625 & 9.7 & 1.25 & - & .034 & - & - & - & 2.00 & .24 & 45. & \\
\hline 10657 & 50529. & 1.275 & $.6<5$ & 9.7 & 1.25 & - & .032 & - & - & - & 2.00 & .34 & 32 . & .01 \\
\hline 0658 & $5052 y$. & 1.141 & .625 & 9.2 & 1.19 & - & .050 & - & - & - & 2.00 & .26 & 42. & \\
\hline$A 6659$ & 50529 . & 1.007 & $.6<5$ & 8.5 & 1.10 & - & .060 & - & - & - & 2.00 & .38 & 23. & \\
\hline 6660 & 50529. & .872 & .625 & 7.8 & 1.01 & - & .060 & - & - & - & 2.00 & .45 & 20 & .0 \\
\hline 661 & 50529. & .738 & $.6<5$ & 7.5 & .97 & - & .054 & - & - & - & 2.00 & .28 & 17. & \\
\hline 1,6662 & 50529 . & .604 & .625 & 7.8 & 1.01 & - & 650. & - & - & - & 2.00 & .18 & 45. & .04 \\
\hline A 0663 & 50529 . & .470 & $.6 \measuredangle 5$ & 8. & 1.09 & - & .061 & - & - & - & 2.00 & .16 & 53. & .01 \\
\hline 664 & 50529 . & .336 & $.6<5$ & 8.8 & 1.13 & - & .044 & - & - & - & 2.00 & .25 & 0 . & .04 \\
\hline 665 & 50529. & .201 & .625 & .3 & 1.03 & - & .066 & - & - & - & 2.00 & .40 & 16. & \\
\hline 666 & 50529 . & .134 & .625 & 7.4 & .95 & - & .077 & - & - & - & 2.00 & - & - & \\
\hline 6667 & 50529. & .067 & .625 & 6. & .82 & - & .100 & - & - & - & 2.00 & 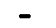 & - & \\
\hline
\end{tabular}

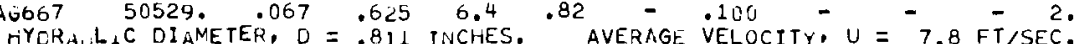

HYCRA, L 1 C DIAMETER, D $=.811$ INCHES, AVERAGE VELOCITY, U $=7.8 \mathrm{FT} / \mathrm{SEC}$.
* QUESTIONAGLE DATA POTNT. 

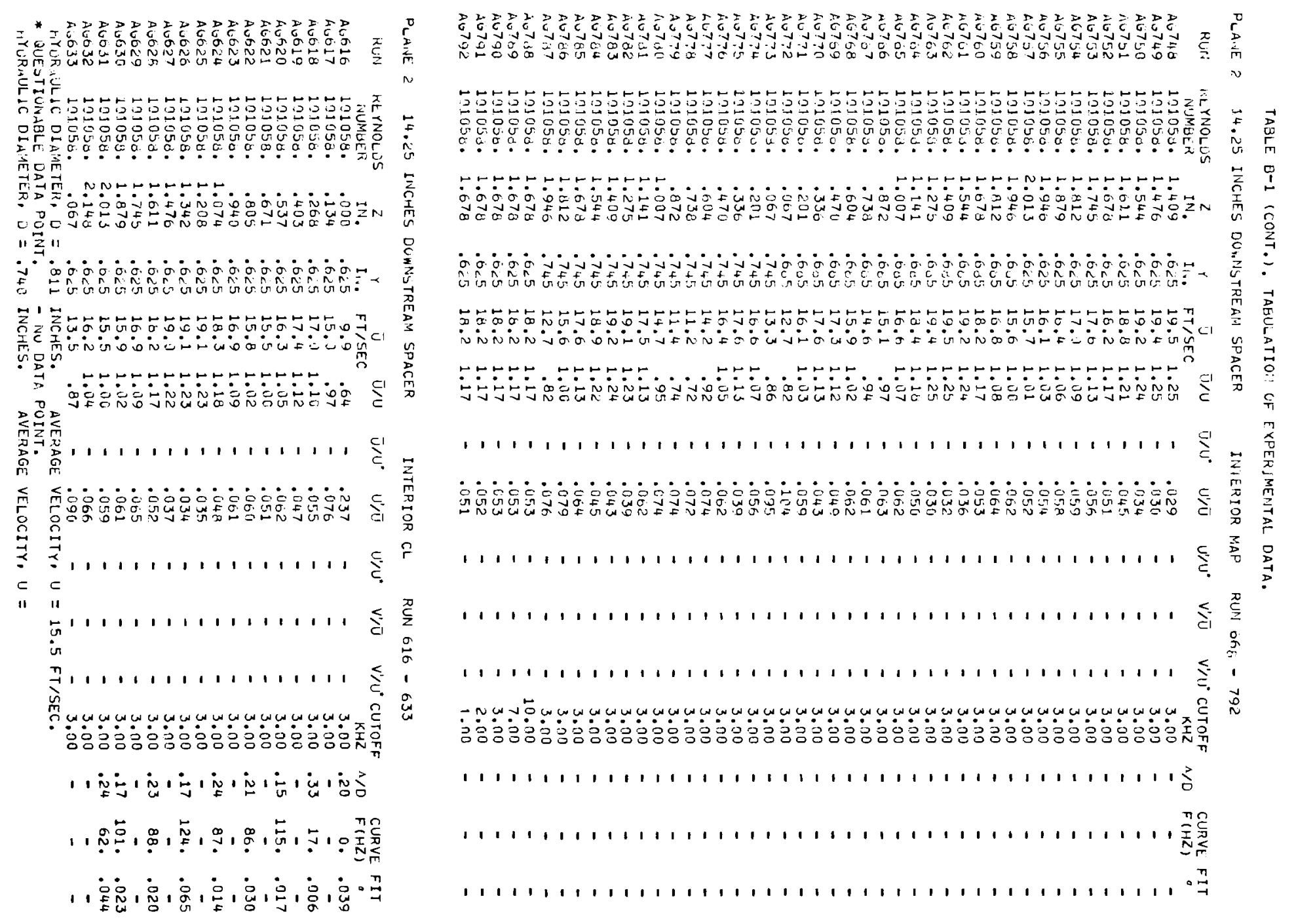
TABLE B-1 (CONT,). TABULATION OF EXPEK\&MENTAL DATA.

PLANE 214.25 INCHES DUMMSTREAM SPACER INTERIOR MAP RUN $668-792$

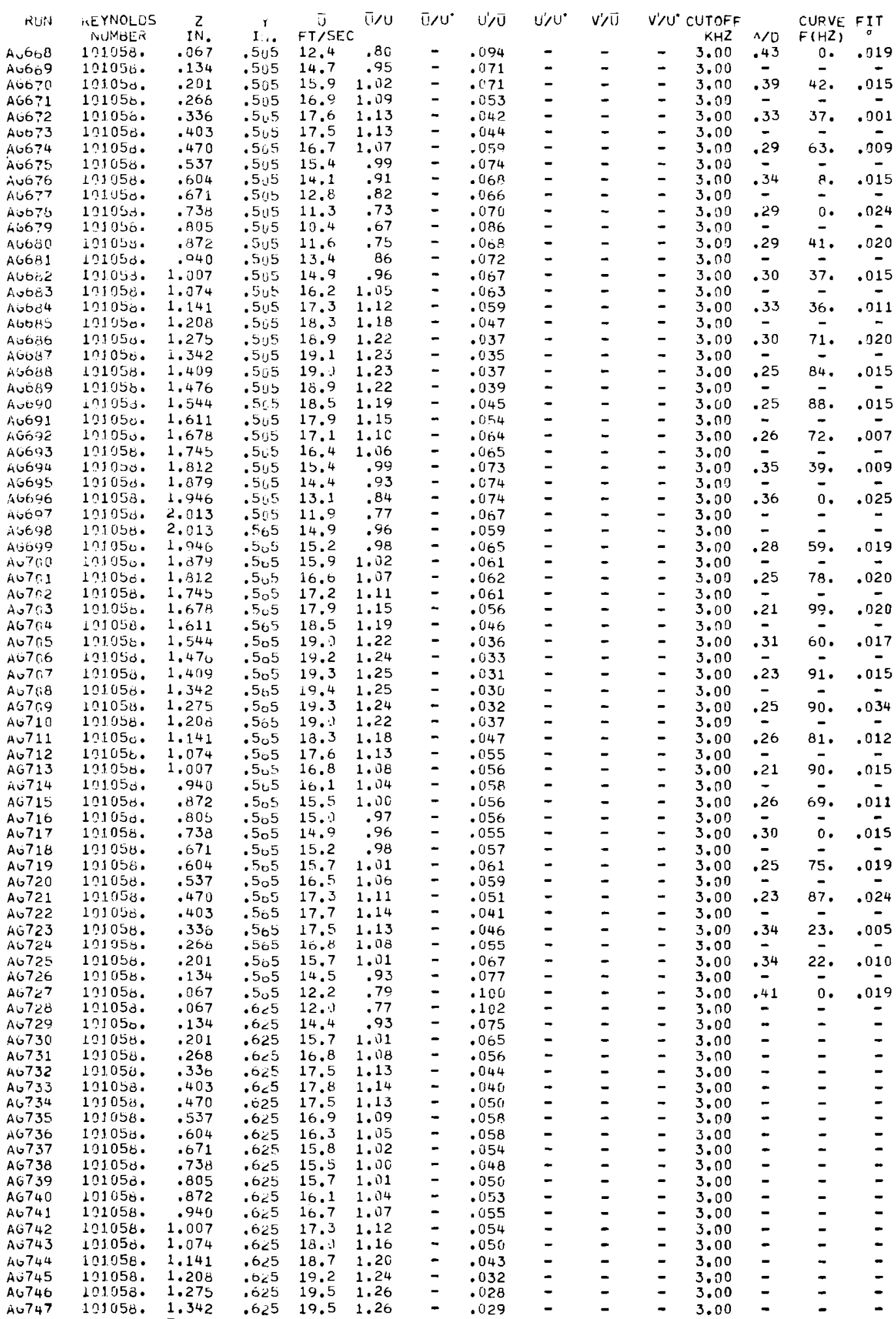

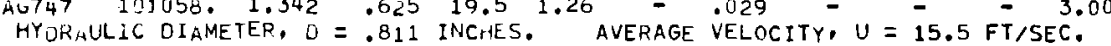

* quejtionable oata point. - nu oata point. 
BNWL -1757

TABLE B-1 (CONT.). TABULATION OF EXPER,MENTAL DATA.

\begin{tabular}{|c|c|c|c|c|c|c|c|c|c|c|c|c|c|}
\hline \multirow{2}{*}{$\begin{array}{l}\text { PLAIIE } \\
\text { RUN }\end{array}$} & \multirow{2}{*}{$\begin{array}{c}14.251 \\
\text { hEYNOLDS } \\
\text { NUMBER }\end{array}$} & INCHES & DOWins & a. 5 & $R$ & & $L$ MAP & & RUP & $825-942$ & & & \\
\hline & & $\underset{I N}{Z}$ & $I_{\text {in. }}^{\prime}$ & $\mathrm{FT} / \mathrm{SEC}$ & $\bar{y} / u$ & $\bar{u} / u^{*}$ & U'su & $U^{\prime} / U^{*}$ & v'ル̃ & $\begin{array}{c}V^{\prime} U^{*} \text { CUTOFF } \\
\text { KHZ }\end{array}$ & $\wedge / D$ & $\begin{array}{l}\text { CURVE } \\
F(H Z)\end{array}$ & FIT \\
\hline A.8325 & 102382 & 2.067 & 1.757 & 8.9 & .57 & - & .139 & - & 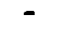 & $-\quad 3.00$ & - & - & . \\
\hline$A G 826$ & 122382 . & 2.067 & 1.757 & 9.1 & .58 & - & .118 & - & - & 3.00 & - & - & - \\
\hline$A 6827$ & 192382 & 1.463 & $1.7 b^{7}$ & 16.4 & 1.06 & - & .055 & - & - & 3.00 & - & - & - \\
\hline$A \cup 823$ & 102382 . & .993 & $1.7 \supset 7$ & 13.1 & .84 & - & .089 & - & - & 3.00 & - & - & - \\
\hline A 6829 & 102382 . & .792 & 1.757 & 5.6 & .36 & - & - 382 & - & - & 3.00 & - & - & - \\
\hline A0830 & 102382 . & .389 & 1.757 & 15.5 & 1.06 & - & .058 & - & - & 3.00 & - & - & - \\
\hline$A G O 31$ & 102382 . & .054 & 1.757 & 12.9 & .83 & - & .102 & - & - & 3.00 & - & - & - \\
\hline$A 6832$ & 102382 & .000 & 1.815 & 9.6 & .62 & - & . 197 & - & - & 3.00 & 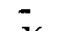 & - & $\overline{30}$ \\
\hline $\begin{array}{l}A 6833 \\
A 6834\end{array}$ & $\begin{array}{l}102382 . \\
102332 .\end{array}$ & $\begin{array}{l}.054 \\
.121\end{array}$ & $\begin{array}{l}1.815 \\
1.815\end{array}$ & $\begin{array}{l}12.8 \\
14.6\end{array}$ & $\begin{array}{r}.82 \\
.94\end{array}$ & $=$ & $\begin{array}{l}.095 \\
.073\end{array}$ & $\overline{-}$ & $\overline{-}$ & $\begin{array}{l}3.00 \\
3.00\end{array}$ & .36 & $\underline{0}$ & .030 \\
\hline$A G 835$ & 102382. & .188 & 1.815 & 15.4 & .99 & - & .057 & - & - & 3.00 & .24 & 0. & .020 \\
\hline$\wedge 6836$ & 102382 & .255 & 1.815 & 15.7 & 1.01 & - & .056 & - & - & 3.00 & - & - & - \\
\hline$A 0837$ & 102382 & .322 & 1.815 & 15.6 & 1.01 & - & .055 & - & - & 3.00 & .25 & 0. & .024 \\
\hline AG838 & 102382 & . 389 & 1.815 & 15.5 & 1.00 & - & .054 & - & - & 3.00 & $\overline{0}$ & $=$ & $\overline{-}$ \\
\hline A6839 & 102382. & .450 & 1.815 & 15.2 & .98 & - & .054 & - & - & 3.00 & .22 & 69. & .030 \\
\hline$A G 840$ & 122382 & .523 & 1.815 & 14.8 & .95 & - & .056 & - & - & 3.00 & - & - & - \\
\hline$A G 841$ & 102382 & .591 & 1.815 & 14.2 & .92 & - & .058 & - & - & 3.00 & .24 & 05. & .048 \\
\hline$A G 842$ & 132382 & .658 & 1.815 & 13.6 & .88 & $=$ & .064 & - & - & 3.00 & $\overline{5}$ & $\overline{0}$ & $\overline{2}$ \\
\hline$A \cup 843$ & 102382 . & .725 & 1.815 & 12.9 & .83 & - & .065 & - & - & 3.00 & .25 & 0. & .021 \\
\hline A 6844 & 132382. & .792 & 1.815 & 12.6 & .81 & - & .067 & - & - & 3.00 & - & - & $\therefore$ \\
\hline A. 845 & 102382 . & .859 & 1.815 & $13 .: 1$ & .84 & - & .067 & - & - & 3.00 & .34 & 36. & .013 \\
\hline A6846 & 102382 & .926 & 1.815 & 13.7 & .88 & - & .069 & - & - & 3.00 & - & - & - \\
\hline$A \leftarrow 847$ & 102382 . & .993 & 1.815 & 14.7 & .95 & - & .065 & - & - & 3.00 & .29 & 51. & .017 \\
\hline$A \cup 848$ & 102382 & 1.060 & 1.815 & 15.0 & 1.01 & - & .059 & - & - & 3.00 & - & - & - \\
\hline$A G 849$ & 102382 . & $1 \cdot 127$ & 1.815 & 16.4 & 1.06 & - & .051 & - & - & 3.00 & .25 & 76. & .028 \\
\hline$A \in 850$ & 102382. & 1.195 & 1.815 & $16 \cdot 9$ & 1.09 & - & .047 & - & - & 3.00 & - & $=$ & - \\
\hline AG85.: & $10238 \mathrm{co}$ & 1.262 & 1.815 & 17.9 & 1.10 & - & .046 & - & - & 3.00 & .25 & 33. & .015 \\
\hline A 852 & 102382 . & 1.329 & 1.815 & 16.8 & 1.08 & - & .051 & - & - & 3.00 & - & - & $=$ \\
\hline$A G 853$ & 102382 & 1.396 & 1.815 & 16.4 & 1.05 & - & .057 & - & - & 3.00 & .28 & 56. & .009 \\
\hline MG854 & 102382 . & 1.463 & 1.815 & 16.0 & 1.03 & - & .061 & - & - & 3.00 & $\bar{x}$ & $=$ & - \\
\hline$A G 855$ & 172382 . & 1.530 & 1.815 & 15.9 & 1.02 & - & .060 & - & - & 3.00 & .33 & 0. & .008 \\
\hline AG856 & 172382 . & 1.597 & $1 \cdot B 15$ & 16.0 & 1.03 & - & .057 & - & - & 3.00 & - & $\bar{x}$ & $\overline{0}$ \\
\hline$A G 8 j 7$ & 102382. & 1.664 & 1.815 & 16.1 & 1.04 & - & .052 & - & - & 3.00 & .23 & 63. & .020 \\
\hline A6858 & 122382. & 1.731 & 1.815 & 15.9 & 1.03 & - & .050 & - & - & 3.00 & - & $=$ & - \\
\hline Aن859 & 102382. & 1.799 & 1.815 & 15.3 & .99 & - & .056 & - & - & 3.00 & .25 & 69. & .031 \\
\hline$A \overline{5} 860$ & 102382 . & 1.866 & 1.815 & 14.5 & .93 & $\overline{-}$ & .062 & $\overline{-}$ & - & 3.00 & - & - & $\bar{s}$ \\
\hline$A=861$ & 102382 . & 1.933 & 1.815 & 13.7 & .88 & $\overline{-}$ & .068 & - & - & 3.00 & .27 & 26. & .016 \\
\hline$A \cup 862$ & 122382 . & 2.000 & 1.815 & $13 \cdot 1$ & .85 & - & .069 & - & - & 3.00 & - & - & $\bar{x}$ \\
\hline$A \cup 863$ & 102382. & 2.067 & 1.815 & 13.3 & .86 & - & .068 & - & - & 3.00 & .24 & 34. & .031 \\
\hline$A 6864$ & 102382. & 2.067 & 1.757 & 9.4 & .61 & $\bar{z}$ & .093 & $\overline{-}$ & - & 3.00 & - & $\overline{7}$ & $.0 \overline{08}$ \\
\hline Ais865 & 1.2382 & 2.000 & $\begin{array}{r}1.875 \\
1.875\end{array}$ & 14.1 & .91 & $\bar{z}$ & .054 & $\overline{-}$ & $\overline{-}$ & & $: 26$ & 27. & $\begin{array}{l}.008 \\
.034\end{array}$ \\
\hline $\begin{array}{l}A G 866 \\
A G 867\end{array}$ & $\begin{array}{l}102382 . \\
102382 .\end{array}$ & $\begin{array}{l}1.866 \\
1.731\end{array}$ & $\begin{array}{l}1.875 \\
1.875\end{array}$ & $\begin{array}{l}14.9 \\
15.4\end{array}$ & $\begin{array}{l}.96 \\
.99\end{array}$ & $\overline{-}$ & $\begin{array}{l}.057 \\
.058\end{array}$ & $\overline{-}$ & $=$ & $\begin{array}{l}3.00 \\
3.00\end{array}$ & $\begin{array}{l}.21 \\
.28\end{array}$ & $\begin{array}{l}83 . \\
45 .\end{array}$ & $\begin{array}{r}.034 \\
.012\end{array}$ \\
\hline 868 & 102382 . & 1.597 & 1.875 & 14.9 & .96 & - & .068 & - & - & 3.00 & .31 & 22. & .007 \\
\hline 869 & 192382 & 1.463 & 1.875 & 14.9 & .96 & - & .069 & - & - & 3.00 & .33 & 0. & .008 \\
\hline 870 & 102382 & 1.329 & 1.875 & 15.9 & 1.02 & - & .065 & - & - & 3.00 & .32 & 14. & .011 \\
\hline$A G 871$ & 122382 & 1.195 & 1.875 & 16.3 & 1.05 & - & .056 & - & - & 3.00 & .28 & 0. & .009 \\
\hline 872 & 102382 . & 1.060 & 1.875 & 15.7 & 1.01 & $\overline{-}$ & .078 & - & - & 3.00 & .23 & 80 . & .038 \\
\hline 873 & 102382 & .926 & 1.875 & 14.5 & .93 & - & .058 & - & - & 3.00 & .23 & 73. & .033 \\
\hline 874 & 102382 & .792 & 1.875 & 13.9 & .89 & - & .051 & - & - & 3.00 & .29 & 0. & .017 \\
\hline 875 & 102382 . & .658 & 1.875 & 14.1 & .91 & - & .053 & - & - & 3.00 & .26 & 60. & .027 \\
\hline 876 & 102382 & .523 & 75 & 14.5 & .93 & $=$ & .060 & $\overline{-}$ & $=$ & 3.00 & .28 & 20 . & $\begin{array}{r}.012 \\
.025\end{array}$ \\
\hline$A 68>7$ & 102382 & . 389 & 1.875 & 14.6 & .94 & - & .061 & - & - & 3.00 & .27 & 0. & .025 \\
\hline$A G 878$ & 102382 & .255 & 1.875 & 14.9 & .96 & - & .061 & - & - & 3.00 & .30 & 0 . & .012 \\
\hline$A 6879$ & 102382 & .121 & 1.875 & 14.3 & -9 & - & .066 & - & - & 3.00 & .32 & 0. & .0 \\
\hline AG880 & 122382 & .054 & 1.875 & 12.6 & .81 & - & .090 & - & - & 3.00 & .39 & 0. & .025 \\
\hline 381 & 132382 & .188 & 1.875 & 14.9 & .96 & - & .058 & - & - & 3.00 & - & - & $\overline{-}$ \\
\hline Á́882 & 1023 & .054 & 25 & 12.4 & .80 & - & .086 & - & - & 3.00 & - & - & $\overline{-}$ \\
\hline AGB 33 & 102382 . & - 121 & 1.925 & 13.9 & .90 & - & .065 & - & - & 3.00 & .31 & 0. & .032 \\
\hline$A G 884$ & 102382 . & .188 & 25 & 14.3 & .92 & - & .067 & - & - & 3.00 & - & - & - \\
\hline & 102382. & .255 & 1.925 & 13.9 & .90 & - & .073 & - & - & 3.00 & .35 & 0 . & .024 \\
\hline ט886 & 122382 . & .389 & $1.9<5$ & 13.5 & .87 & - & .072 & - & - & 3.00 & .37 & 0. & .03 \\
\hline$A G 887$ & 1023 & .523 & 25 & 13.6 & .87 & - & .070 & - & - & 3.00 & .32 & 0. & .019 \\
\hline$A G 8 B 8$ & 1023 & .658 & & 13.5 & .87 & - & .061 & - & - & 3.00 & .37 & 12 . & .016 \\
\hline$A \cup 809$ & 102382 . & .792 & & 13.7 & .88 & - & .053 & - & - & 3.00 & .23 & 0 . & .034 \\
\hline$A \in 890$ & 102382 . & .926 & $<5$ & 14.4 & .93 & - & .056 & $=$ & - & 3.00 & .28 & o. & .046 \\
\hline AG391 & 102382. & 1.060 & 25 & 15.2 & .98 & - & .061 & - & - & 3.00 & .30 & 52. & .01 \\
\hline$A G 892$ & 102382 . & 1.195 & & 15,4 & .99 & - & .071 & - & - & 3.00 & .37 & 0. & .01 \\
\hline & 102382 . & 1.329 & 25 & 15.1 & .97 & - & .071 & - & - & 3.00 & .35 & 0. & .015 \\
\hline$A G 894$ & 102382 . & 1,463 & 1.925 & 14.1 & .91 & $=$ & .078 & - & - & 3.00 & .34 & 0. & .01 \\
\hline AGB95 & 102382 . & 1.597 & & 14.1 & .91 & - & .074 & - & - & 3.00 & .36 & 0. & .017 \\
\hline AG896 & 102382 & 1.731 & 25 & 14.7 & .95 & - & .064 & - & - & 3.00 & .36 & 14. & .014 \\
\hline$A G 897$ & 102382 . & 1.866 & 1.925 & 14.5 & .94 & - & .059 & - & - & 3.00 & .31 & 38. & .01 \\
\hline$A G B 98$ & 102382 . & 2.000 & 1.925 & 14.1 & .91 & - & .053 & - & - & 3.00 & .28 & 0. & .019 \\
\hline A 8999 & 102382 & 2.000 & 1.965 & 13.1 & .84 & - & .056 & - & - & 3.00 & - & - & - \\
\hline$A G 9 \mathbb{G 0}$ & 102382 & 1.866 & 1.965 & 13.5 & .87 & - & .073 & - & - & 3.00 & - & - & - \\
\hline$A 6901$ & 102382 . & 1.731 & 1.905 & 13.5 & .87 & - & .078 & - & - & 3.00 & - & - & 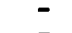 \\
\hline$A G 902$ & 102382 & 1.597 & 1.965 & 12.9 & .83 & - & .083 & - & - & 3.00 & - & - & - \\
\hline$A G 903$ & 102382. & 1.463 & 1.965 & 13.9 & .84 & - & .083 & - & - & 3.00 & - & - & - \\
\hline$A 6904$ & 102382 & 329 & & 14.0 & .90 & - & .078 & - & - & .00 & - & - & - \\
\hline
\end{tabular}

HYOR, ULIC DIAMETER, D $=.811$ INCHES. AVERAGE VELOCITY, U $=15.5 \mathrm{FT} / \mathrm{SEC}$.

* QUESTIONABLE DATA POINT: 
BNWL -1757

TABLE B-1 (CO:JT.). TABULATIO' OF EXPER,MENTAL DATA.

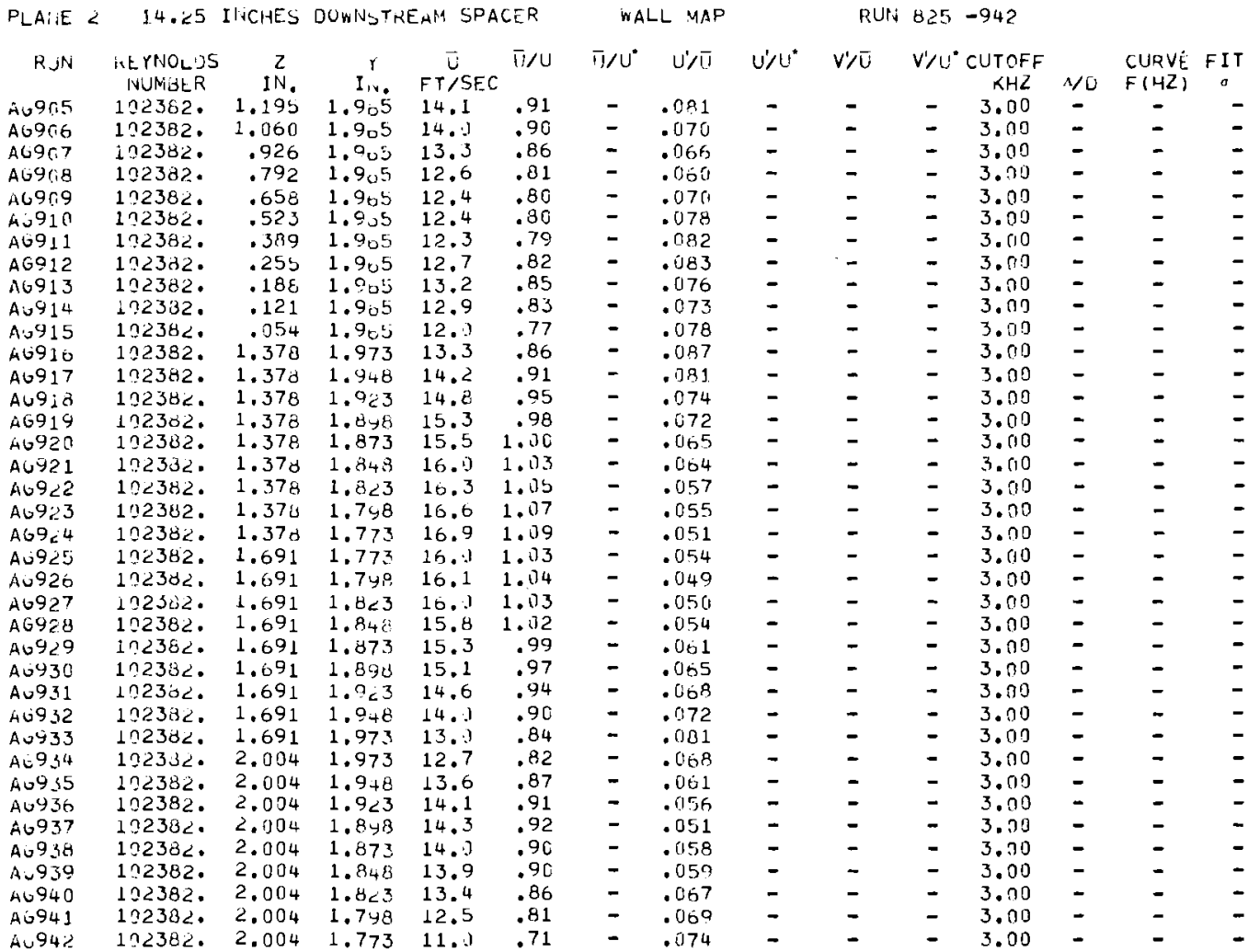

PLANE 214.25 INCHES DONNSTHEAM SPACER

WALL CL-.125 RUN 793 -824

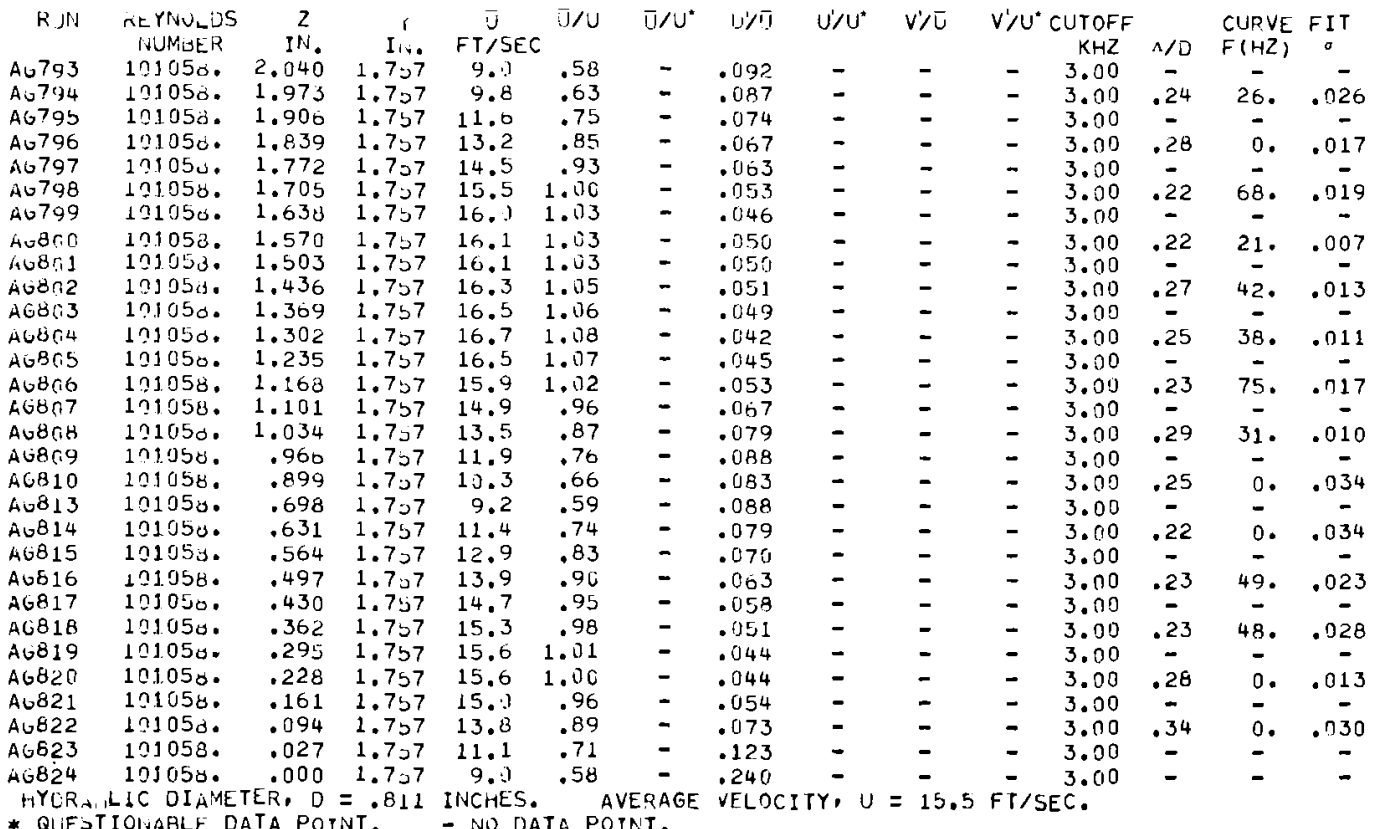




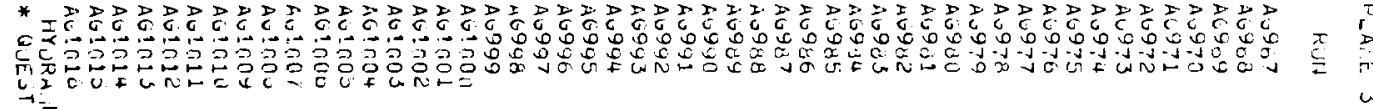

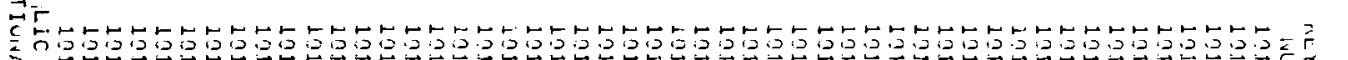

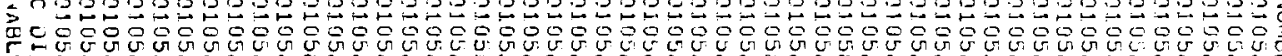
m $\rightarrow$

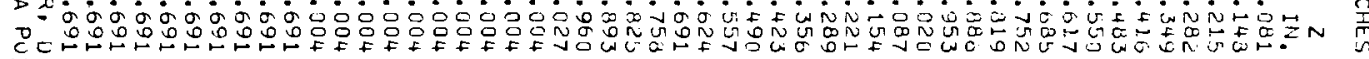
侄"

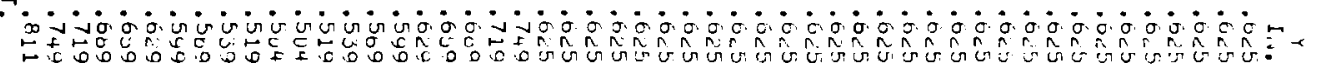

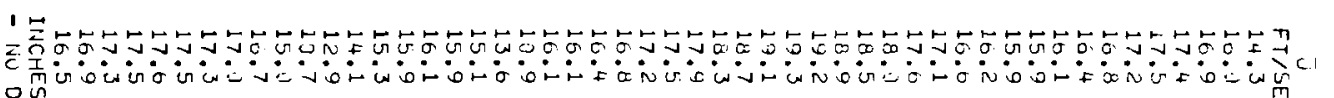
o ón $\stackrel{0}{\stackrel{0}{2}}$ 豙离,

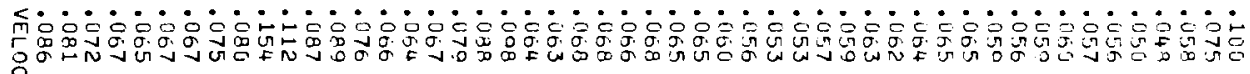

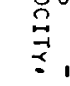

$c$

它

in

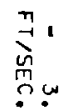

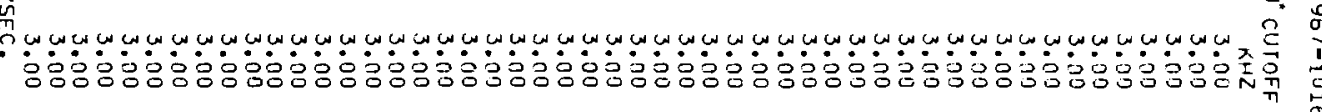

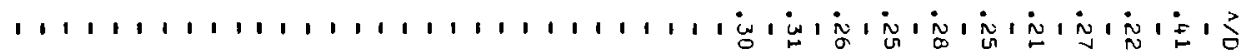

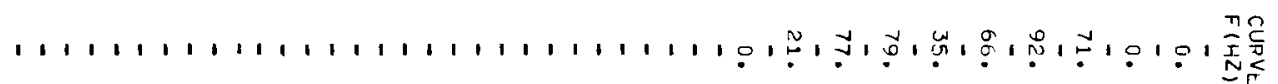

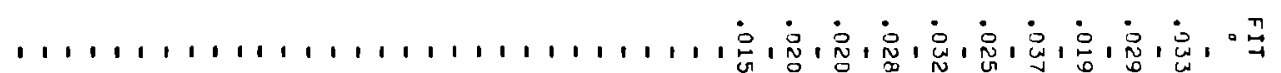

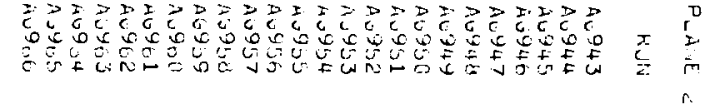

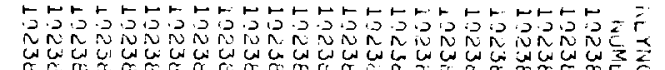

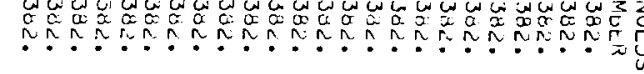
セR:

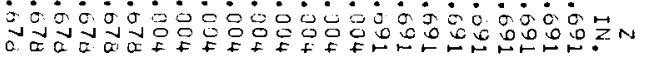
od a da

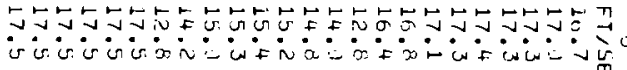

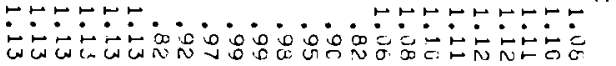

111111111111111111111

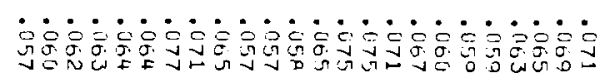

$1,1,1,1,1,1,1,1,1,1$

$1,1,1,1,111,11,1,1$

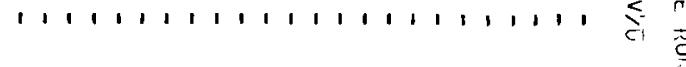
$1111111111111111111111 \sum_{E}^{E}$

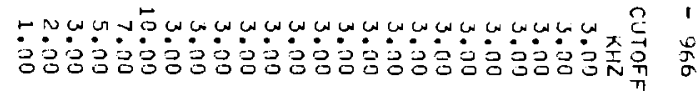
111111111111111111113

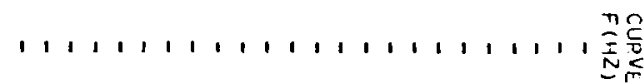

$1,1,11,1,1,1,1,11,1,1,1,0 \frac{\pi}{7}$ (n)

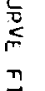


BNWL-1757

83

TABLE E-1 (CONT,). TADULATIOI: OF EXFER_MENTAL DATA.

PLANE 326.25 INCHES DOWHSTREAM SPACER INTERIOR MAP RUN 1050 - 1129

\begin{tabular}{|c|c|c|c|c|c|c|c|c|c|c|c|c|c|}
\hline Kun & $\begin{array}{l}\text { KE YNOLLS } \\
\text { IVUMEER }\end{array}$ & $\stackrel{2}{2}$ & $\stackrel{i}{I_{1+1}}$ & $\begin{array}{c}\bar{U} \\
F T / S E C\end{array}$ & $\bar{u} / U$ & $\bar{u} / u^{*}$ & U'y & $u^{\prime} / u^{*}$ & $v^{\prime} / \bar{u}$ & $\begin{array}{c}\text { V'U' CUTOFF } \\
K H Z\end{array}$ & $\wedge / D$ & $\begin{array}{l}\text { CURVE } \\
F(H Z)\end{array}$ & $\underset{\sigma}{\mathrm{IIT}}$ \\
\hline$A_{0} 105.1$ & 101050. & 2.040 & $.6 \angle 5$ & 16.4 & 1.06 & - & .058 & - & - & 3.00 & - & - & - \\
\hline$A 6 ! 051$ & 101058. & 1.900 & $.62 b$ & 16.6 & 1.07 & - & .058 & - & - & 3.00 & - & - & - \\
\hline$A \cup 1056$ & 121058. & $1.63 d$ & $.0<b$ & 18.2 & 1.17 & - & .060 & - & - & 3.00 & - & - & - \\
\hline$A G: 1150$ & 101058. & 1.369 & $.6 c^{5}$ & 19.5 & 1.26 & - & .0149 & - & - & 3.00 & - & - & - \\
\hline Au? 054 & 101058. & 1.101 & $.6<5$ & 18.3 & 1.18 & - & .057 & - & - & 3.00 & - & - & - \\
\hline Aט!n & 101050. & .832 & $.0 \div<5$ & 16.5 & 1.06 & - & .057 & - & - & 3.00 & - & - & - \\
\hline Au! 150 & 103050. & .564 & $.6 \div 5$ & 16.6 & 1.07 & - & .053 & - & - & 3.00 & - & - & - \\
\hline$A G 1057$ & 191050. & .295 & $.0<5$ & 17.9 & 1.15 & - & .036 & - & - & 3.00 & - & - & - \\
\hline Ao! & 131050. & .161 & .625 & 16.0 & 1.07 & - & .006 & - & - & 3.00 & - & - & - \\
\hline$A G^{1}: 05^{-3}$ & 101056. & .027 & $.6<5$ & $12 . .1$ & .77 & - & .148 & - & - & 3.00 & - & - & - \\
\hline $40 ! 0,601$ & 121050. & .094 & $.6<b$ & 15.1 & .97 & - & .093 & - & - & 3.00 & - & - & - \\
\hline$A G ! 66 \perp$ & 101058. & .094 & .505 & 15.2 & .98 & - & .089 & - & - & 3.00 & - & - & - \\
\hline HG! nó & 131050. & .161 & .505 & 10.6 & 1.07 & - & .063 & - & - & 3.00 & .37 & 0 . & .027 \\
\hline AG!nó & 101058. & $.29 b$ & . 5,5 & 17.8 & 1.14 & - & $.03 A$ & - & - & 3.00 & .29 & 0. & .017 \\
\hline AO! 0.64 & 101050. & .430 & .505 & 17.1 & 1.10 & - & .055 & - & - & 3.00 & .27 & 63. & .025 \\
\hline AG! & 131050. & .564 & .505 & 16.1 & 1.03 & - & .063 & - & - & 3.00 & .28 & 58. & .018 \\
\hline Aulnos & $12105 \%$. & .698 & .505 & 15.5 & 1.00 & - & .059 & - & - & 3.00 & .27 & 0 . & .021 \\
\hline $40 ! 00 ?$ & 103058. & .832 & .505 & 15.8 & 1.01 & - & .066 & - & - & 3.00 & .29 & 0 . & .020 \\
\hline Aot 160 & 101058. & .906 & .505 & 17.1 & 1.09 & - & .059 & - & - & 3.00 & .30 & 62 . & .020 \\
\hline AO!OOX & $1 ? 1050$ & 1.101 & .505 & 17.9 & 1.15 & - & .065 & - & - & 3.00 & .28 & 63. & .015 \\
\hline Au? 0.70 & 101050. & 1.235 & $.5,5$ & 19.1 & 1.22 & - & .050 & - & - & $3 . n 0$ & .34 & 20. & .007 \\
\hline Au! 071 & 101058. & 1.369 & .505 & 19.4 & 1.25 & - & .051 & - & - & 3.00 & .31 & 52. & .018 \\
\hline$A 0 ! n>c$ & 101050. & 1.503 & .505 & 18.8 & 1.21 & - & .060 & - & - & 3.00 & .29 & 58. & .020 \\
\hline $\begin{array}{l}A \cup 900 \\
A G ! 97\end{array}$ & $\begin{array}{l}193050 . \\
191050 .\end{array}$ & $\begin{array}{l}1.038 \\
1.772\end{array}$ & $\begin{array}{l}.505 \\
.505\end{array}$ & $\begin{array}{l}18.1 \\
17.3\end{array}$ & $\begin{array}{l}1.16 \\
1.12\end{array}$ & $\bar{z}$ & $\begin{array}{l}.064 \\
.065\end{array}$ & - & - & $\begin{array}{l}3.00 \\
3.00\end{array}$ & $\begin{array}{r}.28 \\
.27\end{array}$ & $\begin{array}{l}75 . \\
74 .\end{array}$ & $\begin{array}{l}.018 \\
.021\end{array}$ \\
\hline AG:07 & 101050. & 1.900 & .505 & 16.1 & 1.04 & - & .070 & - & - & 3.00 & .30 & 37. & .008 \\
\hline$A \cup 1070$ & 121050. & 2,040 & .505 & 15.7 & 1.01 & - & .071 & - & - & 3.00 & .31 & 0. & .020 \\
\hline Au! 107 & 193058. & 2.040 & .505 & 12.1 & .78 & - & .088 & - & - & 3.00 & .22 & 0. & .026 \\
\hline$A 0 ! 0,70$ & 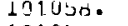 & 1.300 & .505 & 13.8 & .89 & - & .095 & - & - & 3.00 & .29 & 0. & .025 \\
\hline$A O ! 07$ & 101058. & 1.772 & .505 & 16.4 & 1.06 & - & .080 & - & - & 3.00 & .33 & 22. & .018 \\
\hline Aotrid:l & $19105 \mathrm{E}$ & 1.638 & .545 & 17.3 & 1.11 & - & .078 & - & - & 3.00 & .32 & 47. & .008 \\
\hline Au!n81 & 101050. & 1.503 & .505 & 18.4 & 1.18 & - & .056 & - & - & 3.00 & .30 & 47. & .012 \\
\hline$A G ! 082$ & 103050. & 1.369 & .505 & 19.1 & 1.23 & - & .056 & - & - & 3.00 & .28 & 79. & .022 \\
\hline AO! nids & 101050. & 1.235 & .565 & 18.5 & 1.19 & - & .064 & - & - & 3.00 & .34 & 29. & .006 \\
\hline$A G: 0,84$ & 101050. & 1.101 & $.5 \cup 5$ & 17.1 & 1.10 & - & .079 & - & - & 3.00 & .31 & 21 . & .008 \\
\hline$A G !(B)=$ & $12105 \sigma$. & .960 & .505 & 15.1 & .97 & - & .106 & - & - & 3.00 & .31 & 0. & .018 \\
\hline$A G ! 0.80$ & 101058. & .832 & $.5 \cup 5$ & 11.2 & .72 & - & .110 & - & - & 3.00 & - & - & - \\
\hline Ao? $0.8 \%$ & 101058. & .698 & $.5 \vartheta 5$ & 11.4 & .73 & - & .092 & - & - & 3.00 & - & - & - \\
\hline Ao:1,80 & 101058. & .564 & .5 ป5 & 14.3 & .92 & - & .087 & - & - & 3.00 & .30 & 0 . & .026 \\
\hline AG!OH: & 101050. & .430 & .505 & 16.3 & 1.05 & 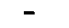 & .069 & - & - & 3.00 & - & - & - \\
\hline$A 0 ? 694$ & 12.1058. & .295 & .505 & 17 & 1.14 & - & .041 & - & - & 3.00 & .29 & 0. & .020 \\
\hline Au! 91 & 101058. & .161 & $.5 \cup 5$ & 16.9 & 1.09 & - & .057 & - & - & 3.00 & - & - & - \\
\hline$A G ! 092$ & 101058. & .094 & .505 & 15.5 & 1.00 & - & .086 & - & - & 3.00 & - & - & - \\
\hline AOQ 1090 & 191050. & .094 & .605 & 15.5 & 1.00 & - & .086 & - & - & 3.00 & - & - & - \\
\hline A 010.94 & 101058. & .161 & .005 & 16.7 & 1.08 & - & .064 & - & - & 3.00 & - & - & - \\
\hline$A 61690$ & 101050. & .295 & .605 & 17.8 & 1.14 & - & .040 & - & - & 3.00 & - & - & - \\
\hline$A G ? 090$ & 121058. & .430 & .605 & 17.2 & 1.11 & - & .055 & - & - & 3.00 & - & - & - \\
\hline AS? 097 & 101058. & .564 & .605 & 16.2 & 1.04 & - & .064 & - & - & 3.00 & - & - & - \\
\hline$A 6 ! 090$ & 101050. & .698 & $.6 \ddot{5}$ & 15.2 & .98 & - & .072 & - & - & 3.00 & - & - & - \\
\hline 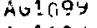 & 101050. & .832 & .605 & 15.6 & 1.00 & - & .075 & - & - & 3.00 & - & - & - \\
\hline$A \cup ? 10 \mathrm{U}$ & 101053. & .966 & .685 & 17.1 & 1.10 & - & .065 & - & - & 3.00 & - & - & - \\
\hline$A G=101$ & 101058. & 1.201 & .665 & 18.1 & 1.17 & - & .006 & - & - & 3.00 & - & - & - \\
\hline$A_{0} ! 102$ & 101058. & 1.235 & .605 & 19.1 & 1.23 & - & .055 & - & - & 3.00 & - & - & - \\
\hline$A G \div 103$ & 101058. & 1.369 & .605 & 19.5 & 1.26 & - & .049 & - & - & 3.00 & - & - & - \\
\hline$A G: 104$ & 101058. & 1.369 & .745 & 19.3 & 1.24 & - & .054 & - & - & 3.00 & - & - & - \\
\hline$A G 1100$ & 101050. & 1.235 & .745 & 18.7 & 1.20 & - & .066 & - & - & 3.00 & - & - & - \\
\hline$A O=100$ & 121058. & 1.201 & .745 & 17.3 & 1.11 & - & .082 & - & - & 3.00 & - & - & - \\
\hline$A G: 107$ & 101058. & .966 & .745 & 15.2 & .98 & - & .097 & - & - & 3.00 & - & - & - \\
\hline Aט?100 & 121050. & .832 & .745 & 11.6 & .75 & - & .127 & - & - & 3.00 & - & - & - \\
\hline Aט!109 & 101058. & .698 & .745 & 11.7 & .75 & - & .095 & - & - & 3.00 & - & - & - \\
\hline$A 0 ! 110$ & 101050. & .564 & .745 & 14.4 & .93 & - & .090 & - & - & 3.00 & - & - & - \\
\hline AG 1111 & 101.056. & .430 & .745 & 16.3 & 1.05 & 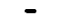 & .072 & - & - & 3.00 & - & - & - \\
\hline $46 ! 116$ & 121058. & .295 & .745 & 17.5 & 1.13 & - & .049 & - & - & 3.00 & - & - & - \\
\hline$A=1113$ & 101050. & .161 & .745 & 16.9 & 1.09 & - & .059 & - & - & 3.00 & - & - & - \\
\hline$A G: 11^{4}$ & 101058. & .094 & .745 & 15.6 & 1.00 & - & .082 & - & - & 3.00 & - & - & - \\
\hline$A G 1115$ & 101058. & 2.004 & .746 & 10.9 & .70 & 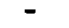 & .104 & - & - & 3.00 & - & - & - \\
\hline AU!110 & 101050. & 2.004 & .716 & 13.7 & .88 & - & .093 & - & - & 3.00 & - & - & - \\
\hline$A G ! 117$ & 121058. & 2.004 & .686 & 15.4 & . 99 & 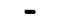 & .073 & . & - & 3.00 & - & - & - \\
\hline$A G 111 d$ & 101050. & 2.004 & .656 & 16.1 & 1.04 & - & .065 & - & - & 3.00 & - & - & - \\
\hline$A 6 ! 119$ & 131050. & $2.00_{4}$ & .626 & 16.4 & 1.06 & - & .056 & - & - & 3.00 & - & - & - \\
\hline$A \cup 1.120$ & 101050. & 2.004 & .596 & 16.2 & 1.05 & - & .058 & 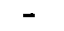 & - & 3.00 & - & - & - \\
\hline$A G ! 12 i$ & 101056 . & 2.004 & .506 & 15.7 & 1.01 & - & .071 & - & - & 3.00 & - & - & - \\
\hline$A G ! 12 C$ & 101050. & 2.004 & .536 & 14.6 & .94 & - & .082 & - & - & 3.00 & - & - & - \\
\hline$A \cup 1123$ & 10.1050. & 2.004 & .506 & 12.3 & .79 & - & .091 & - & - & 3.00 & - & - & - \\
\hline$A G 112+$ & 101058. & 2.004 & .626 & 16.4 & 1.06 & . & .058 & - & - & 10.00 & - & - & - \\
\hline $40 \pm 125$ & 101050. & 2.004 & .626 & 16.4 & 1.06 & - & .058 & - & - & 7.00 & - & - & - \\
\hline$A G 1120$ & 101058. & 2.004 & .626 & 16.4 & 1.06 & - & .057 & - & - & 4.00 & - & - & - \\
\hline$A G \div 127$ & 121056. & 2.004 & .626 & 16.4 & 1.06 & - & .055 & - & - & 2.00 & - & - & - \\
\hline$A G ! 120$ & $10105 \%$. & 2.004 & .626 & 16.4 & 1.06 & 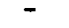 & .053 & - & - & 1.00 & - & - & - \\
\hline 401129 & 101058. & 2.004 & $.6<6$ & 16.4 & 1.06 & & .049 & - & - & .50 & - & - & - \\
\hline
\end{tabular}

HYURA,JLIC DIAMETEK, D $=.811$ INCHES. AVERAGE VELOCITY, U $=\overline{15.5 \mathrm{FT} / \mathrm{SEC} .}$

* guestiunable liata point. - No data point. 


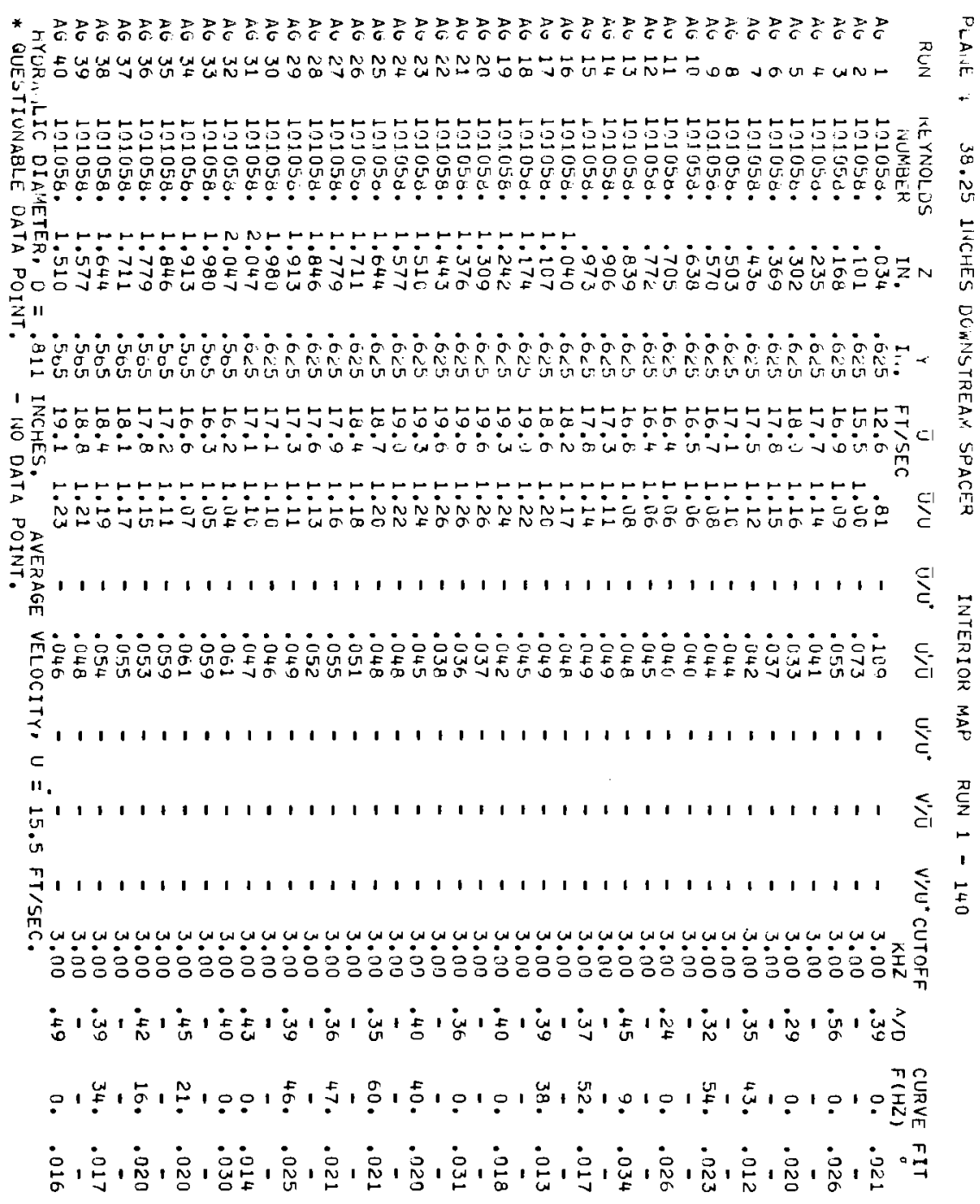

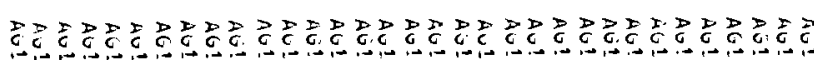

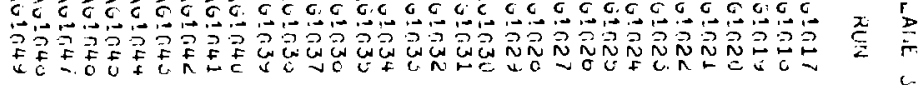

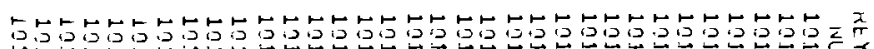

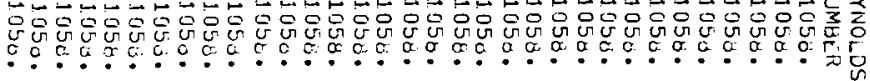

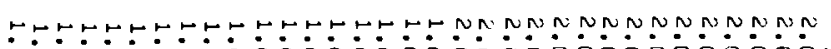

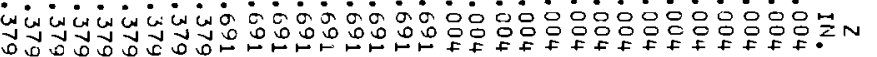

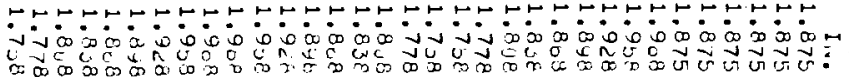

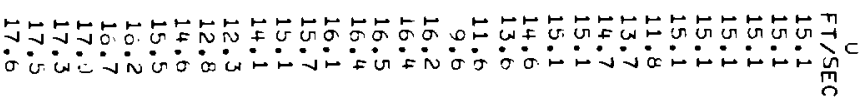

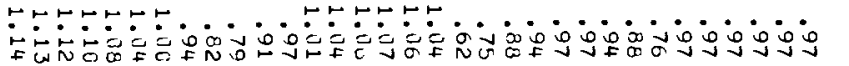
$1,1,1,1,1,1,1,1,1,1,1,1$,

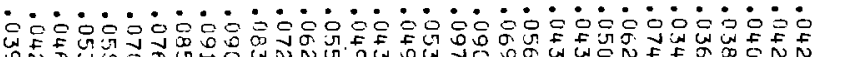

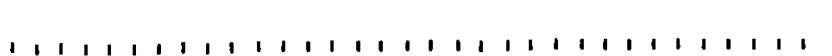

$1,1,1,1,1,1,1,1,1,1,1,1,1$

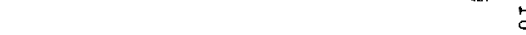
$1111111111111111111 \leq$

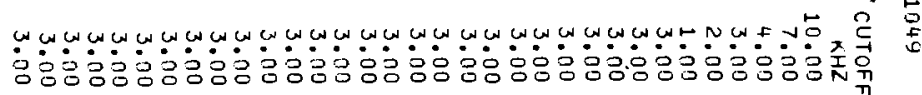

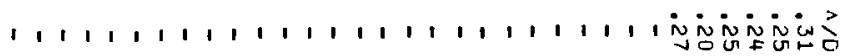

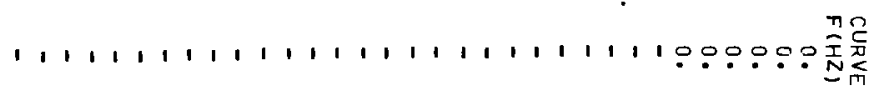

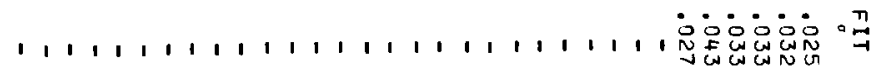


BNWL - 1757

TABLE B-1 (CONT,). TABLLATIO:) OF EXPERINENTAL DATA.

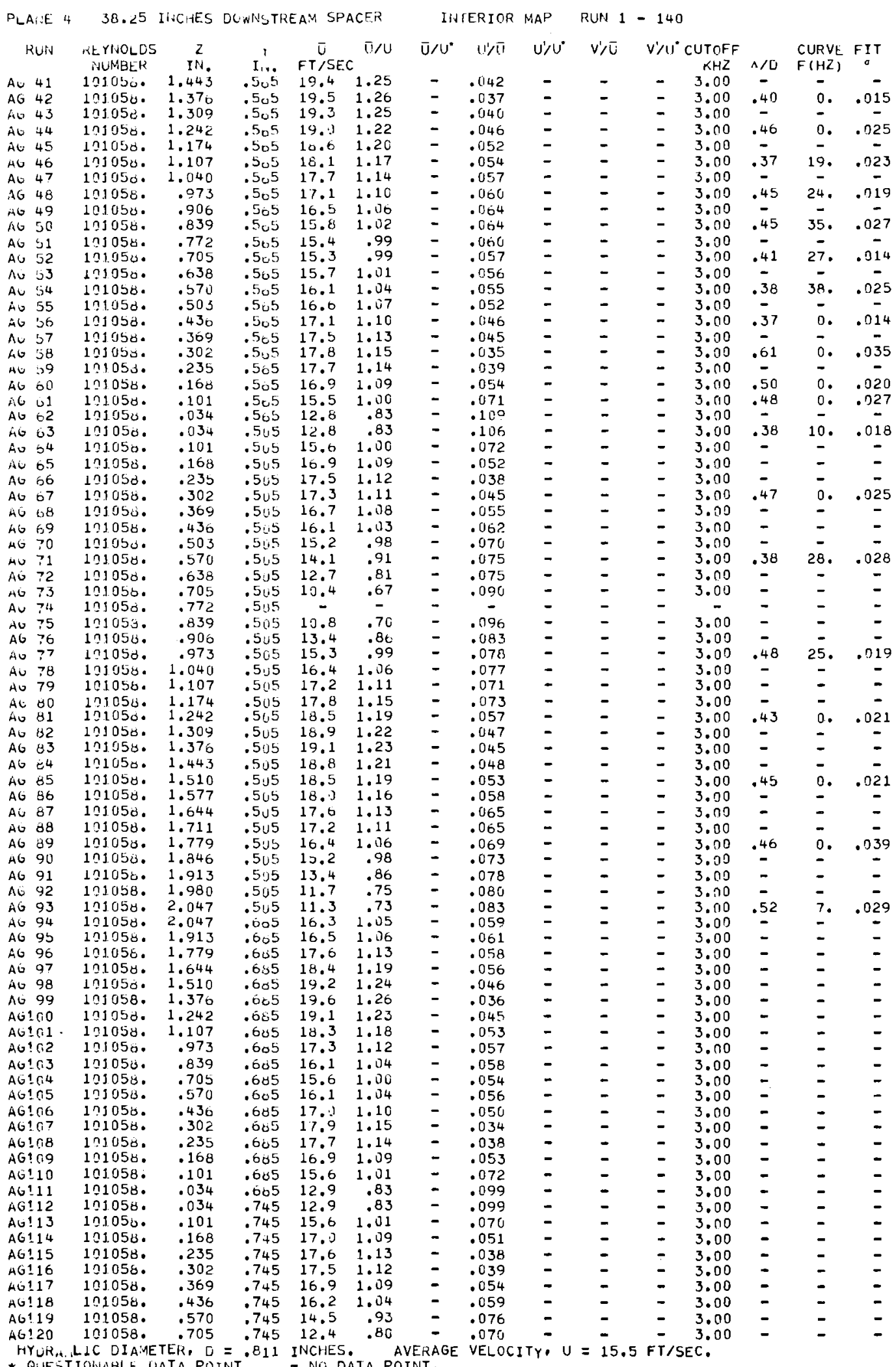




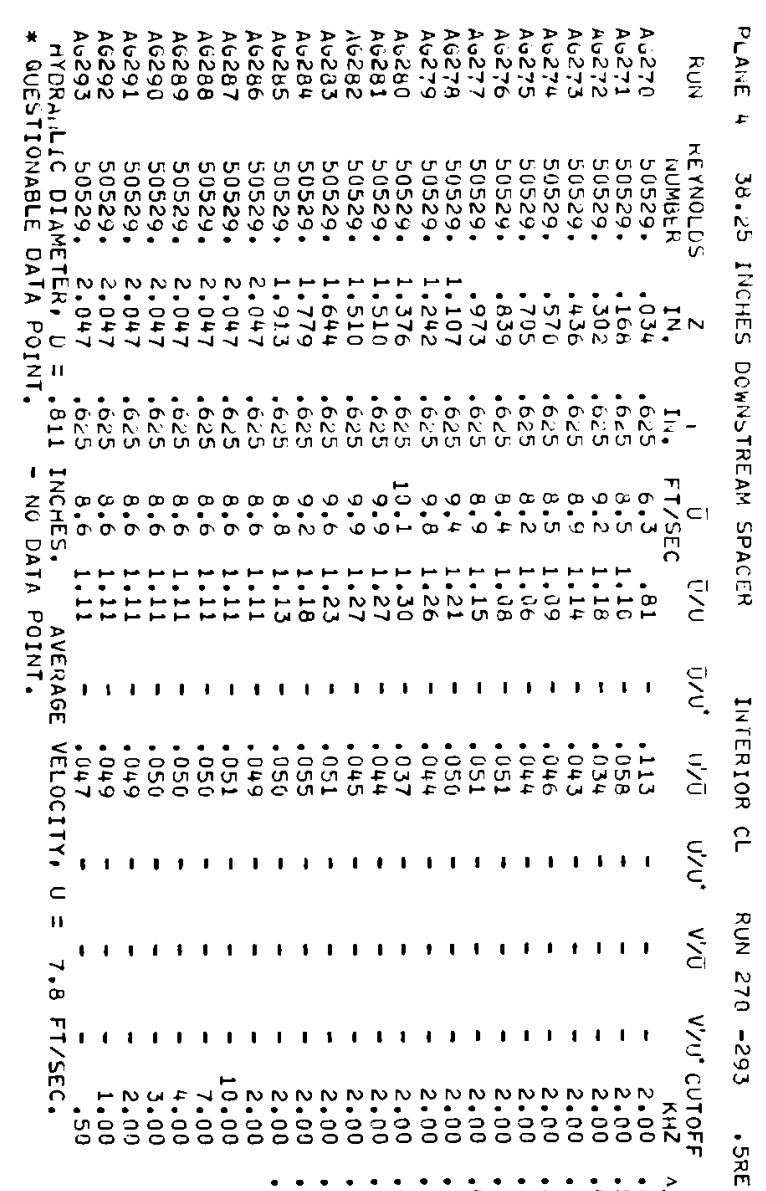

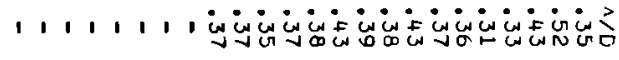

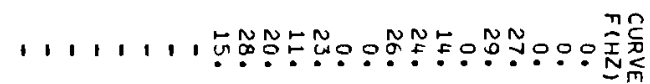

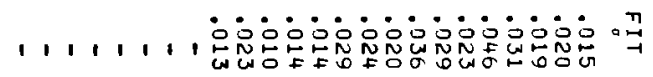

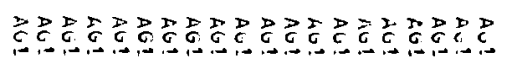

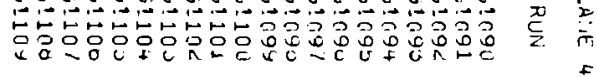

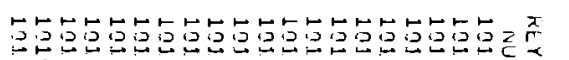

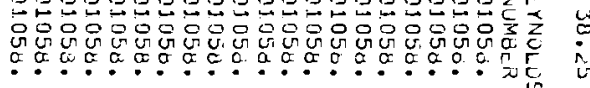

ondon

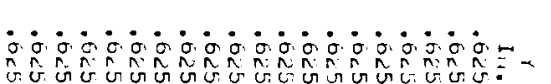

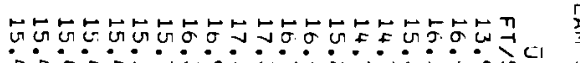

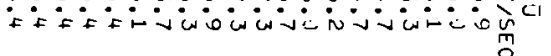

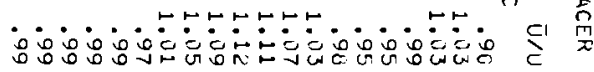
$1,1,1,1,1,1,1,1$

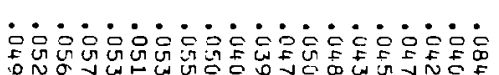

$1,1,1,1,1,1,1$

$, 1,1,1,1,1,1,1$,

$1,1,1,1,1,1,1$

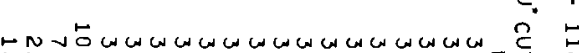

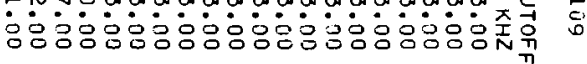

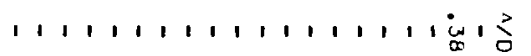

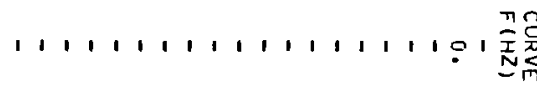
$\ldots \ldots, \ldots \ldots \ldots, 1,1, \dot{N}^{\circ}{ }^{\circ}$

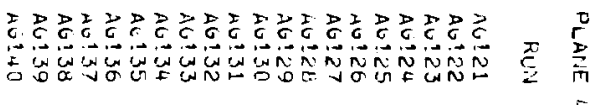

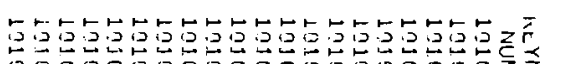

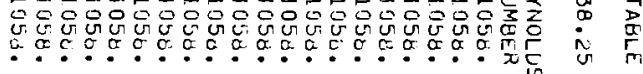

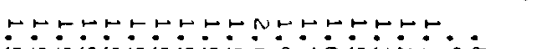

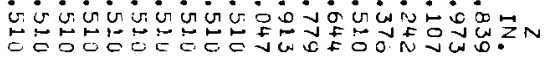

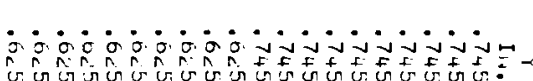

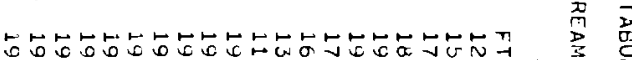

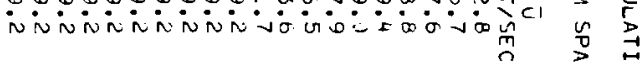

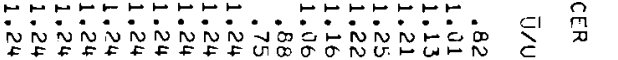

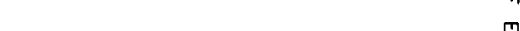

111, 1 1 1 1 1 1 1

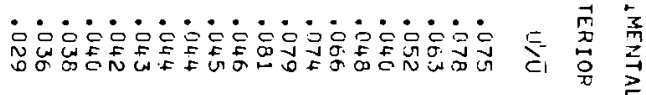

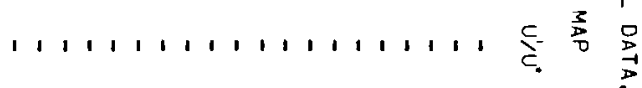

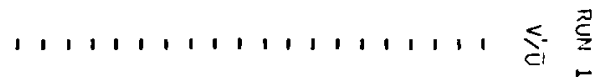

1 1 1 1 1 1 1 1 1

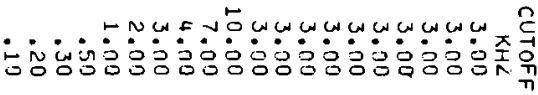

1 $\ldots 1, \ldots \ldots$

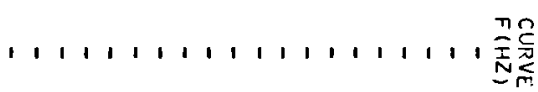

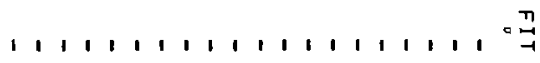


TABLE B-1 (COINT.). TABULATION OF EXPERIMENTAL DATA.

\begin{tabular}{|c|c|c|c|c|c|c|c|c|c|c|c|c|c|}
\hline PLA.VE & 38.25 & INCHES & DOWNSTR & AM SP & CER & WAL & $L$ MAP & & RUN & -269 & & & \\
\hline RuN & $\begin{array}{l}\text { REYNOLOS } \\
\text { NUMBER }\end{array}$ & IN & $I_{\text {ive }}^{Y}$ & $\begin{array}{c}\vec{U} \\
F T / S E C\end{array}$ & $\overline{\mathrm{u}} / \mathrm{U}$ & $\overline{\mathrm{U}} / \mathrm{u}^{*}$ & U'রu & u'/U* & $v^{\prime} / \bar{U}$ & $\begin{array}{c}V^{\prime} / U^{*} \text { CUTOFF } \\
K H Z\end{array}$ & $A / D$ & $\begin{array}{l}\text { CURVE } \\
F(H Z)\end{array}$ & FIT \\
\hline$A G ! 41$ & 101050. & .027 & $1.7 \supset 5$ & 9.9 & .64 & - & .142 & - & - & 3.00 & - & - & - \\
\hline$A G 142$ & 101058 . & .094 & 1.755 & 13.3 & .86 & - & .079 & - & - & 3.00 & - & - & - \\
\hline$A G ! 43$ & 121.050. & .161 & 1.755 & 15.1 & .97 & - & .056 & - & - & 3.00 & - & - & - \\
\hline$A G 144$ & 101050. & .228 & 1.755 & 16.1 & 1.03 & - & .037 & - & - & 3.00 & - & - & - \\
\hline Au1 45 & $10105 d$. & .295 & 1.755 & 16.1 & 1.04 & - & .036 & - & - & 3.00 & - & - & - \\
\hline$A G 146$ & $10105 d$. & .362 & 1.755 & 15.8 & 1.02 & - & .043 & - & - & 3.00 & - & - & - \\
\hline$A \cup: 47$ & 101058. & .430 & 1.755 & 15.1 & .97 & - & .051 & - & - & 3.00 & - & - & - \\
\hline$A \cup 148$ & 101058. & .497 & $1.7 \supset 5$ & 14.4 & .93 & - & .057 & - & - & 3.00 & - & - & - \\
\hline Au! 49 & 131050. & .564 & $1.7 \sqcup 5$ & 13.4 & .86 & $\bar{z}$ & .065 & $\overline{-}$ & $\bar{z}$ & 3.00 & $\bar{z}$ & $\overline{-}$ & $=$ \\
\hline$A G ! 51$ & 171058. & .098 & $1.7>5$ & 10.3 & .66 & - & .084 & - & - & 3.00 & 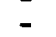 & - & - \\
\hline$A G 152$ & $10105 d$. & .765 & 1.755 & 8.2 & .53 & - & .109 & - & - & 3.00 & - & - & - \\
\hline$A G ! 53$ & 101.058. & .832 & 1.755 & 9.6 & .62 & - & .084 & - & - & 3.00 & - & - & - \\
\hline$A \cup 154$ & 101058 . & .899 & $1.7>5$ & 11.5 & .74 & - & .070 & - & - & 3.00 & - & - & - \\
\hline Au1-b5 & 101053. & .966 & 1.705 & 13.2 & .85 & - & .068 & - & - & 3.00 & - & - & - \\
\hline$A \cup 156$ & 101058. & 1.034 & 1.705 & 14.6 & .94 & - & .066 & - & - & 3.00 & - & - & - \\
\hline$A G ! 57$ & 131058. & 1.101 & 1.705 & 15.6 & 1.01 & - & .059 & - & - & 3.00 & - & - & - \\
\hline$A G ! 38$ & 101058. & 1.168 & 1.755 & 16.4 & 1.06 & - & .054 & - & - & 3.00 & - & - & - \\
\hline AG159 & 101056. & 1.235 & 1.705 & 17.1 & 1.10 & - & .045 & - & - & 3.00 & - & - & - \\
\hline Au? 00 & 101058. & 1.302 & 1.7.5 & 17.7 & 1.14 & - & .037 & - & - & 3.00 & - & - & - \\
\hline$A \cup ! 61$ & 101056. & 1.369 & $1.7 \mathrm{J5}$ & 17.9 & 1.16 & - & .035 & - & - & 3.00 & - & - & - \\
\hline$A \cup ! 62$ & 101050. & 1.436 & 1.75 .5 & 18.3 & 1.16 & - & .035 & - & - & 3.00 & - & - & - \\
\hline$A G 163$ & 12.1050. & 1.503 & 1.755 & 17.9 & 1.15 & - & .037 & - & - & 3.00 & - & - & - \\
\hline$A G ! 64$ & $10905 \mathrm{~d}$ & 1.570 & 1.705 & 17.6 & 1.13 & - & .040 & - & - & 3.00 & - & - & - \\
\hline$A \cup 105$ & $10.105 d$. & 1.638 & 1.7 .55 & 17.1 & 1.10 & - & .045 & - & - & 3.00 & - & - & - \\
\hline AO?66 & 101058. & 1.705 & 1.755 & 16.4 & 1.06 & - & .052 & - & - & 3.00 & - & - & - \\
\hline$A G \div 07$ & 101050. & 1.772 & 1.755 & 15.5 & 1.00 & - & .059 & - & - & 3.00 & - & - & - \\
\hline Aט?68 & 101050. & 1.839 & 1.755 & 14.1 & .91 & - & .068 & - & - & 3.00 & - & - & - \\
\hline$A G ? 69$ & 101053. & 1.906 & 1.755 & 12.6 & .81 & - & .069 & - & - & 3.00 & - & - & - \\
\hline$A \cup ! ? 0$ & 201050. & 1.973 & 1.755 & 11.1 & .71 & - & .073 & - & - & 3.00 & - & - & - \\
\hline$A G 1 ? 1$ & 103050. & 2.040 & 1.755 & 10.4 & .67 & - & .073 & - & - & 3.00 & - & - & - \\
\hline$A G 1 ? 2$ & 121058. & 2.040 & 1.815 & 14.5 & .93 & - & .052 & $=$ & - & 3.00 & .30 & 50. & .045 \\
\hline$A G 173$ & 121050. & 1.973 & 1.815 & 14.7 & .94 & - & .054 & - & - & 3.00 & - & - & - \\
\hline$A G ? ? 4$ & 101058. & 1.906 & 1.815 & 15.1 & .97 & - & .055 & - & - & 3.00 & .39 & 0. & .025 \\
\hline$A=175$ & $10105 d$. & 1.839 & 1.815 & 15.8 & 1.01 & - & .049 & - & ـ & 3.00 & - & - & - \\
\hline A०!?6 & 101058 & 1.772 & 1.815 & 16.4 & 1.06 & - & .045 & - & - & 3.00 & .43 & 0 . & .034 \\
\hline$A G 177$ & 101058. & 1.705 & 1.815 & 16.8 & 1.08 & - & .042 & - & - & 3.00 & - & - & - \\
\hline$A G 178$ & 101058. & 1.638 & 1.815 & 17.1 & 1.10 & - & .043 & - & - & 3.00 & .46 & 0. & .020 \\
\hline$A \in 179$ & 101058. & 1.570 & 1.815 & 17.3 & 1.11 & - & .047 & - & - & 3.00 & - & - & - \\
\hline$A C 180$ & 101058. & 1.503 & 1.815 & 17.5 & 1.12 & - & .046 & - & - & 3.00 & .56 & 0 . & .043 \\
\hline$A G 181$ & 101058 . & 1.436 & 1.815 & 17.6 & 1.13 & - & .045 & - & 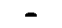 & 3.00 & - & - & - \\
\hline$A G ! 82$ & 101058. & 1.369 & 1.815 & 17.7 & 1.14 & - & .040 & - & - & 3.00 & .48 & 0. & .038 \\
\hline$A G ! 83$ & 101058. & 1.302 & 1.815 & 17.6 & 1.14 & - & .038 & - & - & 3.00 & - & - & - \\
\hline$A B 134$ & 101050. & 1.235 & 1.815 & 17.3 & 1.12 & - & .038 & - & - & 3.00 & .41 & 0. & .036 \\
\hline AG185 & 101058. & 1.268 & 1.815 & 16.9 & 1.09 & - & .042 & - & - & 3.00 & - & - & - \\
\hline$A \cup 186$ & 101.058. & 1.101 & 1.815 & 16.4 & 1.06 & - & .045 & - & - & 3.00 & .43 & 0. & .034 \\
\hline$A \cup ! B 7$ & $101.05 \mathrm{~d}$. & 1.034 & 1.815 & 15.8 & 1.02 & - & .048 & - & - & 3.00 & - & - & - \\
\hline$A \cup ! 88$ & 101058 . & .966 & 1.815 & 15.1 & .97 & - & .052 & - & - & 3.00 & .43 & 0 . & .033 \\
\hline$A G ! 89$ & 101058. & .899 & 1.815 & 14.4 & .93 & - & .052 & - & - & 3.00 & - & - & - \\
\hline$A G \div 90$ & 101050. & .832 & 1.815 & 13.9 & .90 & - & .052 & - & - & 3.00 & .34 & 44. & .027 \\
\hline 40191 & 101.058. & .765 & 1.815 & 13.7 & .88 & - & .052 & - & - & 3.00 & - & - & - \\
\hline$A G ! 92$ & 101050. & .698 & 1.815 & 13.9 & .90 & - & .050 & - & - & 3.00 & .25 & 0. & .036 \\
\hline$A \cup 193$ & 101053 & .631 & 1.815 & 14.4 & .93 & - & .048 & - & - & 3.00 & - & - & - \\
\hline$A \cup 194$ & 101053 . & .564 & 1.815 & 14.9 & .96 & - & .044 & - & 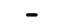 & 3.00 & .27 & 0. & .034 \\
\hline AG!95 & 101058. & .497 & 1.815 & 15.3 & .99 & - & .040 & - & 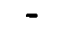 & 3.00 & - & - & - \\
\hline$A G ! 96$ & 101050. & .430 & 1.815 & 15.6 & 1.01 & - & .039 & - & - & 3.00 & .30 & 0. & .036 \\
\hline$A G 197$ & 101058. & .362 & 1.815 & 15.9 & 1.02 & - & .040 & - & - & 3.00 & - & - & - \\
\hline$A G 198$ & 101058 . & .295 & 1.815 & 16.1 & 1.04 & - & .037 & - & 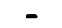 & 3.00 & .47 & 0. & .040 \\
\hline A $\square ! 99$ & in1.058. & .228 & 1.815 & 16.1 & 1.04 & - & .035 & - & - & 3.00 & - & - & - \\
\hline$A \cup 260$ & 101058 . & .161 & 1.815 & 15.3 & .99 & - & .050 & - & - & 3.00 & .40 & 0. & .040 \\
\hline$A \cup 2 \backsim 1$ & 101058. & .094 & 1.815 & 13.5 & .87 & - & .169 & - & - & 3.00 & - & - & - \\
\hline$A G 2 G 2$ & 101058. & .027 & 1.815 & 10.1 & .64 & - & .135 & - & - & 3.00 & .21 & 0. & .030 \\
\hline$A \cup 203$ & $10105 d$. & .027 & 1.875 & 10.0 & .64 & - & .130 & - & - & 3.00 & - & - & - \\
\hline$A \cup 2,4$ & 101058. & .094 & 1.875 & 13.7 & .88 & - & .071 & - & - & 3.00 & - & - & - \\
\hline$A \cup 2 G 5$ & 101058. & .161 & 1.875 & 15.2 & .98 & - & .049 & - & - & 3.00 & - & - & - \\
\hline$A G 26,6$ & $10105 d$. & .295 & 1.875 & 15.4 & .99 & - & .053 & - & - & 3.00 & - & - & - \\
\hline$A G 207$ & 101058. & .430 & 1.875 & 15.2 & .98 & - & .050 & - & 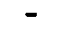 & 3.00 & - & - & - \\
\hline$A G 208$ & 101058. & .564 & 1.875 & 15.9 & .97 & - & .041 & - & - & 3.00 & - & - & - \\
\hline$A G 269$ & 101.058. & .698 & 1.875 & 14.8 & .95 & - & .037 & - & . & 3.00 & - & - & - \\
\hline$A G 210$ & 101058 . & .832 & 1.875 & 14.8 & .95 & - & .037 & - & . & 3.00 & - & - & - \\
\hline$A G 211$ & 101058. & .966 & 1.875 & 15.4 & .99 & - & .044 & - & - & 3.00 & - & - & - \\
\hline$A \cup 212$ & 101058. & 1.101 & 1.875 & 16.1 & 1.04 & - & .049 & - & . & 3.00 & - & - & - \\
\hline$A G 213$ & 101058. & 1.235 & 1.875 & 16.7 & 1.08 & - & .048 & - & 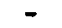 & 3.00 & - & - & - \\
\hline$A G 214$ & 101058. & 1.369 & 1.875 & 16.8 & 1.08 & - & .057 & - & - & 3.00 & - & - & - \\
\hline$A G 215$ & 101058. & 1.503 & 1.875 & 16.5 & 1.07 & - & .061 & - & - & 3.00 & .67 & 0. & .043 \\
\hline$A G 216$ & 101058. & 1.638 & 1.875 & 16.3 & 1.05 & 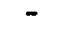 & .060 & - & 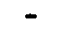 & 3.00 & - & - & - \\
\hline$A G 217$ & 101058. & 1.772 & 1.875 & 16.2 & 1.05 & 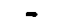 & .047 & - & & 3.00 & - & - & - \\
\hline$A 6218$ & 121058. & 1.906 & 1.875 & 15.7 & 1.01 & - & .043 & - & - & 3.00 & - & - & - \\
\hline$A G 219$ & 101058. & 2.040 & 1.875 & 15.3 & .98 & - & .036 & - & - & 3.00 & - & - & - \\
\hline$A G 220$ & 101050. & 2.040 & $1.9<5$ & & 94 & & .050 & - & 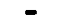 & 3.00 & - & - & 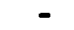 \\
\hline
\end{tabular}

HYDR
OULIC DIAMETER, D $=.811$ INCHES. PVIONABLE DATA POINT.
- NO DATA POINT. 


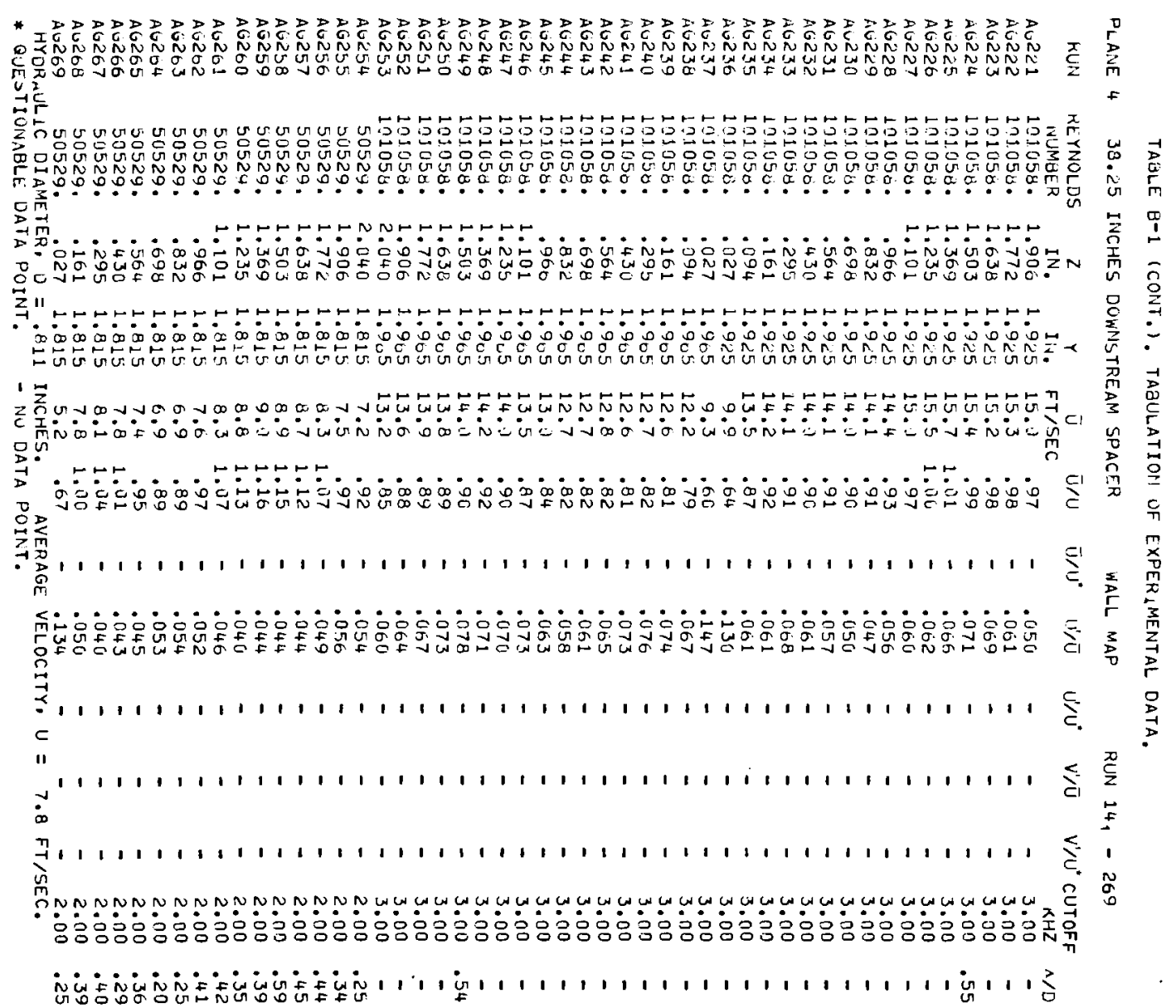

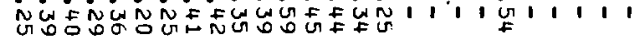

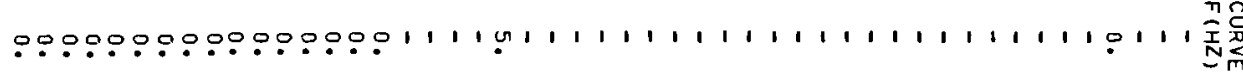

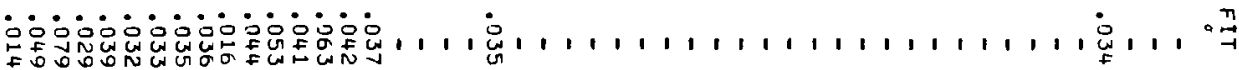


BNWL-1757

TABLE B-1 (CONT,). TAESILATIOII OF EXPER IMENTAL DATA.

PLA,NE 51.25 INCHES DUNINSTREAM SPACER 2 INTERIOR MAP RUN 11,0 - 1169

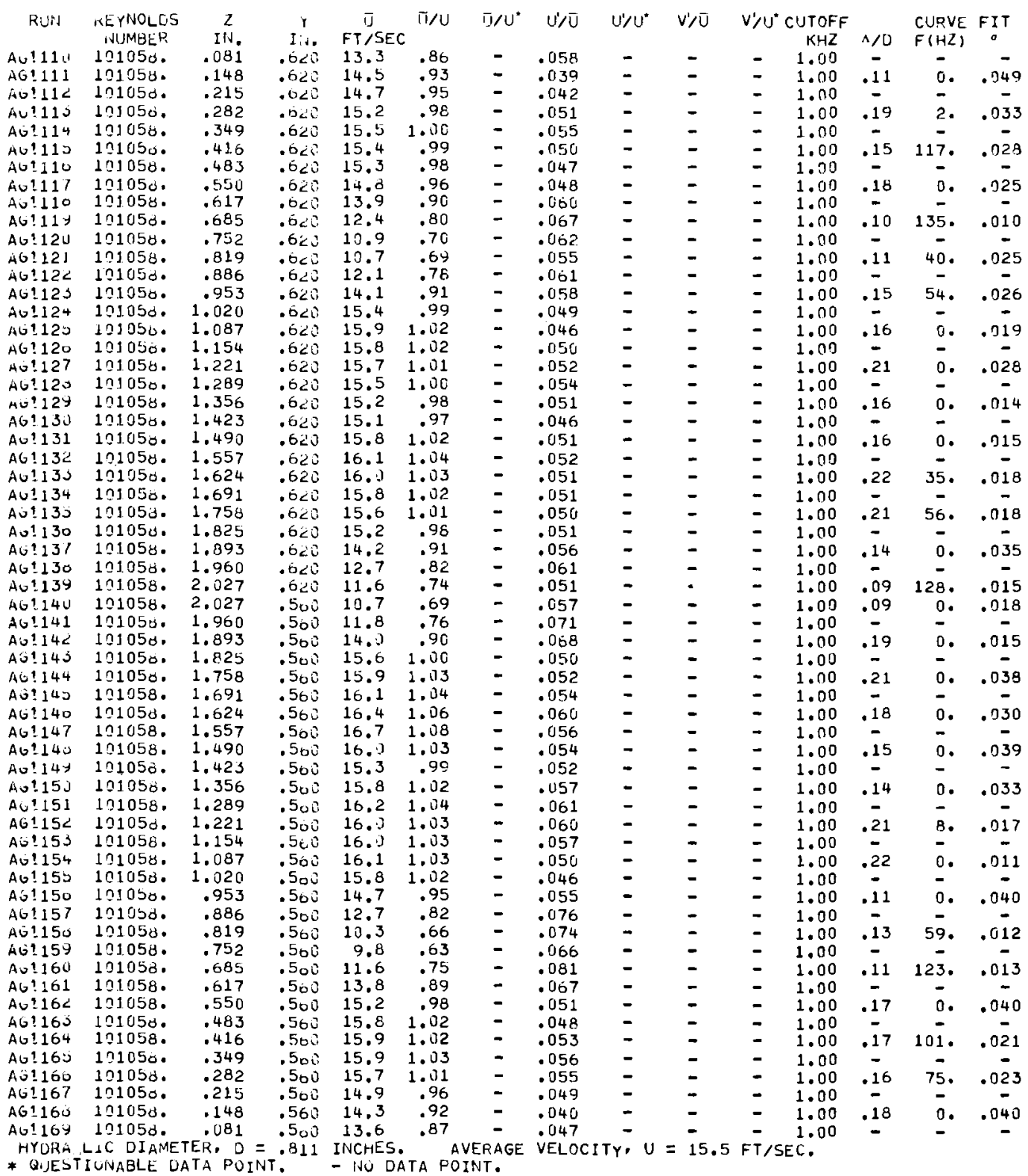




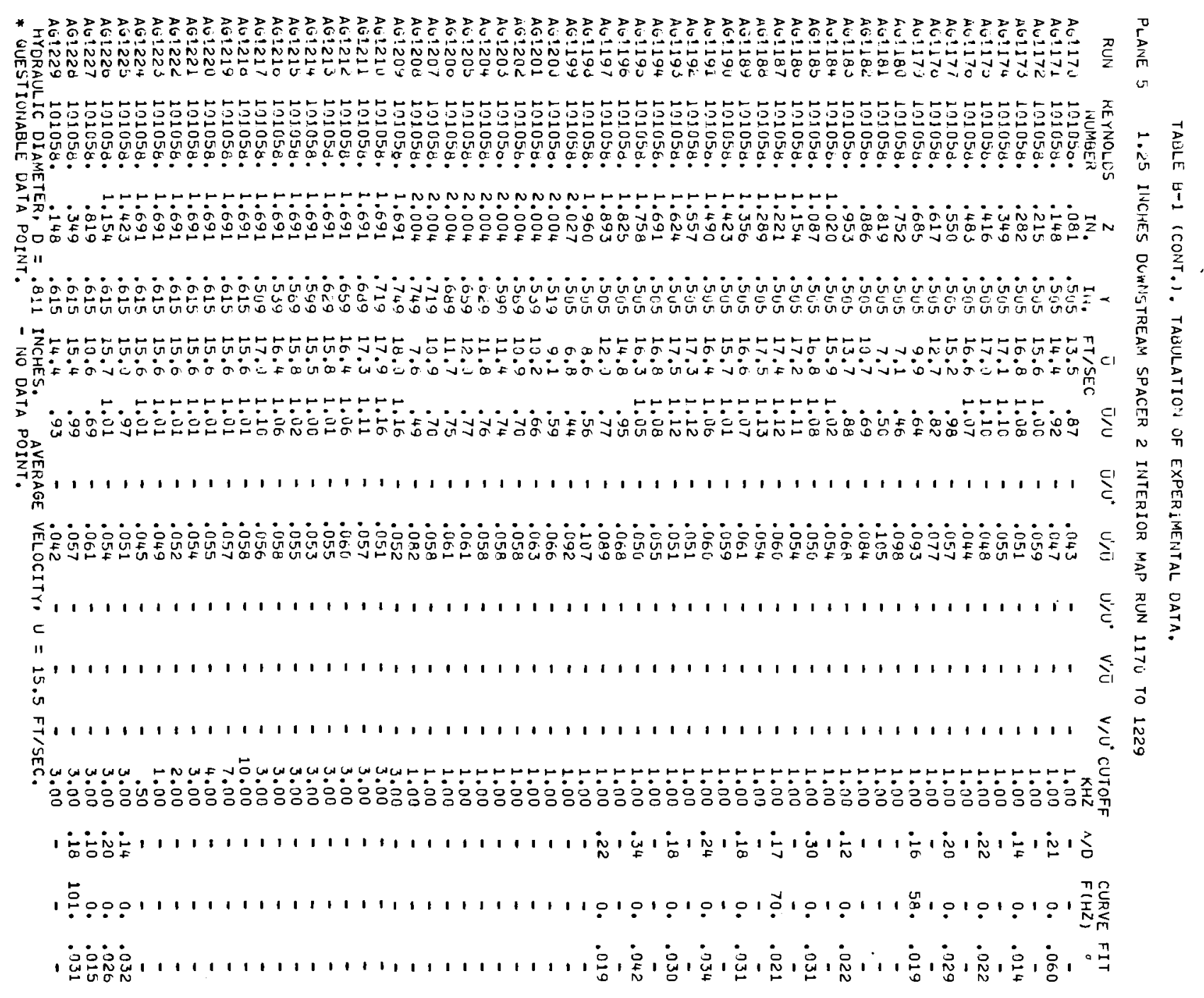


AEC Advisory Committee for Reactor Safeguards Washington, D. C.

M. C. Gaskr

AEC Cinicago Patent Office, Washington, D. C.
A. A. Churm

AEC Directorate of Licensing, Washington, [. C.
E. G. Case (3)
V. Ste110
T. Novak
D. Ross
G. Hi. Laujen

AEC Directorate of Reactor Standarús, Uashington, D. C.

AEC Office of Assistant General Counsel for Patents Washington, D. C.

R. A. Anderson

AEC Technical Information Center

AEC Division of Reactor Development and Technology Washington, D. C.

Assistant Director, Reactor Technology

C'nief, Special Technology Branch

Cnief, Reactor Pinsics Brancil

Assistant Director, Reactor Engineering

Chief, Core Design Brancin

Cnief, Fuel Engineering Branch

Assistant Director, Nuclear Safety

Cinief, Fast Reactor Safety Branch

Chief, Thermal Reactor Safety Branch

Chief, Analys is and Evaluation Brancil

Assistant Director, Plant Engineering

Assistant Director, Program Analys is 
iNo. of

Copies Offsite

Chief, Water Projects Branch

Chief, LMFBR Projects Branch

E. Davidson

F. Goldner

R. Impara

T. Speis

R. H. Scroggins (2)

Argonne National Laboratory

H. Fauske

R. P. Stein

Atomic Energy Commission

Brussels office

U. S. Mission to the European Cormunities

APO, New York, N. Y. 09667

$1 \quad$ Atomic Energy of Canada, Limited

Chalk River, Ontario, Canada

G. A. Wikinammer

5

Atomics International

P. 0. Box 591, Canoga Park, California 91305 Louis Bermath

Donald T. Eggan

David C. Fulton

H. Morowitz

W. B. Wolfe

Babcock and Wilcox Company

P. 0. Box 1260

Lynchburg, Virgiria 24502

R. E. Willard

C. Morgan

2 Babcock and wilcox

AlTiance Research Center

1562 Beeson Strees.

Alliance, Ohio 44601

J. S. Gellerstadt

G. D. Linds trom 


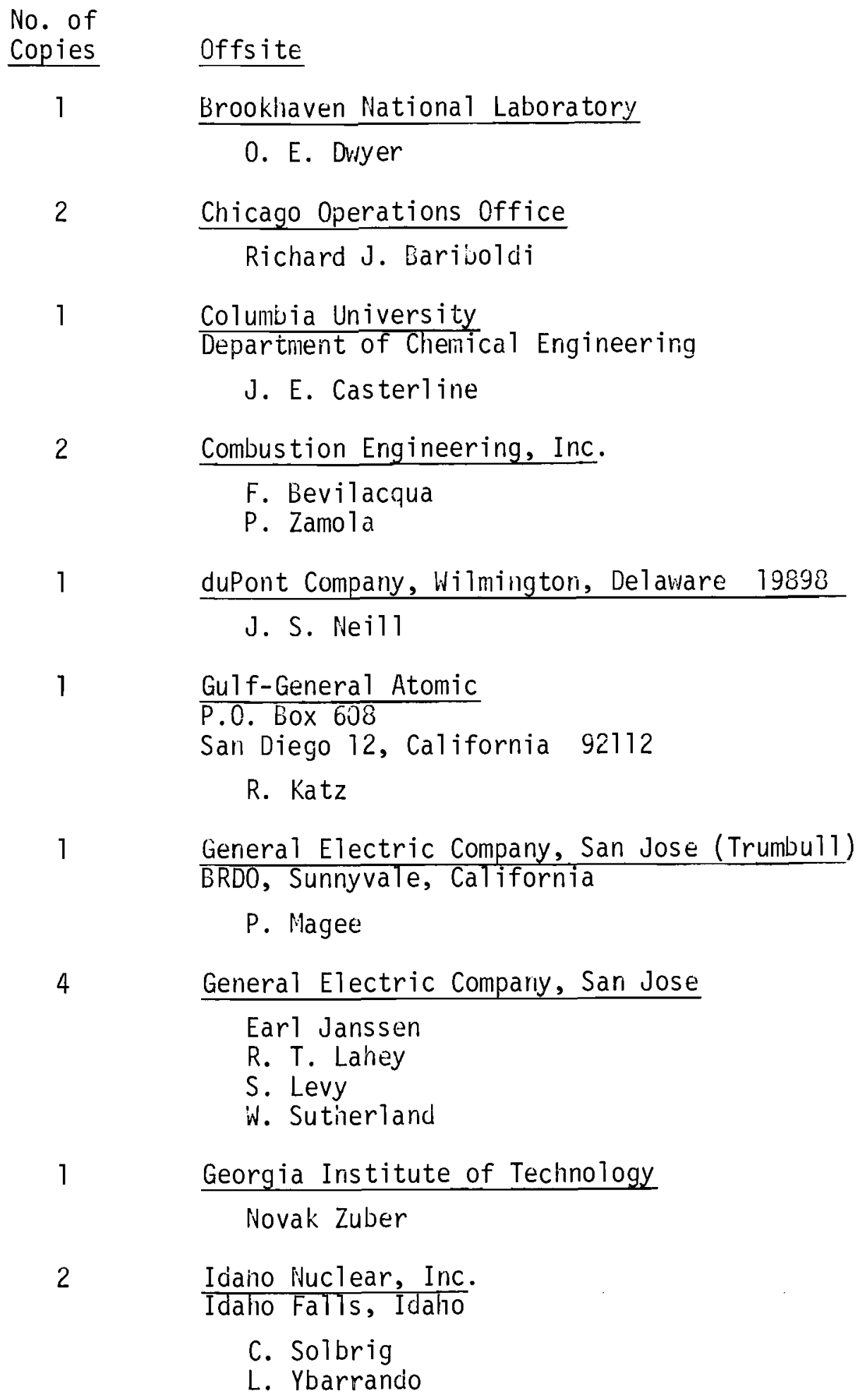


No. of

Copies Offsite

2 Exxon Nuclear Corp.

Bellevue, Washington

L. P. Bupp

G. A. Sofer

1

Knol1s Atomic Power Laboratory

Genera 1 Electric Company

Schenectady, New York

G. H. Halsey

1

Union Cartide Corporation (ORNL)

Floyd L. Culler

1 Nuclear FuE 1 Services

Rockville, Mú.

R. T. Eerringer

1

Union Carbide Corp. (ORNL-Y-12)

M. Fontana

H. W. Hoffman

$1 \quad$ Gulf United Nuclear Fuels Corporation Grasslands Road

Elms ford, New York

H. S. Chung

1 University of Minnesota

Department of Chemical Engineering

Minneapolis, Minnesota 55455

H. S. Istbin

1 Westinghouse Bettis Atomic Power Laboratory

S. Green

2 Westinghouse Electric Corporation

H. Chelemer

L. S. Tong 
No. of

Copies

2

Offsite

Westinghouse Electric Corporation

Waltz Mi11 Site

P. 0. Box 158

Madison, $\mathrm{Pa}$.

E. Novendstern

R. Markley

Onsi te-Hanford

1

AEC/RL Patent Attorney

R. M. Poteat

2

AEC/RL-RDT Sr. Site Representative, PNP

F. Standerfer

58

Battelle-Northwest

D. T. Aase

R. T. Al lemann

N. E. Carter

C. C. Chapman (5)

P. D. Cohn

D. L. Condotta

J. C. Fox

S. Goldsmith

B. M. Johnson

C. W. Lindenmeier

T. I. McSweeney

C. A. Oster

L. T. Peciersen

D. S. Rowe (30)

A. M. Sutey

D. S. Trent

C. L. Wheeler

W. C. Wolkenhauer

F. R. Zaloudek

Technical Information Files (5)

Tecnnical Publications (1) 
No. of

Copies

Onsite-Hanford

2

United Nuclear Industries, Inc.

R. Shoemaker

R. Baars

8 Westinghouse-Hanford

W. M. Gajewski

J. W. Hagan

J. Muraoka

R. E. Peterson

J. M. Yatabe 